\title{
Inorganic Phosphor Materials for Lighting
}

\author{
Yuan-Chih Lin ${ }^{1} \cdot$ Maths Karlsson ${ }^{1} \cdot$ Marco Bettinelli $^{2}$
}

Received: 1 December 2015/Accepted: 21 March 2016/Published online: 4 April 2016

(C) Springer International Publishing Switzerland 2016

\begin{abstract}
This chapter addresses the development of inorganic phosphor materials capable of converting the near UV or blue radiation emitted by a light emitting diode to visible radiation that can be suitably combined to yield white light. These materials are at the core of the new generation of solid-state lighting devices that are emerging as a crucial clean and energy saving technology. The chapter introduces the problem of white light generation using inorganic phosphors and the structureproperty relationships in the broad class of phosphor materials, normally containing lanthanide or transition metal ions as dopants. Radiative and non-radiative relaxation mechanisms are briefly described. Phosphors emitting light of different colors (yellow, blue, green, and red) are described and reviewed, classifying them in different chemical families of the host (silicates, phosphates, aluminates, borates, and non-oxide hosts). This research field has grown rapidly and is still growing, but the discovery of new phosphor materials with optimized properties (in terms of emission efficiency, chemical and thermal stability, color, purity, and cost of fabrication) would still be of the utmost importance.
\end{abstract}

Keywords Light emitting diodes - Phosphors - White light · Lanthanide ions · Luminescence

This article is part of the Topical Collection "Photoluminescent Materials and Electroluminescent Devices"; edited by Nicola Armaroli, Henk Bolink.

Marco Bettinelli

marco.bettinelli@univr.it

1 Department of Physics, Chalmers University of Technology, 41296 Göteborg, Sweden

2 Luminescent Materials Laboratory, University of Verona, 37134 Verona, Italy 


$\begin{array}{ll}\text { Abbreviations } \\ \text { ADP } & \text { Atomic displacement parameter } \\ \text { CB } & \text { Conduction band } \\ \text { CCT } & \text { Correlated color temperature } \\ \text { CIE } & \text { Commission Internationale de l'Éclairage } \\ \text { CRI } & \text { Color rendering index } \\ \text { CT } & \text { Charge transfer } \\ \text { DOS } & \text { Density of states } \\ \text { EXAFS } & \text { Extended X-ray absorption fine structure } \\ \text { FEL } & \text { Free electron laser } \\ \text { FWHM } & \text { Full width at half maximum } \\ \text { IR } & \text { Infrared } \\ \text { LE } & \text { Luminous efficacy } \\ \text { LED } & \text { Light emitting diode } \\ \text { NUV } & \text { Near ultraviolet } \\ \text { PCE } & \text { Photocurrent excitation } \\ \text { pcLED } & \text { Phosphor converted light emitting diode } \\ \text { pcWLED } & \text { Phosphor converted white light emitting diode } \\ \text { PDF } & \text { Pair-distribution function } \\ \text { PL } & \text { Photoluminescence } \\ \text { PLE } & \text { Photoluminescence excitation } \\ \text { QE } & \text { Quantum efficiency } \\ \text { RE } & \text { Rare earth } \\ \text { RGB } & \text { Red, green, blue } \\ \text { RT } & \text { Room temperature } \\ \text { SSL } & \text { Solid state lighting } \\ \text { UV } & \text { Ultraviolet } \\ \text { VB } & \text { Valence band } \\ \text { VRBE } & \text { Vacuum referred binding energy } \\ \text { WLED } & \text { White light emitting diode } \\ \text { XAFS } & \text { X-ray absorption fine structure } \\ \text { XANES } & \text { X-ray absorption near edge structure } \\ \text { XRD } & \text { X-Ray diffraction } \\ & \end{array}$

\section{Introduction}

Lighting accounts for about $19 \%$ of electricity worldwide, and new environmentally friendly and energy efficient lighting devices are strongly required. It is widely accepted that solid state lighting (SSL) will replace the old technologies that have been phased out (incandescent lamps) or are problematic from an environmental point of view (compact fluorescent lamps) [1]. The invention of bright-blue LEDs (light emitting diodes) by Nakamura and others in the mid-1990s [2, 3] has led to the development of devices capable to produce white light in a reliable and efficient way, based on inorganic phosphors [4]. Presently, pcLED (phosphor converted light 
emitting diode) lamps are characterized by a number of important advantages compared to older generations of lamps, as they contain no highly toxic mercury [5], turn on instantly, are mechanically robust, have a longer life expectancy (up to 25,000-30,000 h) and especially have a higher energetic efficiency. In principle, white light could be obtained by combining the three fundamental colors (red, green, and blue, RGB) generated by three distinct LEDs. This method employs multiple LED chips and has a major disadvantage due to the high production costs. For this reason, it is currently preferred to use only one LED combined with suitable phosphors.

Presently, two families of LEDs are easily available on the market: (a) blue emitting LEDs (around 450-480 nm) and (b) near ultraviolet (NUV) emitting LEDs (around 380-410 nm), as described specifically in Sect. 2. The two methods currently offer the production of devices with comparable brightness.

Inorganic phosphors normally consist of a crystalline host material doped with a relatively small amount of rare earth or transition metal ions, called activators, which convert light from shorter wavelength to longer wavelength (Stokes shift) via electronic transitions. In the case of LED lighting, the short wavelength excitation is provided by a blue LED or a NUV LED, and therefore, radiation in this spectral range must be strongly absorbed by the phosphor(s).

This contribution presents a description and survey, taken from the recent literature, of some important phosphor materials that find current or perspective applications in the generation of white light using LED excitation. It is intended to be complementary to the many excellent review articles that have appeared in the literature (e.g., [4-13], to cite only a few).

The chapter is organized as follows. After the introduction, a section will deal with generalities of pcLEDs, followed by a description and discussion of advanced techniques of structural and dynamical characterization of inorganic phosphor materials. A selection of important LED phosphor materials will be then presented, separated on the basis of the various emission colors (Fig. 1). We choose the following wavelength ranges: blue $(435-500 \mathrm{~nm})$, green $(520-565 \mathrm{~nm})$, yellow $(565-590)$, and red $(625-740 \mathrm{~nm})$ [14]; of course this is a very qualitative and approximate description, chosen for the sake of simplicity. The phosphor selection is based on our personal choice and the coverage of this huge research field is not at all intended to be exhaustive. We shall try to give an idea of some of the materials and the concepts used in this rapidly evolving research area. Conclusions and perspectives will close the chapter.

\section{Phosphor Converted White Light Emitting Diodes}

Two of the main types of pcWLEDs are based on (1) a NUV LED chip coated with a mixture of RGB phosphors (Fig. 2a) and (2) a blue LED chip coated with a yellow phosphor (Fig. 2c), with their typical emission spectra shown in Fig. 2b and d, respectively. For the pcWLED in Fig. 2c, the yellow phosphor can be replaced by a mixture of green and red phosphors to have a similar emission profile as depicted in Fig. 2b. Two parameters are useful to define the brightness and the color emitted by 


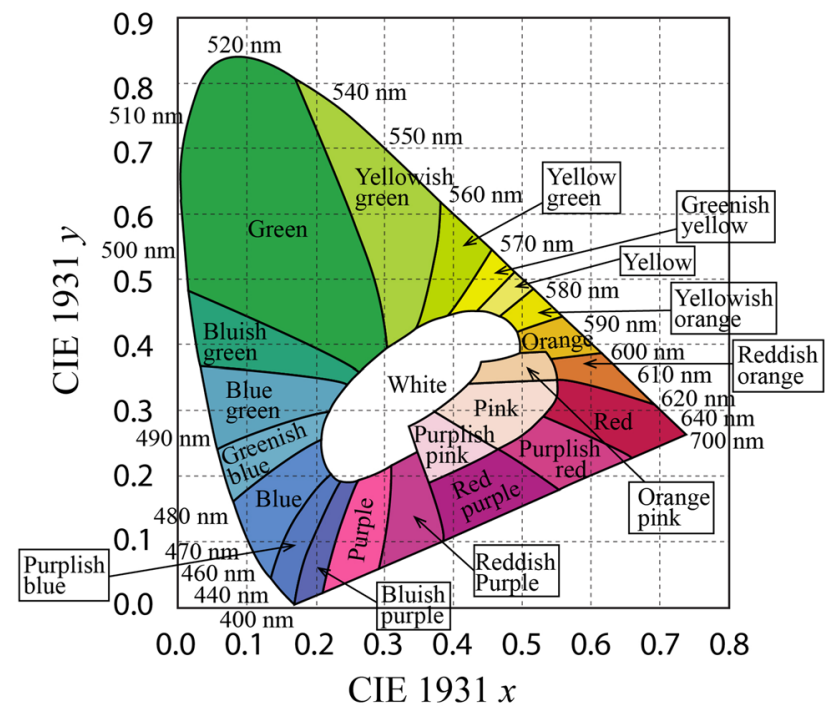

Fig. 1 Approximate color regions on the Commission Internationale de l'Éclairage (CIE) 1931 chromaticity diagram, adapted from [15]

(a) NUV LED + RGB phosphors

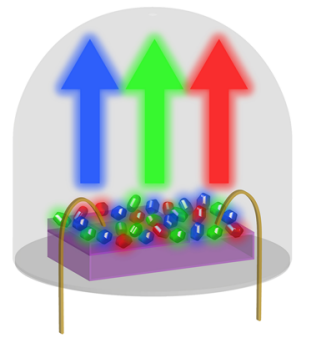

(b) RGB phosphors

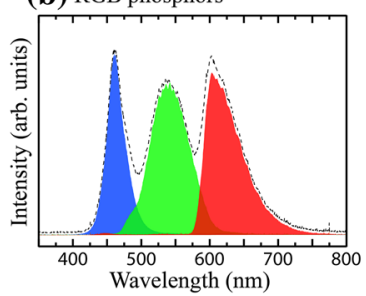

(c) Blue LED + yellow phosphor

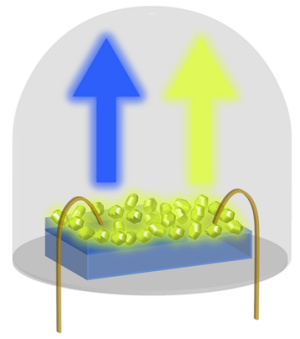

(d) Blue LED + yellow phosphor

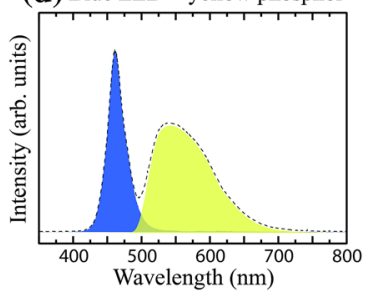

(e)

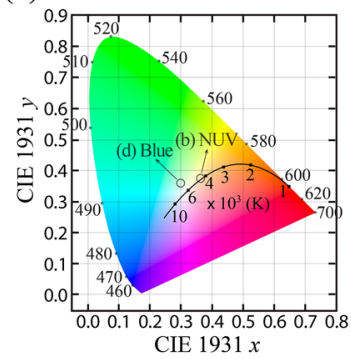

(f)

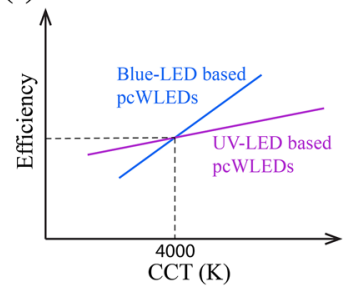

Fig. 2 Schematic depiction of pcWLEDs based on a NUV-LED and a mixture of RGB phosphors, and c a blue LED combined with a yellow phosphor, and their corresponding emission spectra in (b) and (d). e CIE 1931 chromaticity diagram indicating the CIE coordinates converted from the emission spectra in (b) and (d). f A schematic comparison of device efficiency with respect to CCT between NUV- and blueLED based pcWLEDs, adapted from [6]

a pcWLED, the luminous efficacy (LE) and the color rendering index (CRI). The LE expresses how well a light source produces visible light, whereas the CRI measures quantitatively the ability of a light source to reproduce the colors of various objects 
faithfully in comparison with an ideal or natural light source. Figure 2e shows the coordinates of emitted visible light from NUV- and blue-LED based pcWLEDs in the CIE 1931 chromaticity diagram, where the correlated color temperature (CCT) is indicated along the blackbody locus. The higher the CCT is, the colder human beings perceive the light. For comparison, incandescent lamps, as reference sources based on blackbody radiation, have a CRI of 100. A high value of CRI is required for high quality and comfortable lighting.

A comparison between the two types of pcWLEDs (Fig. 2e) shows that the white light emission from the blue-LED based pcWLEDs containing a yellow phosphor has a higher CCT $(7002 \mathrm{~K})$ than that of the NUV-based one $(4521 \mathrm{~K})$, where the

Table 1 Phosphors (red: 625-740 nm, green: 520-565 nm, blue: $435-500 \mathrm{~nm}$ ) for NUV-based pcWLEDs

\begin{tabular}{|c|c|c|c|c|c|c|c|}
\hline \multicolumn{8}{|c|}{ NUV LEDs $(\lambda \approx 380-410 \mathrm{~nm})$} \\
\hline $\begin{array}{l}\text { Color } \\
\text { region }\end{array}$ & Phosphor compositions & $\begin{array}{l}\lambda_{\mathrm{ex}} \\
(\mathrm{nm})\end{array}$ & $\begin{array}{l}\lambda_{\mathrm{em}} \\
(\mathrm{nm})\end{array}$ & CRI & $\begin{array}{l}\text { CCT } \\
(\mathrm{K})\end{array}$ & $\begin{array}{l}\mathrm{QE} \\
(\%)\end{array}$ & $\begin{array}{l}T_{q} \\
(\mathrm{~K})\end{array}$ \\
\hline \multirow[t]{2}{*}{ Red } & $\mathrm{Ca}_{2} \mathrm{GdF}_{4} \mathrm{PO}_{4}: \mathrm{Eu}^{3+}[17]$ & 394 & 611 & - & 2865 & 64 & $>520$ \\
\hline & $\mathrm{CaAlSiN}_{3}: \mathrm{Eu}^{2+}[18]$ & 405 & 650 & - & 3177 & - & $>420$ \\
\hline \multirow[t]{5}{*}{ Green } & $\mathrm{Ca}_{2} \mathrm{Al}_{3} \mathrm{O}_{6} \mathrm{~F}: \mathrm{Eu}^{2+}[19]$ & 400 & 502 & - & 10,598 & - & $\sim 400$ \\
\hline & $\mathrm{NaCaPO}_{4}: \mathrm{Tb}^{3+}[20]$ & 370 & 547 & - & 6660 & - & - \\
\hline & $\begin{array}{l}\mathrm{Ca}_{10} \mathrm{~K}\left(\mathrm{PO}_{4}\right)_{7}: \mathrm{Eu}^{2+}, \mathrm{Tb}^{3+}, \mathrm{K}^{+} \\
\quad[21]\end{array}$ & 400 & 544 & - & 7440 & - & - \\
\hline & $\mathrm{LiSrPO}_{4}: \mathrm{Eu}^{2+}, \mathrm{Tb}^{3+}[22]$ & 400 & 541 & - & 6679 & - & - \\
\hline & $\mathrm{Ca}_{2} \mathrm{GdZr}_{2}\left(\mathrm{AlO}_{4}\right)_{3}: \mathrm{Ce}^{3+}[23]$ & 417 & 500 & - & 9864 & 40 & $\sim 375$ \\
\hline \multirow[t]{4}{*}{ Blue } & $\gamma-\mathrm{KCaPO}_{4}: \mathrm{Eu}^{2+}[24]$ & 380 & 473 & - & $1645^{*}$ & - & $>445$ \\
\hline & $\mathrm{Ca}_{2} \mathrm{PO}_{4} \mathrm{Cl}: \mathrm{Eu}^{2+}[25]$ & 370 & 454 & $93^{*}$ & $4590^{*}$ & 84 & $>520$ \\
\hline & $\mathrm{Ba}_{3} \mathrm{MgSi}_{2} \mathrm{O}_{8}: \mathrm{Eu}^{2+}, \mathrm{Mn}^{2+}[26]$ & 375 & 442 & $85^{*}$ & $5200^{*}$ & - & - \\
\hline & $\mathrm{Sr}_{2} \mathrm{MgSi}_{2} \mathrm{O}_{7}: \mathrm{Eu}^{2+}[27]$ & 395 & 470 & - & - & - & $\sim 550$ \\
\hline \multicolumn{8}{|c|}{ Blue LEDs $(\lambda \approx 450-480 \mathrm{~nm})$} \\
\hline \multirow[t]{3}{*}{ Red } & $\mathrm{Lu}_{2} \mathrm{CaMg}_{2} \mathrm{Si}_{3} \mathrm{O}_{12}: \mathrm{Ce}^{3+}[28]$ & 477 & 605 & $76^{*}$ & $3500^{*}$ & - & $\sim 500$ \\
\hline & $\mathrm{CaZnOS}: \mathrm{Eu}^{2+}[29]$ & 460 & 650 & $85^{*}$ & $4870^{*}$ & 35 & $\sim 400$ \\
\hline & $\beta-\mathrm{SiAlON}: \operatorname{Pr}^{3+}[30]$ & 460 & 624 & - & 4225 & - & - \\
\hline \multirow[t]{3}{*}{ Green } & $\mathrm{CaY}_{2} \mathrm{Al}_{4} \mathrm{SiO}_{12}: \mathrm{Ce}^{3+}[31]$ & 450 & 540 & - & 4318 & 70 & $\sim 420$ \\
\hline & $\mathrm{Ca}_{3} \mathrm{Sc}_{2} \mathrm{Si}_{3} \mathrm{O}_{12}: \mathrm{Ce}^{3+}[32]$ & 455 & 505 & - & 6082 & - & - \\
\hline & $\mathrm{SrBaSiO}_{4}: \mathrm{Eu}^{2+}[33]$ & 430 & 512 & - & 6866 & 78 & $\sim 440$ \\
\hline \multirow[t]{3}{*}{ Yellow } & $\mathrm{Y}_{3} \mathrm{Al}_{5} \mathrm{O}_{12}: \mathrm{Ce}^{3+}[5,34,35]$ & 450 & 565 & $71^{*}$ & $5600^{*}$ & 85 & $\sim 600$ \\
\hline & $\mathrm{Y}_{3} \mathrm{Mg}_{2} \mathrm{AlSi}_{2} \mathrm{O}_{12}: \mathrm{Ce}^{3+}[36]$ & 480 & 600 & $75^{*}$ & $3000^{*}$ & - & - \\
\hline & $\mathrm{Li}-\alpha-\mathrm{SiAlON}: \mathrm{Eu}^{2+}[37]$ & 460 & 573 & $72^{*}$ & $6150^{*}$ & 70 & - \\
\hline
\end{tabular}

The CRI and CCT values marked with asterisk are converted from the white light composed of the emission bands of the selected phosphor and other light emitting component(s)

$Q E$ quantum efficiency, $T_{q}$ thermal quenching temperature, as defined in Sect. $4.3, \lambda_{\text {ex }}$ and $\lambda_{e m}$ refer to the excitation and emission wavelength, respectively 
CCT values are calculated in terms of the chromaticity coordinates shown in Fig. 2e, based on the cubic approximation proposed by McCamy [16]. The CCT values here reveal that the light emitted from NUV-based pcWLEDs is perceived as warmer light than the one from blue-based pcWLEDs. Additionally, the NUV-based LEDs perform with higher efficiency for warmer white light emissions (Fig. 2f). On the downside, they are more difficult to fabricate and hence of higher cost. We also point out that pcWLEDs emitting warm white light can be obtained via exciting green and red phosphors by blue LEDs, with having high efficiency due to the small difference between excitation and emission wavelengths. For the latter reason, many investigations focus on improving the technology based on blue-LEDs, notably with the specific aim of lowering their CCT as well as increasing their CRI. Strategies to improve these properties include for example the addition of highly efficient red components made of InP quantum dots [6]. A compilation of luminescence data for various inorganic phosphors used in pcWLED devices is shown in Table 1. The CIE 1931 coordinates of some selected phosphors for NUV- and blue-LED based pcWLEDs are indicated in Fig. 3.

\section{Advanced Structural and Dynamical Characterization of Inorganic Phosphor Materials}

\subsection{Energetics of the Activator Ions and the Effect and Importance of the Structure and Dynamics of the Host}

Although the activator ions, most often lanthanide ions $\left(\mathrm{Ce}^{3+}-\mathrm{Yb}^{3+}\right.$, denoted as $\mathrm{Ln}^{3+}$, and $\mathrm{Eu}^{2+}$ and $\left.\mathrm{Yb}^{2+}\right)$ have intrinsic characteristics that contribute to the optical properties of phosphors, the electronic energy levels of an activator ion in a crystal differ greatly from those of a free ion. The following discussion refers specifically to activator ions showing $5 d-4 f$ luminescence, such as $\mathrm{Ce}^{3+}$ and $\mathrm{Eu}^{2+}$.

The energy separation of the energy levels can give rise to emission of light from UV across visible wavelengths, depending on the properties of the host crystal. In fact, the local geometry around the activator ion has a remarkable importance in
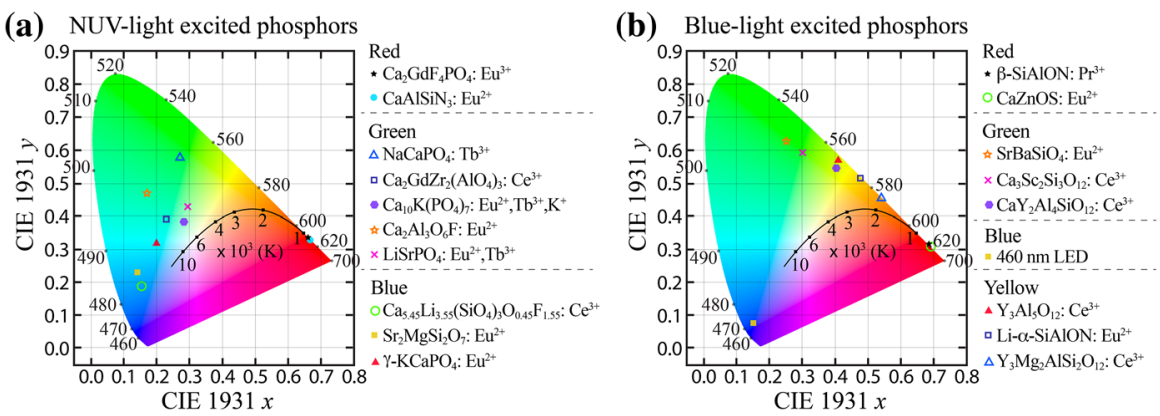

Fig. 3 The CIE 1931 diagram with coordinates of different phosphors typically used in a NUV-LED based and $\mathbf{b}$ blue-LED based pcWLEDs, respectively 
determining the spectroscopic behavior of lanthanide ions incorporated in a host matrix. In particular, the lowering of the energy gap between the $5 d$ and $4 f$ levels, which is commonly referred to as the redshift, is dictated by two major effects; the centroid shift and the ligand field splitting. Figure $4 \mathrm{a}$ shows these effects for $\mathrm{Ce}^{3+}$ embedded in yttrium aluminum garnet, $\mathrm{Y}_{3} \mathrm{Al}_{5} \mathrm{O}_{12}$ (YAG), as an example; the total redshift is labeled $D(A)$ where $A$ refers to the host crystal [4]. As can be seen, both of these processes greatly affect the $5 d$ electrons of the activator ion, whereas the well-shielded $4 f$ electrons are not strongly affected. The position of the $5 d$ levels can indeed change by several $\mathrm{eV}$ from one compound to another.

The first effect, centroid shift, refers to a lowering in the energy of the $5 d$ levels of the activator ion due to a decrease in the interelectron repulsion [4]. This effect depends on the polarizability of the surrounding anion (oxygen) ligands and on the covalency of the chemical bonds between the ligands and the activator ion $[4,38]$. The centroid shift increases with increasing anion polarizability and decreasing average electronegativity of the host cations. As the degree of covalency between the activator ion and surrounding anions increases, the electrons of the metal ion are partly delocalized on the ligands and this decreases their interelectronic repulsion, therefore, decreasing the energy of the excited levels of the metal ion. This feature is called the nephelauxetic effect (Greek for cloud-expanding).

The second effect, ligand field splitting, refers to the difference in energy between the highest and lowest $5 d$ levels, referred to as $y D q$, where $y$ relates to the type of cubic coordination geometry of the activator ion and is again an effect of the host crystal. Its magnitude depends on the bond lengths from the activator ions to the coordinating oxygen ligands, the molecular overlap or degree of covalency between the activator ion and its ligands, the coordination environment, and the symmetry of the activator-ion sites $[4,40]$. Dq, which is proportional to the splitting energy in high symmetry (cubic) environments can be estimated on the basis of a point-charge model according to the following expression:
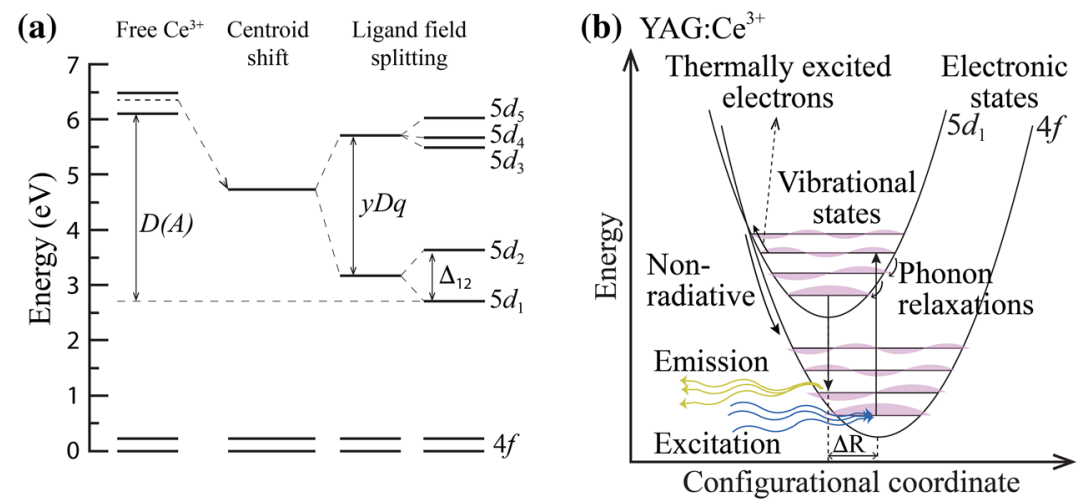

Fig. 4 a Energy diagram of $\mathrm{Ce}^{3+}$ in the free-ion state and when incorporated in a host; the figure is adapted from [39]. b Schematic configurational coordinate diagram for $\mathrm{Ce}^{3+}$ in YAG. Notice that nonradiative relaxations may occur when the $5 d$ electrons are thermally populated to the crossover point of the $5 d_{1}$ and $4 f$ parabolae 


$$
\mathrm{Dq}=\frac{Z e^{2} r^{4}}{6 R^{5}}
$$

where $Z$ is the charge or valence of the anion, $e$ is the charge of an electron, $r$ is the radius of the $d$ wave function, and $R$ is the bond length between the activator ion and its ligand $[4,40]$. Comparing different coordination geometries with the same $R$, Rogers and Dorenbos [41] determined that the ligand field splitting tends to be largest for octahedral coordination, followed by cubal coordination. The smallest ligand field splitting was found for tetrahedral and cuboctahedral coordinations [41].

Furthermore, whereas in many oxide hosts the activator ions occupy well-defined substitutional sites, predictable on the basis of simple arguments based on the charge and the size of the dopant and the substituted ions, this is not the case for all materials. A notable example of this behavior is the non-linear host $\mathrm{LiNbO}_{3}$ [42], which is of great interest for its ability to generate the second harmonic radiation of the light emitted from $\mathrm{Ln}^{3+}$ ions and for which the $\mathrm{Ln}^{3+}$ ions have a different charge with respect to the host cations $\left(\mathrm{Li}^{+}\right.$and $\left.\mathrm{Nb}^{5+}\right)$ and also a different ionic radius $\left(\mathrm{Li}^{+}\right.$ and $\mathrm{Nb}^{5+}$ are smaller than the $\mathrm{Ln}^{3+}$ ions [43]). It is clear that in such cases the local structure around the activator ions is not easily predictable and the simultaneous occupation of multiple substitutional sites cannot be excluded. In this perspective, the nature of the sites occupied by $\mathrm{Ln}^{3+}$ ions has been widely discussed and in the literature many contrasting opinions have been reported. This situation occurs for many classes of host matrices of technological interest and in particular for garnet type host lattices [44-46], such as YAG, which are described in more detail in Sect. 4.1. Moreover, it is well known that garnet crystals (in particular YAG) are subject to significant amounts of native defects that appear during crystal growth depending on the temperature and crystallization procedure [47, 48]. Among these intrinsic defects, antisite defects are dominant. They appear in YAG when some Y and $\mathrm{Al}$ atoms exchange positions. The antisite defects are known to act as electron traps and to affect the structure, luminescence, and other properties of doped and undoped YAG. Moreover, in garnets not containing a large trivalent cation, such as $\mathrm{Ca}_{3} \mathrm{Sc}_{2} \mathrm{Si}_{3} \mathrm{O}_{12}$, the localization of the trivalent dopant is not generally trivial [32]. It can be concluded that it is important to get more insight on this subject.

Additionally, the energetics of the activator ions is determined by the Stokes shift, which refers to the difference in energy between the band maxima of the absorption and emission spectra. This can be understood by the use of a configurational coordinate diagram, in which the potential energy curves of the activator ion in the ground and excited state are plotted against a so-called configurational coordinate that represents the normal coordinate of a vibrational mode localized at the optical center, see Fig. 4b. The potential energy curves of the electronic levels have a parabolic shape in the likely case of a harmonic behavior. The horizontal lines within the parabolae depict the vibrational states relative to each electronic state. According to the Franck-Condon principle, the electronic transitions (absorption and emission) are vertical in nature and (at low temperature) occur from the lowest vibrational level. In effect, this means that once an electron is excited to the $5 d$ level, the surrounding lattice first relaxes to the lowest vibrational level in the electronic excited state before the electron is de-excited to the electronic 
ground state. Since the Stokes shift requires the interaction with phonons, this property is also dictated by the host crystal.

The phonons also play a key role in a phenomenon known as thermal quenching, which describes the pronounced reduction in emission intensity, or quantum efficiency, observed at elevated temperatures, typically a few hundred degree centigrade. Since LED chips produce heat, which may easily get transferred to the phosphor coating, this is of pivotal importance with respect to the energy efficiency of pcLED devices. On a fundamental level, thermal quenching relates to nonradiative relaxation mechanisms of the excited-state electron, other than concentration quenching that relates to the activation of energy processes involving the excited states of the $\mathrm{Ln}^{3+}$ ion and depopulating in a non-radiative way the light emitting levels. In the case of $\mathrm{Ce}^{3+}$ dopants, the two primary mechanisms are thought to be thermal promotion of the $5 d$ electron to the conduction band of the host crystal, and $5 d-4 f$ crossover, of which the latter is illustrated in Fig. 4b. Regardless of the mechanism, phonons are needed to bring the excited activator ion to a point at which non-radiative processes can happen.

\subsection{Advanced Structural and Dynamical Characterization}

As can be understood from above, it can be concluded that a detailed insight into the composition-structure-dynamics relationships in phosphors is crucial for the understanding of their properties and hence for the development of new, nextgeneration, better performing, materials. This requires the combination of several, complementary, techniques, which enable precise structural and dynamical analysis of substituent ions at small concentrations of approximately $1 \mathrm{~mol} \%$. Examples of two powerful techniques for exactly this purpose are neutron and X-ray total (Bragg + diffuse) scattering, and X-ray absorption fine structure (XAFS) spectroscopy. Compared to "conventional" diffraction, i.e., where only the Bragg peaks are considered, the diffuse scattering between the Bragg peaks relates to the local structural details (e.g., symmetry, bond angles and distances) of the investigated materials, and can be analyzed by e.g., reverse Monte-Carlo or pair-distribution function (PDF) analysis [49]. Similar results can be obtained from XAFS spectroscopy, but here the local surrounding, such as the distortive nature, bond distances and angles, and covalency of the chemical bonds, around specific $\mathrm{Ln}^{3+}$ ions are highlighted. Complementary information about the local structure can be obtained for example from vibrational (Raman and infrared) spectroscopy, and inelastic neutron scattering techniques. All together, this allows obtaining information about the real local structure of the sites occupied by the activator ions at a much deeper level than is possible by "conventional" diffraction measurements and simple crystallographic considerations based on ionic radii and charges.

\subsection{Case Studies}

There have been numerous studies aimed to understand the composition-structuredynamics relationships of phosphors, many of them focusing on the correlation between emission color to the local or long-range structures of the material. 
Examples include the study by Robertson et al. [50], who reported on the relation between emission spectra and cation size in $\mathrm{Ce}^{3+}$-doped YAG, the study by Pan et al. [51], who reported on the correlation between the red-shift of emission to the long-range crystalline structure of the same material, and the study by Furman et al. [52], who showed that the quantum efficiency of YAG:Ce ${ }^{3+}$ is related to the degree of crystallinity. Other, more recent examples include the study by Ghigna et al. [53] and George et al. [54], who examined the local structure of the $\mathrm{Ce}^{3+}$ ion using extended XAFS (EXAFS) and found that the nearest eight $\mathrm{Ce}-\mathrm{O}$ distances are expanded by about $3 \%$ compared to the average $\mathrm{Y}-\mathrm{O}$ distances in $\mathrm{Y}_{2.97} \mathrm{Ce}_{0.03} \mathrm{Al}_{5-}$ $\mathrm{O}_{12}$, and Gracia et al. [55] and Muñoz-García and Seijo [56], who showed that the substitution of $\mathrm{Ce}^{3+}$ for $\mathrm{Y}^{3+}$ in $\mathrm{YAG}$ results in a small expansion of the coordination environment around the substituent ion. Further examples include the study by $\mathrm{Wu}$ et al. [57], who reported on a relationship between Ga-induced lattice expansion in $\mathrm{Y}_{3} \mathrm{Al}_{5-x} \mathrm{Ga}_{x} \mathrm{O}_{12}(0 \leq x \leq 5)$ and a corresponding blue-shift of both the excitation and emission spectra. Local structural analysis specifically suggested that the blue-shift effect can be related to a decrease in the so-called distortion parameter $d_{88} / d_{81}$, which is defined in Fig. 5a. The value of $d_{88} / d_{81}$ relates specifically to the degree of tetragonal distortion of the nearly cubic-coordinated $\mathrm{Ce}^{3+}$ ions in YAG. Thus, a smaller $d_{88} / d_{81}$ has the effect of making the $\mathrm{Ce}^{3+}$ local structural environment more cubic-like, which in turn weakens the ligand fields with tetragonal symmetry and hence the splitting energy $\Delta_{12}$ as denoted in Fig. 4a. Consequently, the lowest lying $5 d$ state shifts to a higher energy and a blue-shift effect for the $4 f-5 d$ transitions is observed. The same phenomenon is observed also in other materials, such as $\mathrm{Y}_{3} \mathrm{Sc}_{2} \mathrm{Ga}_{3-x} \mathrm{Al}_{x} \mathrm{O}_{12}: \mathrm{Ce}^{3+}[58]$, and is also supported by theoretical simulations [59]. On the contrary, a (counteracting) red-shift for YAG: $\mathrm{Ce}^{3+}$ substituted with $\mathrm{Mg}^{2+}$ and $\mathrm{Si}^{4+}$ to replace $\mathrm{Al}^{3+}$, i.e., $\mathrm{Y}_{3} \mathrm{Al}_{5-2 x}(\mathrm{Mg}, \mathrm{Si})_{x-}$ $\mathrm{O}_{12}: \mathrm{Ce}^{3+}$ has been observed [60]. Although the introduction of $\mathrm{Mg}^{2+}$ and $\mathrm{Si}^{4+}$ ions leads to an elongation of the $\mathrm{Ce}-\mathrm{O}$ bonds, which should result in a blue-shift, the doping also causes an increase of the $\mathrm{Ce}-\mathrm{O}$ covalency and furthermore increases the distortion of the $\mathrm{CeO}_{8}{ }^{13-}$ dodecahedra, which in effect lead to an overcompensating red-shift. Furthermore, Tien et al. [61], Chiang et al. [62] and Shao

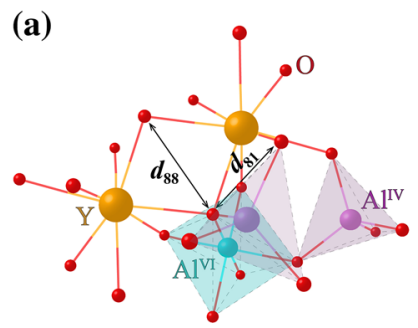

(b)

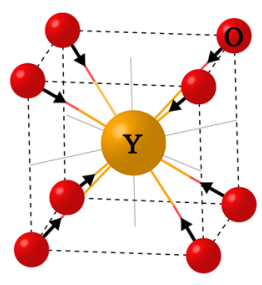

(c)

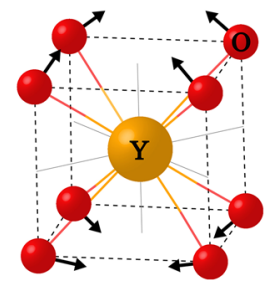

Fig. 5 a Schematic illustration of the local structure of YAG, with the $d_{88}$ and $d_{81}$ distances indicated. The $d_{88}$ distance is referred to as the length of the $\mathrm{O}-\mathrm{O}$ edge shared with another dodecahedron, whereas the $d_{81}$ distance is the distance shared with one tetrahedron, as defined in Ref. [57]. b, c Schematic illustration of the local, dynamical lattice distortions at the Y site in YAG, adapted from [66]. In (b) the symmetric compression is shown, whilst in (c) the symmetric bending vibration is shown 
et al. [63] investigated the effect of doping on the $\mathrm{Y}^{3+}$ site in YAG: $\mathrm{Ce}^{3+}$. The interatomic $M-\mathrm{O}$ distance, where $M$ is the dopant on the $\mathrm{Y}^{3+}$ site, is found to go as $\mathrm{Gd}-\mathrm{O}>\mathrm{Tb}-\mathrm{O}>\mathrm{Y}-\mathrm{O}>\mathrm{Lu}-\mathrm{O}$ [64]. A key observation was the observation of a red-shift when the lattice expands and a corresponding blue-shift when it contracts. A general conclusion can be made here that the local structure around $\mathrm{Ce}^{3+}$ is more distorted as larger cations replace $\mathrm{Y}^{3+}$ in $\mathrm{YAG}: \mathrm{Ce}^{3+}$, and the local lattice distortion intensifies the ligand fields which strengthen the red-shift effect. The collected data from previously measured luminescence spectra of $\mathrm{Ce}^{3+}$-doped $(\mathrm{Gd}, \mathrm{Y}, \mathrm{Lu})_{3}$ $(\mathrm{Al}, \mathrm{Ga})_{5} \mathrm{O}_{12}$ by Dorenbos [39] indicate that the blue-/red-shift effect is mainly attributed to the splitting energy $\Delta_{12}$ instead of Dq, cf. Fig. 4(a). The photoluminescence (PL) and PL excitation (PLE) spectra of a series of $\mathrm{Ce}^{3+}$ and $\mathrm{Li}^{+}$-doped garnet phosphors have been investigated by Kalaji et al. [65], and the results for the blue-/red-shift effect originating from different lattice size, bond length and local lattice distortions, are consistent with the conclusions found for $(\mathrm{Gd}, \mathrm{Tb}, \mathrm{Y}, \mathrm{Lu})_{3}$ $(\mathrm{Al}, \mathrm{Ga})_{5} \mathrm{O}_{12}: \mathrm{Ce}^{3+}$ [64]. In more detail, Wu et al. [57] and Seijo et al. [66] found that the red-shift effect is related to static as well as vibrationally induced tetragonal distortions around the $\mathrm{Ce}^{3+}$ ions. The vibrationally induced distortions refer specifically to symmetric compression and bending motion of $\mathrm{Ce}-\mathrm{O}$ bonds at the dodecahedral sites (of $\mathrm{D}_{2}$ symmetry). These vibrational modes are depicted in Fig. 5b, c.

\section{Yellow Phosphors}

Yellow emitting phosphors can be used for SSL when they are excited by a NUV $(\lambda \approx 380-410 \mathrm{~nm})$ or blue $(\lambda \approx 450-480 \mathrm{~nm})$ source. Emission bands from yellow phosphors are centered in the region of 565-590 nm. Since yellow light can be obtained by combining green and red light, the roles of green and red phosphors in pcWLEDs made of a NUV LED chip and RGB phosphors can be substituted by yellow phosphors. Therefore, yellow phosphors are preferably employed with a blue LED chip to generate white light if a high CRI is not needed. Whereas, when a high CRI is required, RGB phosphors coated on a NUV LED chip or RG (red and green) ones with a blue LED pump are favorable. The activator ions for yellow radiations are primarily $\mathrm{Ce}^{3+}$ and $\mathrm{Eu}^{2+}$. As discussed below in Sects. 5 and 6, the luminescence of $\mathrm{Ce}^{3+}$ and $\mathrm{Eu}^{2+}$ derives from $5 d-4 f$ transitions and is red-shifted from the blue/green to the yellow region because $5 d$ states shift to lower energy levels due to stronger interactions between activator ions and host materials. Since $5 d-4 f$ transitions are allowed electric dipole transitions, the emission from $\mathrm{Ce}^{3+}$ and $\mathrm{Eu}^{2+}$ is relatively bright and such strong transitions are ideal for pcWLED applications.

Examples of host matrices for the generation of yellow light are oxynitrides, silicates, and aluminates. The most important class of hosts of technological interest is based on garnet type lattices such as YAG, which when $\mathrm{Y}^{3+}$ is substituted with a few $\mathrm{mol} \%$ of $\mathrm{Ce}^{3+}$ ions, is a luminescent material that has nearly ideal optical characteristics for the generation of white light and has been widely commercially used in pcWLEDs. In the following sections, we describe in detail the general 
characteristics of structural, dynamical, and optical properties of garnet type host lattices, with a specific focus on YAG: $\mathrm{Ce}^{3+}$, in order to provide a basis for the understanding of this technologically important material.

\subsection{Garnet Type Host Lattices and YAG: $\mathrm{Ce}^{3+}$}

The garnet structure was firstly reported by Menzer [67] — according to Geller [68]. It has been found that the garnet structure exists in a number of minerals, particularly in oxide minerals. For oxide garnets, the chemical formula can be generally expressed as $A_{3} B_{2}\left(X_{4}\right)_{3}$, where $A, B, X$ stand for cations, and $\mathrm{O}$ is an oxygen anion. Different oxide garnets have been used as host lattices for phosphors, such as silicates (e.g., $\left.\mathrm{Ca}_{3} \mathrm{Sc}_{2} \mathrm{Si}_{3} \mathrm{O}_{12}\right)$, aluminates (e.g., $\left.(\mathrm{Gd}, \mathrm{Tb}, \mathrm{Y}, \mathrm{Lu})_{3} \mathrm{Al}_{5} \mathrm{O}_{12}\right)$ and more complex compositions such as $\mathrm{Y}_{3} \mathrm{Mg}_{2} \mathrm{AlSi}_{2} \mathrm{O}_{12}$ and $\mathrm{Ca}_{2} \mathrm{GdZr}_{2} \mathrm{Al}_{3} \mathrm{O}_{12}$, to mention a few. As seen in Table 1, the optical properties of identical activator ions accommodated in different garnet structured host lattices vary substantially. Hence, it is critical to explore the local crystal structure of the host lattice with and without activator ions.

Regarding the canonical compound, YAG, this can be described in terms of a body centered cubic unit cell containing 160 atoms ( 80 atoms in the primitive cell) in the $I a \overline{3} d$ space group, where the primitive cell consists of four molecules of $\mathrm{Y}_{3} \mathrm{Al}_{2}^{\mathrm{VI}}\left(\mathrm{Al}^{\mathrm{IV}} \mathrm{O}_{4}\right)_{3}$. The superscripts VI and IV refer to octahedral and tetrahedral coordination, respectively. The $\mathrm{Y}^{3+}$ ions thus occupy the $12(c)$ Wyckoff position (W.P.) and are dodecahedrally coordinated to eight $\mathrm{O}^{2-}$ ions, leading to a $\mathrm{D}_{2}$ site symmetry, whereas the $\mathrm{Al}$ ions occupy the sites $8(a)$ and $12(d)$ and the oxygen ions occupy the site $48(h)$. It follows that the YAG structure may be viewed as a $3 \mathrm{D}$ network of $\mathrm{Al}^{\mathrm{VI}} \mathrm{O}_{6}{ }^{9-}$ octahedra and $\mathrm{Al}^{\mathrm{IV}} \mathrm{O}_{4}{ }^{5-}$ tetrahedra, and $\mathrm{YO}_{8}{ }^{13-}$ dodecahedra with shared $\mathrm{O}^{2-}$ ions at the corners (Fig. 6a).

Since in YAG: $\mathrm{Ce}^{3+}$ the activator ions replace $\mathrm{Y}^{3+}$ ions on the $12(c)$ positions, it is especially important to investigate the local structural properties at and around these sites. In a local view, each $\mathrm{Y}^{3+}\left(\right.$ or $\left.\mathrm{Ce}^{3+}\right)$ ion is surrounded by two nearest $\mathrm{Al}^{\mathrm{IV}} \mathrm{O}_{4}{ }^{5-}$ tetrahedra and four nearest $\mathrm{Al}^{\mathrm{VI}} \mathrm{O}_{6}{ }^{9-}$ octahedral (Fig. 6b). Several
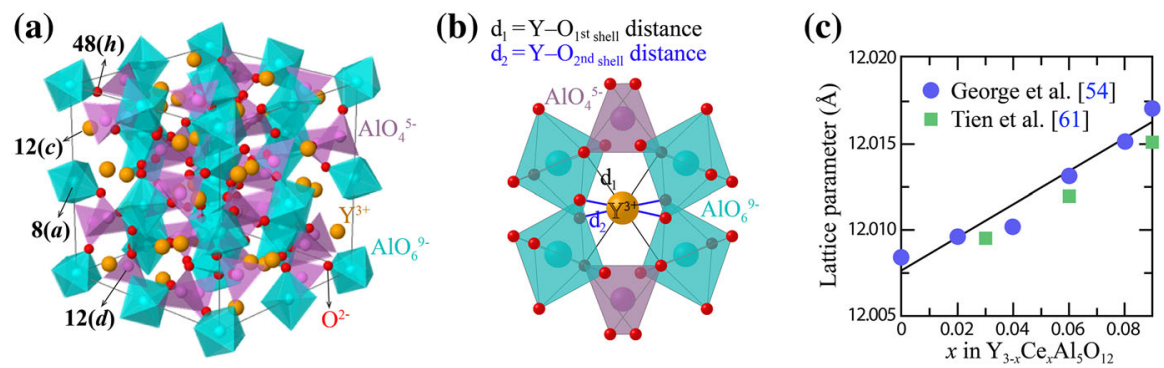

Fig. 6 a Schematic picture of the YAG unit cell containing tetrahedral $\mathrm{AlO}_{4}{ }^{5-}$, octahedral $\mathrm{AlO}_{6}{ }^{9-}$, and dodecahedral $\mathrm{YO}_{8}{ }^{13-}$ moieties, with the W.P.s for the different types of ions indicated in the figure. b Local view of the structure around the $\mathrm{Y}^{3+}$ ions in $\mathrm{YAG}$, where the $\mathrm{Ce}-\mathrm{O}$ bonds of the first two shells are indicated. The figure is adapted from [69]. c Figure over the $\mathrm{Ce}^{3+}$ induced lattice expansion in YAG: $\mathrm{Ce}^{3+}$, adapted from [54]. The lattice expansion obeys Vegard's law $[54,70]$ 
previous works have focused specifically on the difference in local structure with and without $\mathrm{Ce}^{3+}$ doping. The introduction of $\mathrm{Ce}^{3+}$ dopants leads to a lattice expansion, see Fig. 6c, (about $3 \%$ for the first and second shell Ce-O distances, cf. Fig. 6b), but significantly less than expected from the $12 \%$ increased size in ionic radius $\left(\mathrm{Ce}^{3+}: 101 \mathrm{pm}\right.$ and $\left.\mathrm{Y}^{3+}: 90 \mathrm{pm}\right)$. This means that the $\mathrm{Ce}^{3+}$ ions are "squeezed" into the lattice, or in other words that the $\mathrm{Ce}^{3+}$ ion local environment is relatively compressed, which is strongly related to the material's optical properties. Table 2 shows the interatomic distances between $\mathrm{Y}^{3+} / \mathrm{Ce}^{3+}$ and the 1 st-6th shell ions denoted by $Z$, as have been measured by using EXAFS and XRD. Figure $6 \mathrm{c}$ shows the $\mathrm{Ce}^{3+}$ ion concentration dependence of the lattice parameter obtained from XRD.

Further details into the local structural properties of YAG and YAG:Ce ${ }^{3+}$ can be obtained from the atomic displacement parameters (ADPs), or so called B factors, which relate to the degree of thermal motions and/or static disorder in the materials. Table 3 shows the $\mathbf{B}$ factors for YAG and YAG: $\mathrm{Ce}^{3+}$ as extracted from neutron diffractions [54]. A general observation can be made here that the $\mathbf{B}$ factors of all constituent atoms ( $\mathrm{Y} / \mathrm{Ce}, \mathrm{Al}$, and $\mathrm{O}$ ) increase as the $\mathrm{Ce}^{3+}$ ions are incorporated in the YAG matrix. The increase of the $\mathbf{B}$ factors is further seen as a decrease of the Debye temperatures $\left(\theta_{\mathrm{D}}\right)$ of these atoms, which in turn gives a larger accessibility of vibrations, particularly low-frequency vibrational modes [54]. Since the lowestfrequency vibrations in YAG: $\mathrm{Ce}^{3+}$ are specifically related to localized vibrations around the $\mathrm{Ce}^{3+}$ ions, these local vibrational modes are believed to play a key role in luminescent properties, especially at elevated temperatures (This will be further elucidated in Sects. 4.3, 4.4).

\subsection{4f-5d Transitions in YAG: $\mathrm{Ce}^{3+}$}

Generally, the energy levels of the activator ions in phosphors determine their excitation and emission properties and are directly related to the $4 f$ and $5 d$ energy levels. Among the RE ions, optical transitions can occur between $4 f$ and $5 d$ levels. For parity allowed $4 f-5 d$ transitions, the excitation and emission spectra may be substantially affected by the host crystal, because the $5 d$ orbitals are strongly affected by the surrounding lattice, leading to large variation in the emission/

Table 2 Interatomic $\mathrm{Ce}-Z$ distances for $\mathrm{YAG}: \mathrm{Ce}^{3+}$

\begin{tabular}{llllll}
\hline Shell & Atom $Z$ & Co. Nr. & \multicolumn{2}{l}{ Ce-Z distance $(\AA)$} & \\
\cline { 3 - 5 } & & & XRD [54] & EXAFS [54] & EXAFS [53] \\
\hline 1 & $\mathrm{O}_{1}$ & 4 & $2.3090(2)$ & $2.40(2)$ & $2.38(1)$ \\
2 & $\mathrm{O}_{2}$ & 4 & $2.4401(2)$ & $2.50(2)$ & $2.52(2)$ \\
3 & $\mathrm{Al}^{\mathrm{IV}}$ & 2 & $3.00238(2)$ & $3.05(1)$ & $3.06(4)$ \\
4 & $\mathrm{Al}^{\mathrm{VI}}$ & 4 & $3.35677(2)$ & $3.41(1)$ & $3.36(3)$ \\
5 & $\mathrm{Al}^{\mathrm{IV}}$ & 4 & $3.67715(2)$ & $3.71(1)$ & $3.68(7)$ \\
6 & $\mathrm{Y}$ & 4 & $3.67715(2)$ & $3.71(1)$ & $3.71(2)$ \\
\hline
\end{tabular}

Co. Nr. coordination number 
Table 3 Crystallographic data of YAG and YAG:Ce ${ }^{3+}$

\begin{tabular}{llllllll}
\hline Atom & S.S. & W.P. & x [69] & y [69] & z [69] & B [54] YAG & B [54] YAG:Ce ${ }^{3+}$ \\
\hline $\mathrm{Y} / \mathrm{Ce}$ & $\mathrm{D}_{2}$ & $12 c$ & 0.1250 & 0.0000 & 0.2500 & 0.178 & 0.36 \\
$\mathrm{Al}^{\mathrm{VI}}$ & $\mathrm{S}_{6}$ & $8 a$ & 0.0000 & 0.0000 & 0.0000 & 0.215 & 0.33 \\
$\mathrm{Al}^{\mathrm{IV}}$ & $\mathrm{S}_{4}$ & $12 d$ & 0.3750 & 0.0000 & 0.2500 & 0.210 & 0.34 \\
$\mathrm{O}$ & $\mathrm{C}_{1}$ & $48 h$ & 0.28029 & 0.10124 & 0.19936 & 0.255 & 0.43 \\
\hline
\end{tabular}

S.S. site symmetry

excitation wavelength depending on the choice of crystal. For the specific case of YAG: $\mathrm{Ce}^{3+}$, the energy of $4 f-5 d_{1}$ transitions is around $2.7 \mathrm{eV}$, i.e., in the visible range, which may be compared to the $4 f-5 d$ transitions for a free $\mathrm{Ce}^{3+}(6.12 \mathrm{eV})$, which is in the UV range [39], cf. Fig. 7a. More specifically, the nephelauxetic effect is for YAG:Ce ${ }^{3+}$ particularly strong since the orbitals of $\mathrm{Ce}^{3+}$ ions and of nearest eight-coordinated $\mathrm{O}^{2-}$ ions overlap extensively, leading to significant $\mathrm{Ce}-\mathrm{O}$ covalency, which results in a large centroid shift $\varepsilon_{c}$. Apart from the nephelauxetic effect, ligand fields also have a significant impact on the $5 d$ electronic states of $\mathrm{Ce}^{3+}$. If $\mathrm{Ce}^{3+}$ ions are surrounded by adjacent oxygens with a cubic configuration, the centroid shifted $5 d$ states are split into triplet ${ }^{2} \mathrm{~T}_{2 \mathrm{~g}}$ states with higher energy and doublet ${ }^{2} \mathrm{E}_{\mathrm{g}}$ states with lower energy. The splitting energy between ${ }^{2} \mathrm{~T}_{2 \mathrm{~g}}$ and ${ }^{2} \mathrm{E}_{\mathrm{g}}$ states for $5 d$ orbitals of $\mathrm{Ce}^{3+}$ is $\Delta=8 / 9(10 \mathrm{Dq})$ [41] for cubal symmetry of $\mathrm{CeO}_{8}{ }^{13-}$, where Dq can be approximately estimated by using Eq. (1). However, $\mathrm{Ce}^{3+}$ ions are not located in a perfectly cubic environment in the YAG host lattice but located at sites affected by tetragonal deformations. Such locally environments create additional ligand-field components which lead to further energy splitting of the ${ }^{2} \mathrm{~T}_{2 \mathrm{~g}}$ states and the ${ }^{2} \mathrm{E}_{\mathrm{g}}$ states, thus all five $5 d$ states of $\mathrm{Ce}^{3+}$ are then nondegenerate. For YAG: $\mathrm{Ce}^{3+}$, the combined influence of the nephelauxetic effect and ligand-field splitting gives rise to a large redshift, $D(A)$, which makes some of the

$\begin{array}{ll}\text { (a) } \mathrm{Free} \mathrm{Ce}^{3+} & \text { (ii) Nephelauxetic (iii) Cubic }\end{array}$ (iv) Tetragonal (v) Stokes shift

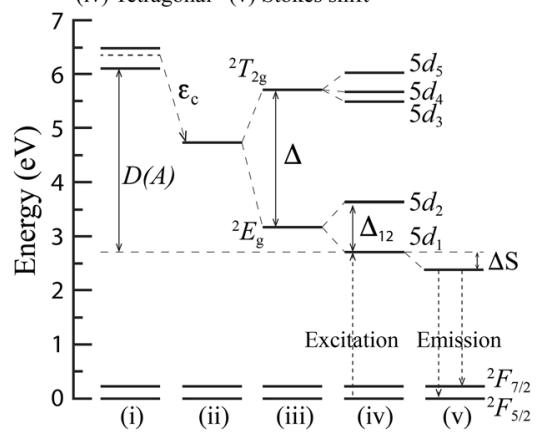

(b)

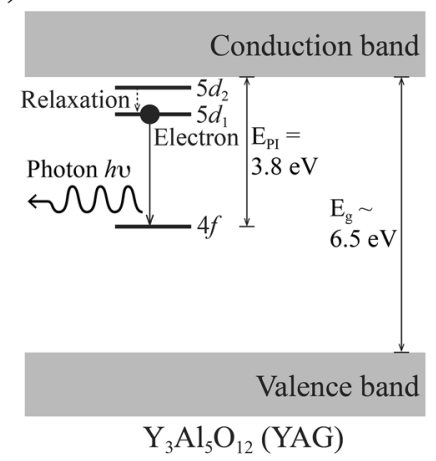

Fig. 7 a A schematic energy level diagram for $\mathrm{Ce}^{3+}$ showing the effect of the centroid shift and ligand field splitting as $\mathrm{Ce}^{3+}$ ions are embedded in YAG, adapted from $[39,72]$. b The energy level scheme of YAG: $\mathrm{Ce}^{3+}$ illustrating the relative energy states of $\mathrm{Ce}^{3+}$ with respect to the conduction and valence bands of $\mathrm{YAG}$. $\mathrm{E}_{\mathrm{PI}}$ and $\mathrm{E}_{\mathrm{g}}$ are photoionization and band-gap energy respectively, adapted from [73] 
$4 f-5 d$ transitions of $\mathrm{Ce}^{3+}$ observable in the range of visible light. Apparently, the electronic states of $\mathrm{Ce}^{3+}$ are significantly altered as the ion is doped in crystals. The effect of local structural distortions on the optical properties of YAG: $\mathrm{Ce}^{3+}$ has been investigated for example by Seijo et al. [71].

The optical transitions within energy levels of $\mathrm{Ce}^{3+}$ are the major processes for photon emission; however, the energetic position of these levels with respect to the conduction band (CB) and the valence band (VB) of the host lattice can also play an important role, particularly for the luminescence thermal stability of inorganic phosphors. To construct the energy level scheme of YAG:Ce ${ }^{3+}$ as depicted in Fig. 7b, Ueda et al. [73] have investigated the activation energy for thermally stimulated ionization processes for $5 d$ electrons of $\mathrm{Ce}^{3+}$ to be promoted to the $\mathrm{CB}$ of YAG. The energy level scheme of YAG: $\mathrm{Ce}^{3+}$ reveals that the first two $5 d$ states of $\mathrm{Ce}^{3+}$ are situated between the CB and VB of YAG, and it also implies that the $4 f-5 d$ transitions of $\mathrm{Ce}^{3+}$ will effectively proceed when an excitation source $(h v<3.8 \mathrm{eV})$ is provided and the thermal energy is lower than the activation energy required for the thermally stimulated ionization. For instance, when YAG: $\mathrm{Ce}^{3+}$ is excited by a $340 \mathrm{~nm}(\approx 3.64 \mathrm{eV})$ NUV LED the $5 d_{2}$ state is populated, and then relaxes to the $5 d_{1}$ state via coupling to phonons, giving rise to a Stokes shift $\Delta S$ and a radiative emission process to emit yellow light, as illustrated in Fig. 7. The excitation bands $4 f-5 d_{1}\left(\lambda_{\max } \approx 460 \mathrm{~nm}\right)$ and $4 f-5 d_{2}\left(\lambda_{\max } \approx 340-\right.$ $\mathrm{nm})$ are observed in the PLE spectra and a broad emission band $\left(\lambda_{\max } \approx 565 \mathrm{~nm}\right)$ is present in the PL spectrum, see Fig. 8a. A red-shift of the emission band with increasing $\mathrm{Ce}^{3+}$ concentration can be observed. Although the higher $\mathrm{Ce}^{3+}$ leads to an elongation of $\mathrm{Ce}-\mathrm{O}$ bond distances, which weakens the ligand fields and should induce a blue-shift, the probability of energy transfer from excited $\mathrm{Ce}^{3+}$ ions to neighboring $\mathrm{Ce}^{3+}$ ions of lower energy. This leads to a counteracting and predominating red-shift [54]. A comparison with the low-temperature spectrum for one selected composition, YAG:0.0033 $\% \mathrm{Ce}^{3+}$, reveals splitting of the $4 f$ states into ${ }^{2} F_{5 / 2}$ and ${ }^{2} F_{7 / 2}$ states due to spin-orbit coupling [4], see Fig. 8b.

(a)

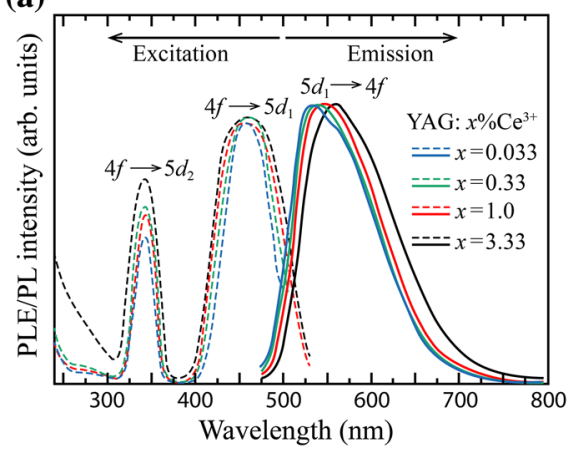

(b)

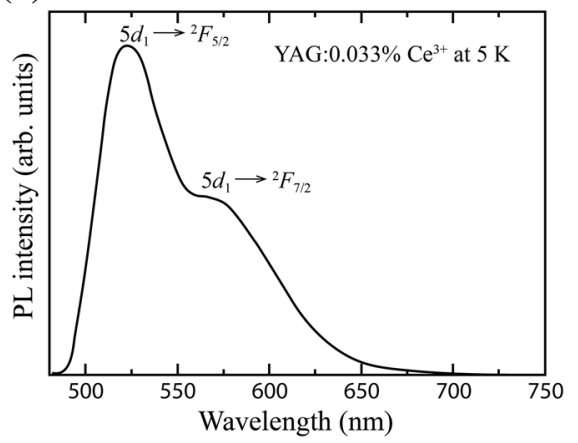

Fig. 8 a Room temperature PLE and PL spectra of YAG:Ce $\mathrm{Ce}^{3+}$ as a function of $\mathrm{Ce}^{3+}$ concentration. b Low temperature PL spectrum of YAG:0.033\% $\mathrm{Ce}^{3+}$. Both figures are adapted from [74] 


\subsection{Thermal Quenching in YAG: $\mathrm{Ce}^{3+}$}

The quenching temperature $\left(T_{q}\right)$ of $\mathrm{YAG}: \mathrm{Ce}^{3+}$, i.e., the temperature at which the emission intensity or emission decay time is reduced to half of the low-temperature value, can be as high as about $600 \mathrm{~K}$ if the $\mathrm{Ce}^{3+}$ concentration is sufficiently low, see Fig. 9, which is higher than for most other phosphors (cf. Table 1). The reduced quenching temperature with increasing $\mathrm{Ce}^{3+}$ concentration (Fig. 9b) has been related to thermally activated concentration quenching [74], but has also been explained in terms of $\theta_{\mathrm{D}}$ [54]. More specifically, it has been found that the increasing concentration of $\mathrm{Ce}^{3+}$ in YAG leads to a systematic decreasing in the $\theta_{\mathrm{D}}$ of YAG: $\mathrm{Ce}^{3+}$. Such a decreased $\theta_{\mathrm{D}}$ means that for a fixed temperature more phonons are activated, which in turn increases the probability for non-radiative processes (via $5 d-4 f$ crossover according to Fig. $4 \mathrm{~b}$ ) to happen. But, additionally, thermal ionization of $5 d$ electrons to the CB of the YAG garnet crystal may also be at play. For this purpose, Ueda et al. [73, 75] and Dorenbos [39] constructed the VRBE diagrams of various garnet crystals, notably YAG: $\mathrm{Ce}^{3+}, \mathrm{Y}_{3} \mathrm{Al}_{2} \mathrm{Ga}_{3} \mathrm{O}_{12}: \mathrm{Ce}^{3+}$ (YAGG: $\mathrm{Ce}^{3+}$ ), and $\mathrm{Y}_{3} \mathrm{Al}_{5-x} \mathrm{Ga}_{x} \mathrm{O}_{12}: \mathrm{Ce}^{3+}(x=0-5)$. A key result is that the substitution with $\mathrm{Ga}^{3+}$ lowers the $\mathrm{CB}$ level and also reduces the splitting energy, $\Delta_{12}$, between the $5 d_{1}$ and $5 d_{2}$ states (see Fig. 10a). This leads to a concomitant lowering of activation energy for $5 d_{1}-\mathrm{CB}$ transitions, i.e., of $\Delta E_{1}$ in Fig. $10 \mathrm{~b}$, which in turn leads to a lower $T_{q}$ [76]. In addition, it has been shown that the thermally stimulated ionization of $5 d$ electrons occurs not only from the $5 d_{1}$ state, but may also occur from defect states related to the presence of intrinsic defects such as oxygen vacancies, bound excitons, or other types of "impurities", cf. Fig. 10b. Since the presence of such defects is inevitable, the investigations of their nature and specifically their relation to the materials' optical properties have become increasingly important. Examples of recent works in this context include studies by Stanek et al. [77] and Muñoz-García et al. [78], who have predicted different defect structures in garnet phosphors and the effects of antisite defects on the electronic configurations of $\mathrm{Ce}^{3+}$ for $\mathrm{YAG}: \mathrm{Ce}^{3+}$.

(a)

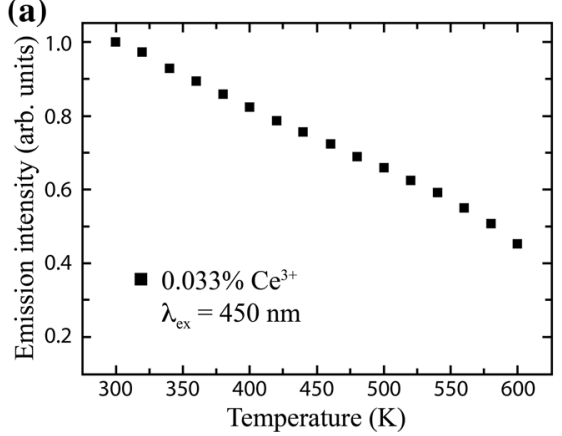

(b)

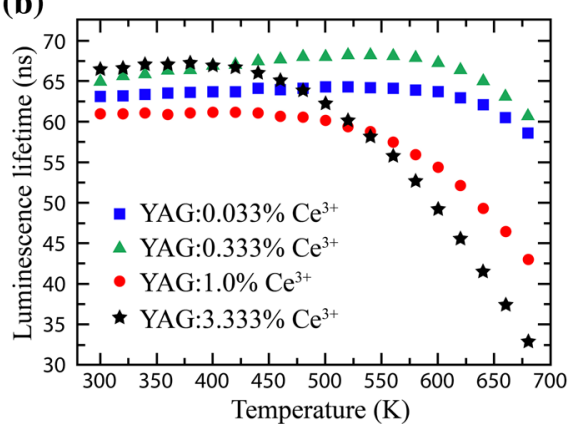

Fig. 9 a Emission intensity and b luminescence lifetime of $\mathrm{YAG}: \mathrm{Ce}^{3+}$ as a function of temperature, adapted from [74] 

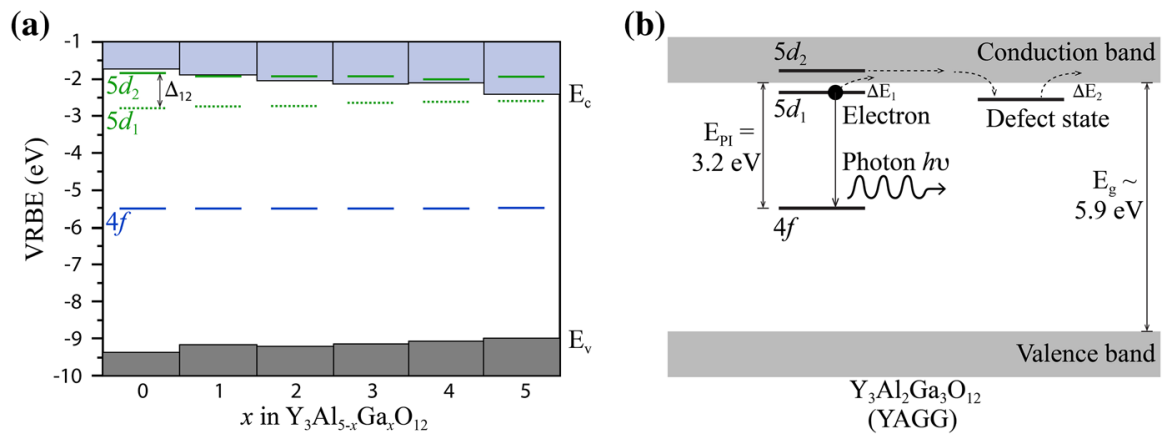

Fig. 10 The VRBE diagrams of $\mathbf{a} \mathrm{Y}_{3} \mathrm{Al}_{5-x} \mathrm{Ga}_{x} \mathrm{O}_{12}: \mathrm{Ce}^{3+}$ and $\mathbf{b}$ YAGG:Ce ${ }^{3+}$, adapted from Dorenbos [39] and Ueda et al. [73], respectively. In (a), $E_{c}$ and $E_{v}$ denote the energy levels for the $C B$ and VB of the host lattice (YAGG). In (b), $E_{\mathrm{g}}, \mathrm{E}_{\mathrm{PI}}, \Delta E_{1}$, and $\Delta E_{2}$ are the band-gap energy, photoionization energy, and activation energies for $5 \mathrm{~d}_{1}-\mathrm{CB}$ and defect-CB transitions, respectively

Apart from the pronounced reduction in emission intensity at elevated

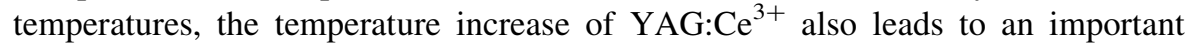
red-shift of the emission wavelength (Fig. 11a). Generally, the energy difference between the excited and ground states at a given temperature can be estimated by the Varshni equation,

$$
E(T)=E_{0}-\frac{\alpha T^{2}}{T+\beta},
$$

where $T$ is the operating temperature, $E_{0}$ is the energy difference between the ground and excited state at $0 \mathrm{~K}$, and $\alpha$ and $\beta$ are fitting constants [79]. Although blue-shifted emissions are observed for most phosphors and may be expected since while the lattice thermally expands and as an effect ligand fields are reduced, the converse effect observed for YAG: $\mathrm{Ce}^{3+}$ is most likely attributed to its highly rigid

(a)

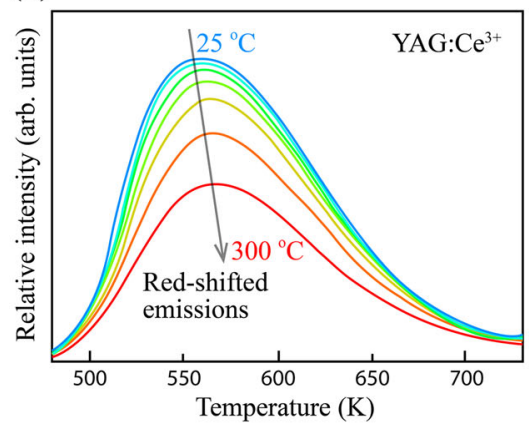

(b)

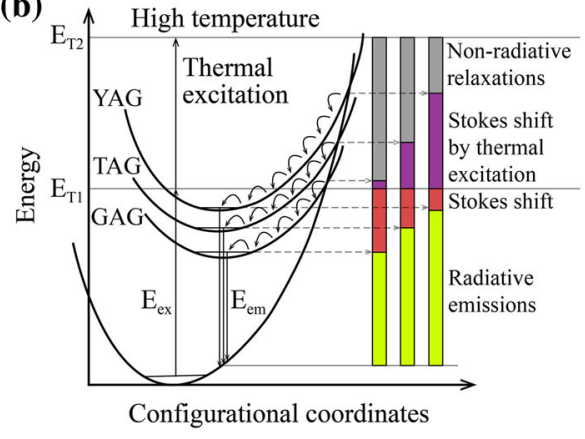

Fig. 11 a Temperature dependence of the emission spectra for YAG: $\mathrm{Ce}^{3+}$, adapted from [6]. b Configurational coordinate diagrams of YAG: $\mathrm{Ce}^{3+}$, TAG: $\mathrm{Ce}^{3+}$, and GAG:Ce ${ }^{3+}$, indicating the correlation of radiative emissions, Stokes shift, thermally excited Stokes shift, and non-radiative relaxations. The figure is adapted from [62] 
structure [54]. Chiang et al. [62] have explained that rigid structures have a larger energy barrier for thermal red-shifted emissions to occur prior to non-radiative relaxations as illustrated in Fig. $11 \mathrm{~b}$. Since the rigidity of the host lattice $(\mathrm{Y}, \mathrm{Gd}, \mathrm{Tb})_{3} \mathrm{Al}_{5} \mathrm{O}_{12}$, abbreviated by $\mathrm{YAG}, \mathrm{GAG}$, and TAG, respectively, goes as YAG > TAG > GAG, YAG: $\mathrm{Ce}^{3+}$, this would explain the greatest capacity for thermal red-shifted emissions among these $\mathrm{Ce}^{3+}$-doped garnet phosphors. An alternative explanation invoked in the literature for other hosts involves Jahn-Teller couplings [80].

\subsection{Lattice Vibrations in YAG: $\mathrm{Ce}^{3+}$}

As understood from above, the vibrational dynamics of inorganic phosphors is crucial in determining their optical properties. The processes involving both optical and vibrational transitions are known as vibronic transitions [81]. For the specific case of YAG: $\mathrm{Ce}^{3+}$, the presence of vibronic transitions is evident from the presence of phonon side bands of the low temperature luminescence spectra [72] as shown in Fig. 12. The phonon side bands are specifically located in the range $131-211 \mathrm{~cm}^{-1}$, which, for simplicity, has been averaged to $200 \mathrm{~cm}^{-1}$ [74]. The broadening of the excitation/absorption and emission bands with increasing temperature is attributed to complex electron-phonon coupling which may be pictured via the overlapping of wavefunctions of vibronic transitions in the configurational coordinate diagram, see Fig. $4 \mathrm{~b}$. The strength of the electron-phonon coupling can be evaluated by the Huang-Rhys parameter, $S$, which can be determined from the following relationship: Stokes shift $=2 S \hbar \omega$, where $\hbar \omega$ is the energy of the relevant phonon [82, 83]. For YAG: $\mathrm{Ce}^{3+}, S \approx 6$, which is classified in terms of strong electron-phonon coupling [84]. Strong electron-phonon coupling implies a large offset $\Delta R$ in the nuclear coordinate between the minima of the excited and ground parabolic potential curves (see Fig. 4b), thus increasing the probability for non-radiative processes. However, other phonons rather than those of $131-211 \mathrm{~cm}^{-1}$ could possibly result in non-radiative relaxation via electron-phonon coupling. For example, some phonons of higher vibrational frequency than $200 \mathrm{~cm}^{-1}$ were also found by Robbins [72] to be involved in vibronic transitions in the NUV absorption

Fig. 12 Low temperature $(T=4.2 \mathrm{~K})$ luminescence spectra of YAG: $\mathrm{Ce}^{3+}$ showing phonon side bands fine structure in both the absorption and emission spectra, adapted from [72]

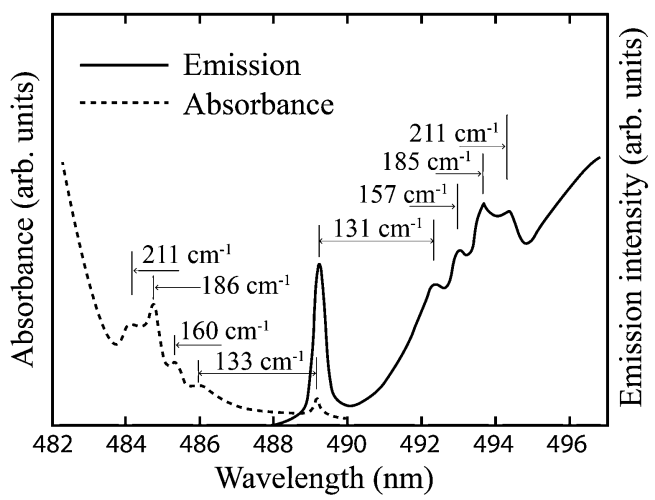


spectrum of YAG: $\mathrm{Ce}^{3+}$; however, these are not observed in the luminescence spectrum, probably due to a smearing-out effect caused by multi-phonon couplings in the electronic $4 f-5 d$ transitions.

Of particular interest is to understand which particular phonons, and local structures that are of importance in electron-phonon coupling processes. The phonons of YAG can be represented in terms of their irreducible representation:

$$
\begin{aligned}
\Gamma= & 5 \mathrm{~A}_{1 \mathrm{u}}+3 \mathrm{~A}_{1 \mathrm{~g}}+5 \mathrm{~A}_{2 \mathrm{u}}+5 \mathrm{~A}_{2 \mathrm{~g}}+10 \mathrm{E}_{\mathrm{u}}+8 \mathrm{E}_{\mathrm{g}}+14 \mathrm{~T}_{1 \mathrm{~g}}+18 \mathrm{~T}_{1 \mathrm{u}}+14 \mathrm{~T}_{2 \mathrm{~g}} \\
& +16 \mathrm{~T}_{2 \mathrm{u}} .
\end{aligned}
$$

The 25 modes having symmetries $\mathrm{A}_{1 \mathrm{~g}}, \mathrm{E}_{\mathrm{g}}$ and $\mathrm{T}_{2 \mathrm{~g}}$ are Raman active, while 17 of the modes having $\mathrm{T}_{1 \mathrm{u}}$ symmetry are IR active (the 18 th $\mathrm{T}_{1 \mathrm{u}}$ is acoustic). Here, the $\mathrm{E}_{\mathrm{g}}$ modes are doubly degenerated and the $T_{2 g}, T_{1 u}$ are triply degenerated. In Fig. 13a the IR and Raman spectra of YAG are shown. As can be seen, there are 17 distinguishable bands in the IR spectrum and 25 bands in the Raman spectrum, plotted over the frequency range $100-900 \mathrm{~cm}^{-1}$, which is in agreement with the grouptheoretically predicted number of modes. Here, the lower-frequency part of the spectra $\left(<200 \mathrm{~cm}^{-1}\right)$ is related to vibrational modes involving the heavy $\mathrm{Y}$ ions, whereas the higher-frequency part $\left(200-900 \mathrm{~cm}^{-1}\right)$ relates primarily to vibrational modes of the lighter $\mathrm{O}$ and $\mathrm{Al}$ atoms. This is seen in Fig. 13b, which shows the one phonon density of states (DOS) of the rare-earth aluminate garnets $\left(\mathrm{RE}_{3} \mathrm{Al}_{5} \mathrm{O}_{12}\right)$ [85]. To assign each band to specific vibrational motions, researchers have used different methods [86, 87], and both YAG and its RE-doped variants have been studied in detail. Drawing in complementary local structural information, which generally indicates only small differences in the structure between these different materials, notably related to slight lattice expansion/distortion upon the $\mathrm{Ce}^{3+}$ doping with no change of the overall (average) structural symmetry [54]. It follows that the vibrational spectra of YAG: $\mathrm{Ce}^{3+}$ can be expected to be similar to that of YAG, meaning that the vibrational properties of the undoped compound may be used as a very good starting point for the understanding of the vibrational dynamics in these technologically important materials. Further research along these lines may be very rewarding for elucidating the mechanistic aspects of luminescence in YAG type

(a)

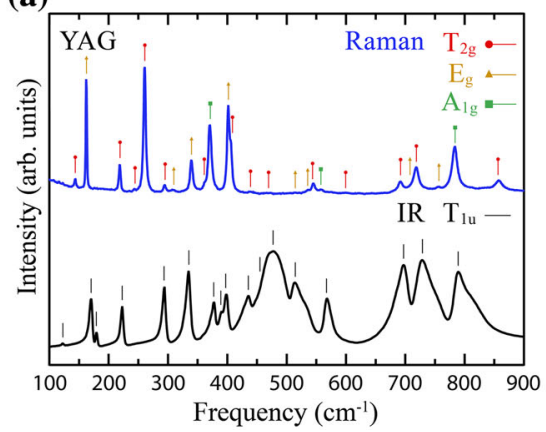

(b)

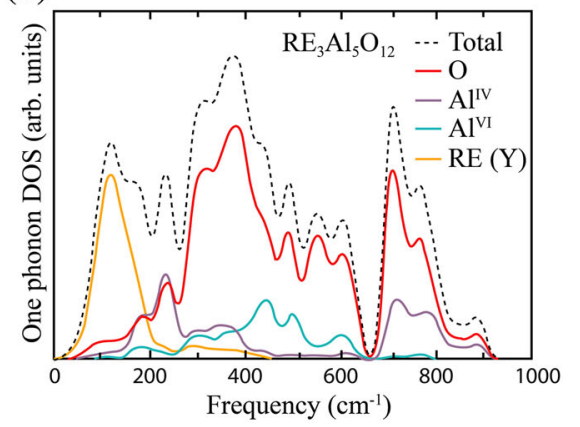

Fig. 13 a IR and Raman spectra of YAG as measured at $300 \mathrm{~K}$, adapted from [88] (b) One phonon DOS of $\mathrm{RE}_{3} \mathrm{Al}_{5} \mathrm{O}_{12}\left(\mathrm{Y}_{3} \mathrm{Al}_{5} \mathrm{O}_{12}\right)$, adapted from [85] 
phosphors, which would be central for understanding inorganic phosphors generally.

\subsection{Other Yellow Phosphors}

Although the performance of YAG: $\mathrm{Ce}^{3+}$ as a yellow phosphor coupled with a blue LED chip is almost ideal for LED lamps with a high CCT, and this has slightly hampered the research of new improved materials, a variety of other classes of inorganic, yellow-emitting phosphors have been developed and are now attracting increased attention. Examples are materials based on oxynitrides, such as $\mathrm{Ca}-\alpha-$ SiAlON:Eu ${ }^{2+}$ and $\mathrm{Li}-\alpha-\mathrm{SiAlON}: \mathrm{Eu}^{2+}[37,89]$. The CIE coordinates of $\mathrm{Ca}-\alpha-$ SiAlON:Eu ${ }^{2+}(0.491,0.497)$ and Li- $\alpha-S i A l O N: E^{2+}(0.48,0.51)$ and YAG:Ce ${ }^{3+}$ $(0.41,0.57)$ reveal that these two oxynitride phosphors are more suitable to produce warm white light in pcWLEDs than YAG: $\mathrm{Ce}^{3+}$. Furthermore, pcWLEDs using Ca$\alpha$-SiAlON:Eu ${ }^{2+}$ have better chromaticity stability, i.e., small variations of the CIE coordinates, in the temperature range of $25-200{ }^{\circ} \mathrm{C}$ than based on YAG:Ce ${ }^{3+}$ [37]. However, the absorption and external quantum efficiency of $\mathrm{Li}-\alpha-\mathrm{SiAlON}: \mathrm{Eu}^{2+}$ are about 70 and $40 \%$, respectively, which are lower than for YAG:Ce ${ }^{3+}, 90$ and $75 \%$, respectively [90]. Other examples include phosphors based on silicates, such as $\mathrm{Sr}_{3} \mathrm{SiO}_{5}: \mathrm{Eu}^{2+}$ [91], which provide a warmer white light compared to YAG:Ce ${ }^{3+}$, when combined with an identical blue source. As comparing to YAG: $x \% \mathrm{Ce}^{3+}$ generally for different $\mathrm{Ce}^{3+}$ concentrations (e.g., $x=0.033-3.33$ [74]), $\mathrm{Sr}_{3} \mathrm{SiO}_{5}$ :$\mathrm{Eu}^{2+}$ also shows better thermal stability of the emission intensity as the temperature increases from 25 to $250{ }^{\circ} \mathrm{C}$ [91]; however, the quantum efficiency (68 \%) and CRI (64) are still worse than for YAG:Ce ${ }^{3+}$. Another silicate phosphor is $\mathrm{Li}_{2} \mathrm{SrSiO}_{4}$ :$\mathrm{Eu}^{2+}$ [92]. PLE measurements of $\mathrm{Li}_{2} \mathrm{SrSiO}_{4}: \mathrm{Eu}^{2+}$ show that the excitation spectrum is relatively broad, covering both the NUV (380-410 $\mathrm{nm}$ ) and blue $(450-480 \mathrm{~nm})$ ranges, whereas the emission band is centered at $562 \mathrm{~nm}$ and a strong orange-yellow light is typically perceived. When combined with a $455 \mathrm{~nm}$ blue LED, it generates white light located at the CIE coordinates $(0.3346,0.3401)$, corresponding to a CCT of $5406 \mathrm{~K} . \mathrm{Li}_{2} \mathrm{SrSiO}_{4}$ doped with $0.005 \mathrm{~mol} \% \mathrm{Eu}^{2+}$ shows the strongest emission intensity compared to the other $\mathrm{Eu}^{2+}$ doping concentrations, whereas $x \mathrm{~mol} \%$ $(x=0.0025-0.05)$ and the LE is comparable to that of YAG:Ce ${ }^{3+}$.

Further strategies to develop new, better performing phosphors include the tuning of the optical properties of YAG:Ce ${ }^{3+}$ by co-doping with a 2nd or even a 3rd dopant atom, on either the $\mathrm{Y}^{3+}$ and/or the $\mathrm{Al}^{3+}$ site(s). For example, the influences on optical properties resulting from cation substitutions have been discussed previously for $(\mathrm{Y}, \mathrm{Tb}, \mathrm{Gd}, \mathrm{Lu})_{3}(\mathrm{Al}, \mathrm{Ga})_{5} \mathrm{O}_{12}: \mathrm{Ce}^{3+}[57,61-65]$ and $\mathrm{Y}_{3} \mathrm{Al}_{5-2 x}(\mathrm{Mg}, \mathrm{Si})_{x} \mathrm{O}_{12}: \mathrm{Ce}^{3+}$ [36]. According to Katelnikovas et al. [36], the pcWLEDs comprising $\mathrm{Y}_{3} \mathrm{Mg}_{2-}$ $\mathrm{AlSi}_{2} \mathrm{O}_{12}: \mathrm{Ce}^{3+}$ (YMASG:Ce ${ }^{3+}$ ) and a $483 \mathrm{~nm}$ blue LED emit warm white light characterized by the coordinates $(0.4338,0.4030)$ in the CIE 1931 chromaticity diagram. The emitted white light corresponds to a CCT of $3000 \mathrm{~K}$ and a CRI of 75. The peak position of the emission band is at around $600 \mathrm{~nm}$ as excited by a $440 \mathrm{~nm}$ blue LED. A strong red-shift $(40-50 \mathrm{~nm})$ takes place when $\mathrm{Mg}^{2+}$ and $\mathrm{Si}^{4+}$ substitute $\mathrm{Al}^{3+}$ in YAG:Ce ${ }^{3+}$, and the observed red shift is attributed to increased covalency and Stokes shift. The LE of the pcWLEDs containing YMASG:Ce ${ }^{3+}$ is 
about $81 \%$ of that of the pcWLEDs coated with YAG: $\mathrm{Ce}^{3+}$. The annealing temperature $\left(1400-1550{ }^{\circ} \mathrm{C}\right)$ and $\mathrm{Ce}^{3+}$ concentrations $(0.5-2 \%)$ for YMASG:Ce ${ }^{3+}$ synthesized via sol-gel combustion methods have shown about 10 and $20 \%$ impacts on the luminescence decay time, respectively.

\section{Blue Phosphors}

Blue emitting phosphors can be useful for SSL if they can be excited by a NUV LED, i.e., they convert radiation in the range $380-410 \mathrm{~nm}$ to light centered in the blue region (420-500 nm, including part of the violet range). It has been pointed out that it is presumably impossible to develop an efficient blue emitting phosphor that can be excited at $\lambda \geq 410 \mathrm{~nm}$ due to Stokes shift requirements [12]. This constraint limits possible applications to materials showing suitable (and possibly allowed) absorption and emission bands in those two spectral regions. In practice, the only two activator ions that have attracted interest for the development of blue phosphors for WLEDs (White Light Emitting Diodes) are $\mathrm{Eu}^{2+}$ and $\mathrm{Ce}^{3+}$. This section will be mainly devoted to these ions.

Both activators give rise to luminescence bands due to $5 d-4 f$ transitions $\left(4 f^{6} 5 d^{1} \rightarrow 4 f^{7}\right.$ and $5 d^{1} \rightarrow 4 f^{1}$, respectively) with radiative decay times of the order of $1 \mu \mathrm{s}$ for the former [93], and some tens of nanoseconds for the latter [94]. The $5 d-4 f$ transitions are allowed through the electric dipole mechanism and, therefore, are generally very strong. Their quantum efficiency at room temperature (RT) is in principle high, apart from the cases in which photoionization occurs, i.e., escape of an electron to the conduction band $[95,96]$.

Among the inorganic hosts developed for blue LED phosphors, prominent are oxide-based materials, such as phosphates, silicates, aluminates; on the other hand, additional host compositions have been proposed and developed successfully, such as nitrides, oxynitrides, and others. These two host categories will be reviewed separately.

\subsection{Blue Phosphors-Oxide Hosts: Phosphates, Silicates, Aluminates}

An important class of blue phosphors for pcLEDs is the phosphate family, which couples a relatively easy preparation to a great structural flexibility. Moreover, it has been shown that $\mathrm{Eu}^{2+}$ gives rise in many cases to blue emission in these hosts [97]. Possible explanations are a low centroid shift of the $4 f^{6} 5 d^{1}$ configuration, a weak ligand field and/or a small Stokes shift. The same consideration applies to the case of $\mathrm{Ce}^{3+}[98-101]$.

Please note that in the rest of this chapter the doping level will always be given in mol\%, which will be abbreviated as $\%$ for simplicity.

The apatite family of phosphate crystalline materials has attracted attention as a host for $\mathrm{Ce}^{3+}$ and $\mathrm{Eu}^{2+}$. Shang et al. [101] have reported on the synthesis, luminescence, and energy transfer properties of the apatite $\mathrm{Ca}_{8} \mathrm{La}_{2}\left(\mathrm{PO}_{4}\right)_{6} \mathrm{O}_{2}$ activated with $\mathrm{Ce}^{3+}$ and/or $\mathrm{Eu}^{2+}$. Samples were made using a Pechini-type solgel method. Both dopants show blue photoluminescence emission upon UV 
excitation, and efficient energy transfer from $\mathrm{Ce}^{3+}$ to $\mathrm{Eu}^{2+}$ has been demonstrated. The best results are obtained for a sample containing $4 \%$ of $\mathrm{Ce}^{3+}$ and $2 \%$ of $\mathrm{Eu}^{2+}$, showing emission of high color purity and a PLE spectrum spanning the whole UV region (Fig. 14). A similar host, doped with $\mathrm{Eu}^{2+}$, but containing chlorine, $\mathrm{Ca}_{2} \mathrm{PO}_{4} \mathrm{Cl}$ with the spodiosite crystal structure, was investigated by Chiu et al. [25]. Phosphors containing various amounts of dopants were prepared by solid state reaction; the sample containing $11 \%$ of $\mathrm{Eu}^{2+}$ showed intense blue emission peaking at $454 \mathrm{~nm}$ upon excitation at $400 \mathrm{~nm}$, with internal and external quantum efficiencies of 85 and $61 \%$, respectively. These phosphors are considered good candidates for pcLEDs.

Double orthophosphates containing an alkali and an alkaline earth cation have also been widely studied. $\mathrm{KBaPO}_{4}: \mathrm{Eu}^{2+}$ has been considered by $\mathrm{Im}$ et al. [102] who have reported on its synthesis, crystal structure, and luminescence spectroscopy. The material emits at $420 \mathrm{~nm}$, which is almost in the violet range, with excitation extending over the whole UV region. When the surface is coated with a $\mathrm{SiO}_{2}$ layer, the phosphor shows an excellent moisture resistance. The phosphor $\gamma-\mathrm{KCaPO}_{4}: \mathrm{Eu}^{2+}$ has been studied by Yim et al. [24] who have reported on the synthesis and optical spectroscopy. The material can be excited in a wide spectral range in the UV and visible (200-450 nm) (Fig. 15), and the emission peaks at $473 \mathrm{~nm}$, resulting in a whitish blue luminescence with CIE coordinates $(0.199,0.319)$ for the sample doped with $3.2 \% \mathrm{Eu}^{2+}$. Another example of double orthophosphate is $\mathrm{LiCaPO}_{4}$ :$\mathrm{Eu}^{2+}$. Zhang et al. [103] have reported on the structure-properties relationships of this phosphor, and shown that when the dopant concentration is optimized to $3 \%$, the peak luminescence is at $470 \mathrm{~nm}$ with excitation at $395 \mathrm{~nm}$, the CIE coordinates are $(0.119,0.155$, greenish-blue) and the quantum efficiency is $52 \%$.

Diphosphates are another class of phosphate hosts that has been explored for blue phosphors. $\beta-\mathrm{Ca}_{2} \mathrm{P}_{2} \mathrm{O}_{7}$, in which $5 \% \mathrm{Eu}^{2+}$ substitutes for $\mathrm{Ca}^{2+}$, has been prepared by combustion synthesis by $\mathrm{Ta}$ and Chen [104]. Excitation at 387 or shorter wavelengths originates emission peaking at $421 \mathrm{~nm}$ (more violet than blue) but extending to about $475 \mathrm{~nm}$ in the blue. A similar host is the boro-diphosphate

Fig. 14 The CIE chromaticity diagram for the $\mathrm{Ca}_{8} \mathrm{La}_{2}\left(\mathrm{PO}_{4}\right)_{6} \mathrm{O}_{2}: 0.04 \mathrm{Ce}^{3+}$ (point 1), and $\mathrm{Ca}_{8} \mathrm{La}_{2}\left(\mathrm{PO}_{4}\right)_{6} \mathrm{O}_{2}: 0.05 \mathrm{Eu}^{2+}$ (point 2) samples, adapted from [101]

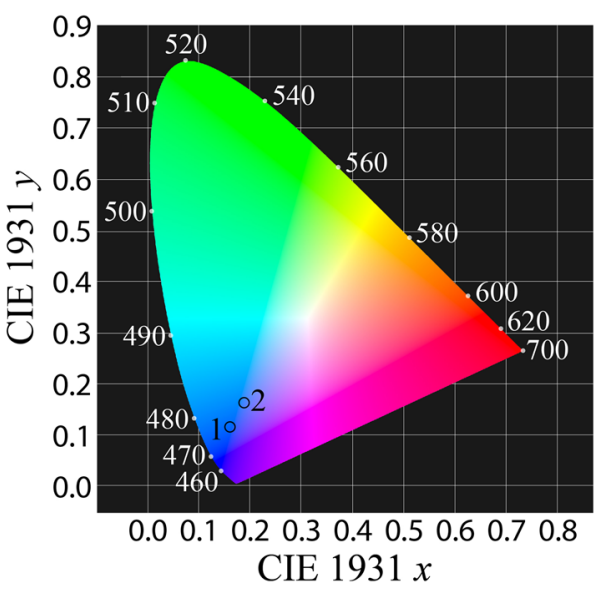


Fig. 15 Excitation (a) and emission spectra (b) of $\mathrm{KCa}_{1-}$ ${ }_{x} \mathrm{PO}_{4}: x \mathrm{Eu}^{2+}(x=0.032)$ phosphor. The inset shows the emission spectra of the different excitation peaks, adapted from [24]

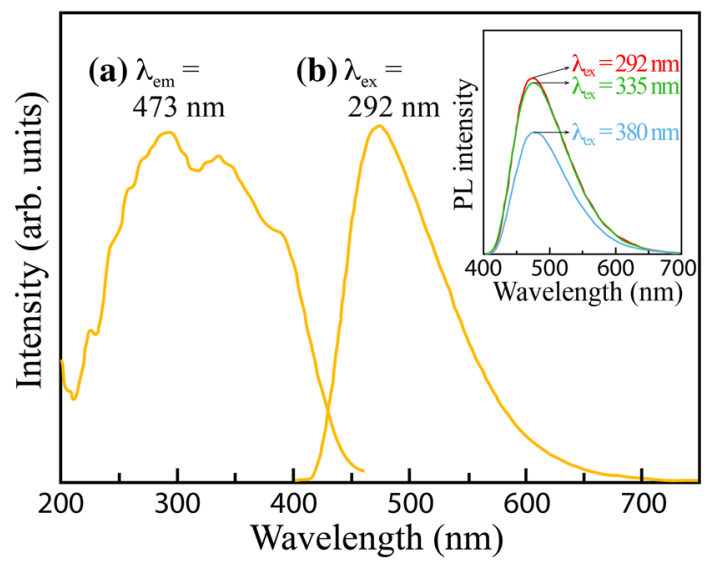

$\mathrm{KBaBP}_{2} \mathrm{O}_{8}$ having a tetragonal structure. Sun et al. have reported on the material doped with $\mathrm{Eu}^{2+}$ [105], showing that upon excitation in a broad spectral region extending from 250 to $420 \mathrm{~nm}$, emission peaking at $445 \mathrm{~nm}$ is observed. This emission is very broad and extends up to $600 \mathrm{~nm}$. The ideal $\mathrm{Eu}^{2+}$ concentration appears to be $3 \%$, since higher concentration samples suffer from concentration quenching.

Another important class of blue phosphors is the silicate family, characterized by excellent chemical stability and again large composition variability, although the synthetic procedures might require higher temperatures than phosphates. Liu et al. [106] have reported on the phosphor $\mathrm{Li}_{2} \mathrm{Sr}_{1-3 x / 2} \mathrm{Ce}_{x} \mathrm{SiO}_{4}(x=0.0025-0.07)$. The material was prepared by high temperature solid state synthesis as a single phase and it was found that $\mathrm{Ce}^{3+}$ is located in the $\mathrm{Sr}^{2+}$ site. The phosphor produces broad blue emission peaking at $442 \mathrm{~nm}$ with a broad excitation profile covering the spectral region from 200 to $400 \mathrm{~nm}$. The thermal quenching is weak and the internal and external quantum efficiencies are 81 and $66 \%$, respectively, upon $358 \mathrm{~nm}$ excitation. The phosphor is promising for SSL applications.

The doped disilicate $\mathrm{Sr}_{2} \mathrm{MgSi}_{2} \mathrm{O}_{7}: \mathrm{Eu}^{2+}$ (well known in the field of persistent luminescence [107]) has been investigated as blue phosphor for pcLEDs by Zhang et al. [27]. The material was prepared by solid state reaction as a single phase and showed broad and asymmetric emission centered at $470 \mathrm{~nm}$, upon excitation at the peak located just below $400 \mathrm{~nm}$. The optimum $\mathrm{Eu}^{2+}$ concentration was found to be $6 \%$ and the CIE coordinates (measured in a blue LED fabricated ad hoc) were $(0.142,0.228)$. $\left(\mathrm{Ca}_{1-x}, \mathrm{Eu}_{x}\right) \mathrm{MgSi}_{2 y} \mathrm{O}_{6+\delta}$ ( $x$ ranging from 0.001 to $0.06, y$ from 1.0 to 2.0) has been considered as a blue phosphor by Jung et al. [108]. The samples were produced by spray pyrolysis from suitable precursors. The highest emission intensity around $450 \mathrm{~nm}$ was found for $y$ above 1.0, i.e., in the presence of a silicon excess. In particular, for $x=0.04$ and $y=1.3$, the emission intensity showed an increase of about $150 \%$ compared to the stoichiometric sample with $x=0.01$ and $y=1.0$.

The novel fluoro-silicate phosphor $\mathrm{Ca}_{5.45} \mathrm{Li}_{3.55}\left(\mathrm{SiO}_{4}\right)_{3} \mathrm{O}_{0.45} \mathrm{~F}_{1.55}$ doped with $\mathrm{Ce}^{3+}$ has been developed by Zhou et al. [109]. The material was prepared by high 
temperature solid state reaction yielding a single phase in which the $\mathrm{Ce}^{3+}$ ions substitute for $\mathrm{Ca}^{2+}$. The luminescence spectra of the sample containing $3 \% \mathrm{Ce}^{3+}$ show a broad asymmetrical emission band peaking around $470 \mathrm{~nm}$ (Fig. 16), which is excited in a broad wavelength range with maxima at about 256 and $371 \mathrm{~nm}$. The RT decay times of the emission are close to $60 \mathrm{~ns}$, a value typical for $\mathrm{Ce}^{3+}$ emitting in the visible region. For the optimal dopant concentration of $3 \%$, the color coordinates are $(0.154,0.188)$, and the internal quantum efficiency is $82 \%$. The phosphor shows high color purity and good thermal stability.

An interesting approach was proposed by Park et al. [110] in order to identify silicate phosphors for WLEDs. They employed combinatorial chemistry, developing quaternary and ternary combinatorial libraries to synthesize, process, and screen silicate materials. This combinatorial chemistry consisted of solution-based combinatorial synthesis and characterization, and swift scanning of luminance. The authors found several candidates not only for blue, but also green and red, efficient emission upon NUV excitation.

Aluminates are another important phosphor family. $\mathrm{BaMgAl}_{10} \mathrm{O}_{17}: \mathrm{Eu}^{2+}$ (BAM: $\mathrm{Eu}^{2+}$ ) is a commercial phosphor emitting blue light in fluorescent lamps. Wang et al. [111] have studied its spectroscopic behavior as a phosphor for pcLEDs. The samples were prepared by solid state reaction in the presence of different amounts of $\mathrm{H}_{3} \mathrm{BO}_{3}$. Excitation spectra cover the range 280-400 nm and the emission is broad, peaking at about $440 \mathrm{~nm}$ and extending to $520 \mathrm{~nm}$. For the sample prepared with a $6 \%$ excess of boric acid the CIE coordinates are $(0.151$, 0.058). BAM:Eu ${ }^{2+}$ appears to be suitable for the use in SSL. Cui et al. have studied $(\mathrm{Mg}, \mathrm{Sr}) \mathrm{Al}_{2} \mathrm{O}_{4}: \mathrm{Eu}^{2+}$ as a blue phosphor for WLEDs [112]. Various materials were prepared with different amounts of $\mathrm{Mg}$ and $\mathrm{Sr}$ and of the dopant. The materials were characterized by XRD and electron microscopy. $\mathrm{MgAl}_{2} \mathrm{O}_{4}: \mathrm{Eu}^{2+}$ shows blue luminescence in the range $400-600 \mathrm{~nm}$ peaking around $460 \mathrm{~nm}$, with excitation extending in the UV up to $400 \mathrm{~nm}$. The addition of $\mathrm{Sr}^{2+}$ increases the phosphor emission intensity up to $6 \%$. The material $\mathrm{Sr}_{3} \mathrm{Al}_{2} \mathrm{O}_{6}$ doped with $\mathrm{Ce}^{3+}$ and alkali ions has been synthesized by solid state reaction and its luminescence has been investigated by $\mathrm{Li}$ et al. [113]. For all samples the excitation spectrum shows a

Fig. 16 Excitation and emission spectra of $\mathrm{Ca}_{5.45} \mathrm{Li}_{3.55}\left(\mathrm{SiO}_{4}\right)_{3} \mathrm{O}_{0.45} \mathrm{~F}_{1.55}$. The inset shows the comparison of the emission spectra of $\mathrm{Ce}^{3+}$ doped and the undoped host, adapted from [109]

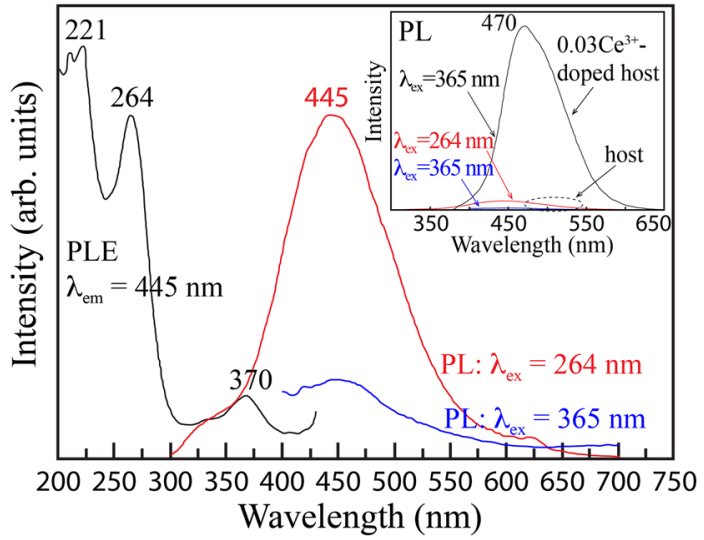


strong peak at $395 \mathrm{~nm}$, and excitation at this wavelength produces a very broad band peaking at about $460 \mathrm{~nm}$ and extending up to $600 \mathrm{~nm}$. The addition of $\mathrm{Li}^{+}$, $\mathrm{Na}^{+}, \mathrm{K}^{+}$or $\mathrm{Rb}^{+}$, slightly changes the profile of the excitation bands, but does not affect the emission profile. However, the spectral intensity appears to increase with the alkali ion doping, and the highest increase is obtained with the addition of $4 \%$ $\mathrm{Rb}^{+}$. The decay times of the $\mathrm{Ce}^{3+}$ luminescence in the presence of alkali ions is rather short around $20 \mathrm{~ns}$.

\subsection{Blue Phosphors-Other Hosts}

In this subsection other hosts will be discussed, not belonging to the category of common oxide hosts such as phosphates, silicates, and aluminates. The main focus will be on nitrides and oxynitrides, but also other hosts will be considered. Also, another activator ion $\left(\mathrm{Ce}^{4+}\right)$ will be briefly discussed.

Nitride and oxynitride phosphors have become important in the field of SSL due to their high efficiency, stability, and strong absorption in the NUV and blue spectral regions [8]. As an example, the phosphor $\mathrm{BaSi}_{7} \mathrm{~N}_{10}$ doped with $\mathrm{Eu}^{2+}$ has been reported by $\mathrm{Li}$ et al. [114]. The material can be produced by sol-gel, followed by direct gas reduction and nitridation. The luminescence spectra are composed of a strong green-blue emission band centered at about $482-500 \mathrm{~nm}$ (Fig. 17), with corresponding excitation profile in the region $250-400 \mathrm{~nm}$ with a maximum around $300 \mathrm{~nm}$. The external QE reaches $52 \%$ upon excitation at $300 \mathrm{~nm}$, for the sample doped with $20 \% \mathrm{Eu}^{2+}$. The coordinates of the phosphors containing various concentrations of $\mathrm{Eu}^{2+}$ fall in the cyan region of the CIE diagram. The strong emission, high QE and low thermal quenching show that these phosphors are suitable for pcLEDs applications. Tang et al. have developed a blue emitting oxynitride phosphor of formula $\mathrm{BaSi}_{3} \mathrm{Al}_{3} \mathrm{O}_{4} \mathrm{~N}_{5}: \mathrm{Eu}^{2+}$ [115], synthesized at high temperature in flowing $\mathrm{N}_{2}$ atmosphere. The phosphor shows a blue emission peak around $470 \mathrm{~nm}$ and a broad excitation spectrum in the NUV. The optimum concentration of the dopant is $15 \%$ replacing $\mathrm{Ba}^{2+}$. At this doping level, the decay time of the emission is just above $800 \mathrm{~ns}$. The internal and external quantum efficiencies of the luminescence are 85 and $79 \%$, with excitation at $305 \mathrm{~nm}$. The

Fig. 17 Temperature dependence of emission intensity of $\mathrm{BaSi}_{7} \mathrm{~N}_{10}: \mathrm{Eu}^{2+}$ (20 mol\%) phosphors excited by $300 \mathrm{~nm}$ radiation, adapted from [114]

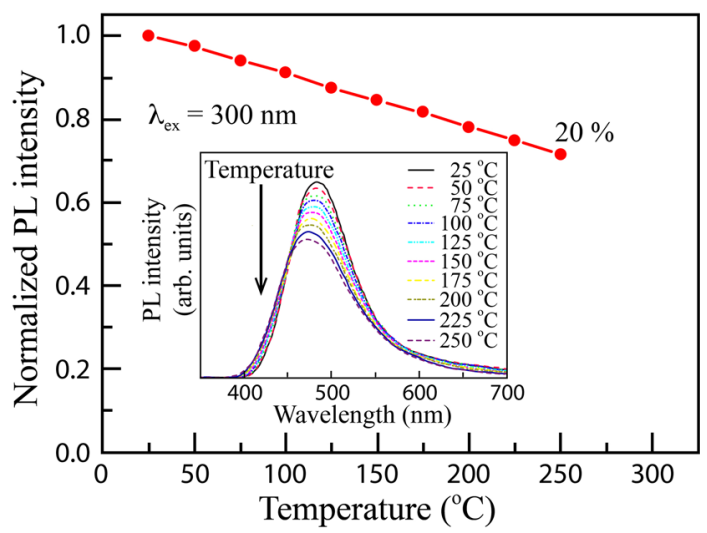


phosphor appears to be superior to commercial BAM:Eu ${ }^{2+}$ because it has a much higher converted efficiency than the latter material under the emission spectrum of a NUV LED chip. The oxynitride material $\beta$-SiAlON activated with $\mathrm{Ce}^{3+}$ was investigated by Ryu et al. [116]. The hexagonal compound was prepared with various amounts of the dopant and suitably characterized using XRD and other techniques. The phosphors emit blue light with a maximum at about $470-490 \mathrm{~nm}$ and an excitation peak at $410 \mathrm{~nm}$. The optimum dopant concentration appears to be $2 \%$ (replacing $\mathrm{Si}$ ). It was found that the thermal quenching is significantly smaller than for YAG: $\mathrm{Ce}^{3+}$, confirming the good properties of this material as a blue phosphor.

Mikami and Kijima have studied in depth how covalency affects the position of the $5 d$ levels of rare earth ions in nitride and oxynitride phosphors [117]. Using theoretical arguments, they conclude that the idea of covalency does not seem to be fully reliable in tailoring the position of $5 \mathrm{~d}$ levels of $\mathrm{Ce}^{3+}$ and $\mathrm{Eu}^{2+}$ in nitrides and oxynitrides. They propose that quantitative dielectric properties reflecting spectroscopic polarizability should be used in addition to covalency. These ideas have been applied to a series of nitride and oxynitride phosphors such as $\mathrm{LaSi}_{3} \mathrm{~N}_{5}: \mathrm{Ce}^{3+}$ (blue), $\mathrm{La}_{3} \mathrm{Si}_{6} \mathrm{~N}_{11}: \mathrm{Ce}^{3+}$ (yellow), $\mathrm{BaSi}_{2} \mathrm{O}_{2} \mathrm{~N}_{2}: \mathrm{Eu}^{2+}$ (bluish green), $\mathrm{Ba}_{3} \mathrm{Si}_{6} \mathrm{O}_{9} \mathrm{~N}_{4}: \mathrm{Eu}^{2+}$ (bluish green), and $\mathrm{Ba}_{3} \mathrm{Si}_{6} \mathrm{O}_{12} \mathrm{~N}_{2}: \mathrm{Eu}^{2+}$ (green).

The oxychalcogenide phosphor $\mathrm{CaLaGa}_{3} \mathrm{~S}_{6} \mathrm{O}: \mathrm{Ce}^{3+}$ was developed by $\mathrm{Yu}$ et al. in order to obtain a suitable material for the absorption of light emitted by InGaN chips [118]. The phosphor was prepared by using a solid state reaction starting from appropriate sulfide and oxide precursors. Luminescence spectra are composed of a double peaked emission feature with maxima at 442 and $478 \mathrm{~nm}$, and excitation is dominated by a peak at $398 \mathrm{~nm}$. Maximum intensity is obtained for the sample containing $10 \% \mathrm{Ce}^{3+}$; for this sample the decay time of the $\mathrm{Ce}^{3+}$ emission at RT is close to $16 \mathrm{~ns}$. The color coordinates of the light emitted by a suitably fabricated pcLED are $(0.147,0.089)$ and fall in the blue region. We note that the experimental decay time of the blue emission is quite short, and this could indicate that the quantum efficiency is not very high.

The chloroborate compounds $\mathrm{M}_{2} \mathrm{~B}_{5} \mathrm{O}_{9} \mathrm{Cl}(\mathrm{M}=\mathrm{Sr}, \mathrm{Ca})$ were proposed as hosts for $\mathrm{Eu}^{2+}$ by Guo et al. [119]. These materials already show possible applications as storage phosphors for X-Ray imaging and were then considered as blue phosphors for SSL. For both phosphors, the optimal concentration of $\mathrm{Eu}^{2+}$ was found to be $8 \%$. In the case of $\mathrm{M}=\mathrm{Sr}$, the luminescence excitation spectrum features a broad band between 250 and $410 \mathrm{~nm}$, and the emission one shows a strong peak centered at $425 \mathrm{~nm}$. For $\mathrm{M}=\mathrm{Ca}$, the excitation profile is more or less similar, but the emission peak red-shifts to $452 \mathrm{~nm}$. As a consequence, the CIE coordinates are different, but in both cases in the blue region $[(0.162,0.015)$ for $\mathrm{M}=\mathrm{Sr}$ and $(0.143$, 0.048 ) for $\mathrm{M}=\mathrm{Ca})]$.

A different approach for the development of a blue phosphor has been used by Luo et al. [120], based on $\mathrm{Eu}^{2+}$ doped glass ceramics containing $\mathrm{BaF}_{2}$ nanocrystals. The authors prepared an oxyfluoride glass containing $\mathrm{SiO}_{2}$ under reducing conditions, and then heated samples at various temperatures to obtain glass ceramics. These materials showed luminescence spectra characterized by blue emission centered at $450 \mathrm{~nm}$ that could be excited between 370 and $390 \mathrm{~nm}$. It can 
be inferred that $\mathrm{Eu}^{2+}$ is formed from the $\mathrm{Eu}^{3+}$ precursor and that it is preferentially located in the $\mathrm{BaF}_{2}$ nanocrystals.

In order to improve the performance of the well-known $\mathrm{Sr}_{2} \mathrm{CeO}_{4}$ phosphor upon excitation in the NUV, Hsu et al. have proposed the mixed oxide material $\mathrm{Sr}_{2} \mathrm{Ce}_{1 \text { - }}$ ${ }_{x} \mathrm{Sn}_{x} \mathrm{O}_{4}(0>x \geq 0.07)$ as a blue phosphor [121]. In these materials the optical transitions are based on a ligand-to-metal charge transfer $(\mathrm{CT})$ from $\mathrm{O}^{2-}$ to $\mathrm{Ce}^{4+}$ $[122,123]$. It was found that the addition of $\mathrm{Sn}^{4+}$ modifies the excitation profile, so that the low energy feature around $345 \mathrm{~nm}$ becomes dominant for $x=0.07$. Upon excitation in this feature, the intensity of the broad emission band centered around $480 \mathrm{~nm}$ is highest when $x=0.07$. The presence of the tin dopant makes the phosphor more suitable for NUV excitation.

\section{Green Phosphors}

Green emitting phosphors can be employed for SSL either upon excitation of a NUV or a blue LED so that they convert radiation in the ranges 380-410 or $450-480 \mathrm{~nm}$ to light centered in the green region $(520-565 \mathrm{~nm})$. In this case, the arsenal of activator ions that can be used for the development of green phosphors for WLEDs is larger than for the blue ones, as $\mathrm{Eu}^{2+}$ and $\mathrm{Ce}^{3+}$ are supplemented by $\mathrm{Tb}^{3+}$ and $\mathrm{Mn}^{2+}$. The core of this section will be devoted to these ions.

As presented above, the two former ions give rise to luminescence bands due to $5 d-4 f$ transitions. On the other hand, the latter two ions emit through $4 f-4 f$ and $3 d-$ $3 d$ transitions, respectively. These intraconfigurational transitions are parityforbidden through the electric dipole mechanism and are, therefore, weak. This can create problems in the phosphor performance, as the available excitation transitions are in general also forbidden and weak. For this reason, in many cases excitation of $\mathrm{Tb}^{3+}$ and $\mathrm{Mn}^{2+}$ in these materials occurs through an energy transfer scheme in which $\mathrm{Ce}^{3+}$ or $\mathrm{Eu}^{2+}$ are used as sensitizers for the activator ions (or the other way around).

As in the section above, common oxide-based hosts, such as phosphates, silicates, and aluminates, and other host compositions will be reviewed separately.

\subsection{Green Phosphors-Oxide Hosts: Phosphates, Silicates}

Also, in the case of green phosphors for pcLED, the phosphate family has proved to be important, as the considerations mentioned above about preparation and structural flexibility still apply. The eulytite material $\mathrm{Sr}_{3} \mathrm{Gd}\left(\mathrm{PO}_{4}\right)_{3}$ co-doped with $\mathrm{Ce}^{3+}$ and $\mathrm{Eu}^{2+}$ has been investigated by Sun et al. [124]. Single phase samples containing various amounts of the dopants were prepared by solid state reaction in a reducing atmosphere. Energy transfer was found to occur from $\mathrm{Ce}^{3+}$ to $\mathrm{Eu}^{2+}$, with an efficiency of about $95 \%$ for the highest concentration of $\mathrm{Eu}^{2+}(2 \%)$. The emission profile of $\mathrm{Eu}^{2+}$ peaks at $518 \mathrm{~nm}$ in the green spectral region. The authors point out that in the co-doped samples the excitation of the $\mathrm{Eu}^{2+}$ luminescence (spanning the whole UV region) is greatly enhanced due to the energy transfer 
process mentioned above, without increasing the $\mathrm{Eu}^{2+}$ concentration and therefore avoiding the onset of concentration quenching.

The double phosphate $\mathrm{NaCaPO}_{4}$ doped with $\mathrm{Tb}^{3+}$ has been proposed as a green phosphor for NUV LEDs by Ratnam et al. [20]. Samples containing 1-7 \% $\mathrm{Tb}^{3+}$ were obtained by solid state reaction and characterized by XRD and electron microscopy. The optimal concentration for $\mathrm{Tb}^{3+}$ emission was found to be $5 \%$. At this doping level, blue and violet luminescence from ${ }^{5} D_{3}$ is quenched by cross relaxation processes [125] and the emission spectrum is dominated by the ${ }^{5} D_{4} \rightarrow{ }^{7} F_{5}$ band in the green at $547 \mathrm{~nm}$. The excitation spectrum of this feature is composed of stronger $4 f-4 f$ bands peaking around $370 \mathrm{~nm}$, accompanied by weaker $4 f-5 d$ bands (presumably spin-forbidden) at lower wavelength. Upon excitation in the NUV, the CIE coordinates for this $\mathrm{Tb}^{3+}$ concentration are about $(0.27,0.58)$, which falls in the green region. In principle this phosphor could be useful for pcLEDs, but the excitation bands are probably too weak for practical purposes. Excitation of the green $\mathrm{Tb}^{3+}$ emission can be enhanced through energy transfer from a suitable donor ion, such as $\mathrm{Eu}^{2+}$. These phenomena have been studied in the double phosphates $\mathrm{Ca}_{10} \mathrm{~K}\left(\mathrm{PO}_{4}\right)_{7}$ [21] and $\mathrm{LiSrPO}_{4}$ [22] co-doped with the sensitizer $\mathrm{Eu}^{2+}$ and the activator $\mathrm{Tb}^{3+}$. Both phosphors were prepared by solid state reaction yielding single phase materials. The $\mathrm{Eu}^{2+}-\mathrm{Tb}^{3+}$ transfer allows exciting the ${ }^{5} D_{4} \mathrm{~Tb}^{3+}$ emission around $540 \mathrm{~nm}$ efficiently in the UV, in the region where NUV LEDs operate. The energy transfer is not complete (the efficiency is about $66 \%$ for $\mathrm{LiSrPO}_{4}$ ), so that the broad luminescence of $\mathrm{Eu}^{2+}$ is still present in the spectra in the blue region. pcLEDs devices were built by coupling a $398 \mathrm{~nm}$ NUV LED with the phosphors in which the concentration of the dopants had been optimized. The color coordinates were found to be $(0.283,0.383)$ for $\mathrm{Ca}_{10} \mathrm{~K}\left(\mathrm{PO}_{4}\right)_{7}$ and $(0.294,0.428)$ for $\mathrm{LiSrPO}_{4}$; both points appear to be located in the green part of the CIE diagram, indicating that these materials are suitable as green phosphors.

The borophosphate material $\mathrm{Sr}_{6} \mathrm{BP}_{5} \mathrm{O}_{20}: \mathrm{Eu}^{2+}$ was prepared by Zhang et al. [126] and used as a bluish-green phosphor in the fabrication of a WLED. The sample containing $9 \%$ of $\mathrm{Eu}^{2+}$ was characterized by XRD. The emission spectrum of $\mathrm{Eu}^{2+}$ has a peak at $475 \mathrm{~nm}$ and extends up to $650 \mathrm{~nm}$, whilst the excitation spectrum shows maxima at 290 and $365 \mathrm{~nm}$, with a shoulder at $390 \mathrm{~nm}$. The decay time of the emission is in the $\mu$ s range, typical for this dopant. The color coordinates of the phosphor are $(0.174,0.312)$ located in the bluish-green region. A mixed silicophosphate material $\mathrm{Ca}_{5}\left(\mathrm{PO}_{4}\right)_{2} \mathrm{SiO}_{4}$ doped with $\mathrm{Eu}^{2+}$ and having the silicocarnotite structure has been proposed by Roh et al. [127] as a green emitting phosphor. Luminescence from this material can be excited from 220 to above $400 \mathrm{~nm}$, and is composed of a broad band peaking at $530 \mathrm{~nm}$. This feature is asymmetric, reflecting the multi-site nature of the host. The optimum concentration for $\mathrm{Eu}^{2+}$ was found to be $5 \%$; with this composition, a pcLED was fabricated by coupling with a NUV LED emitting at $380 \mathrm{~nm}$. The yellow-green emission spectrum of the device was stable as a function of the DC current.

As it is well known, $\mathrm{Eu}^{2+}$ in many cases gives rise to green emission in silicate hosts. Also $\mathrm{Ce}^{3+}$ in silicate garnet hosts has been found to produce green emission (see below). For this reason, silicate compounds are important hosts for green emitting phosphors for pcLEDs. Shimomura et al. [32] reported in 2007 on the 
luminescence and crystal structure of $\mathrm{Ca}_{3} \mathrm{Sc}_{2} \mathrm{Si}_{3} \mathrm{O}_{12}: \mathrm{Ce}^{3+}$ prepared by solid state reaction. The material has a cubic garnet structure and XAFS data evidenced that the $\mathrm{Ce}^{3+}$ dopant enters the structure in the $\mathrm{Ca}^{2+}$ dodecahedral site. The emission spectrum shows an asymmetric band peaking at $505 \mathrm{~nm}$, with a corresponding excitation profile peaking at 455 and extending to higher wavelengths; this is very suitable for excitation using a blue LED. The color coordinates obtained upon excitation at $455 \mathrm{~nm}$ are $(0.30,0.59)$, which is in the green range. The temperature quenching is not significantly efficient. This material appears to be a useful phosphor. An alternative synthesis of this phosphor (based on the sol-gel technique) has been described by Liu et al. [128].

$\mathrm{Ba}_{2} \mathrm{MgSi}_{2} \mathrm{O}_{7}: \mathrm{Eu}^{2+}$ has been investigated by Zhang et al. [129] as a green phosphor for pcLEDs. The material was prepared by solid state reaction and suitably characterized. The excitation spectrum is very broad and covers all the region ranging from 250 to $450 \mathrm{~nm}$. Excitation at 395 gives rise to a broad emission feature peaking at $505 \mathrm{~nm}$ and extending to almost $650 \mathrm{~nm}$. In the case of a $7 \%$ doping level for $\mathrm{Eu}^{2+}$, the QE was found to be $92 \%$, and the temperature quenching appears to be very weak. This green phosphor is efficient and suitable for excitation with NUV chips. The double orthosilicate $\mathrm{SrBaSiO}_{4}: \mathrm{Eu}^{2+}$ was also considered by Zhang et al. [33]. In this case, the excitation is less broad, but spans the NUV region, peaking around $430 \mathrm{~nm}$. Excitation in this range originates a relatively sharp emission in the green (full width at half maximum of $80 \mathrm{~nm}$ ) with a peak around

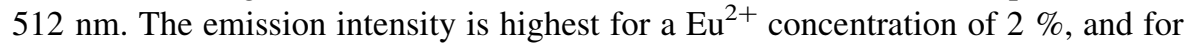
this sample the internal QE was found to be $78 \%$. The quenching temperature $T_{q}$, at which the emission intensity is reduced to $50 \%$, is $170{ }^{\circ} \mathrm{C}$. Xia et al. [130] have reported on the phosphor $\mathrm{Na}_{3} \mathrm{Y}_{1-x} \mathrm{Sc}_{x} \mathrm{Si}_{3} \mathrm{O}_{9}: \mathrm{Eu}^{2+}$. This material can be prepared by high temperature solid state reaction in a reducing atmosphere. Samples with $x$ ranging from 0.1 to 0.9 were synthesized and fully characterized. The best composition in terms of spectroscopic properties was found to be the one with $x=0.7$, and $3 \% \mathrm{Eu}^{2+}$ (substituting for $\mathrm{Na}^{+}$). In this case, the excitation is very broad in the UV with several features up to $430 \mathrm{~nm}$. The corresponding emission spectrum upon excitation at $365 \mathrm{~nm}$ is characterized by broad emission at about $500 \mathrm{~nm}$. The decay times of the emission amount to several hundreds of $\mathrm{ns}$, depending on the $\mathrm{Eu}^{2+}$ concentration. Thermal quenching reduces the $\mathrm{RT}$ intensity to $63 \%$ at $100{ }^{\circ} \mathrm{C}$. The $\mathrm{CIE}$ coordinates upon excitation at $365 \mathrm{~nm}(0.164,0.549)$ show that the phosphor emits green light with high color purity.

The luminescence of the aluminosilicate $\mathrm{MAl}_{2} \mathrm{Si}_{2} \mathrm{O}_{8}(\mathrm{M}=\mathrm{Sr}, \mathrm{Ba})$ codoped with $\mathrm{Eu}^{2+}$ and $\mathrm{Mn}^{2+}$ has been investigated by $\mathrm{Ye}$ et al. [131]. Materials containing various amounts of the dopant ions were prepared by solid state reaction under reducing atmosphere. It was found that the optimal concentrations for luminescence are $1 \% \mathrm{Eu}^{2+}$ and $10 \% \mathrm{Mn}^{2+}$. Excitation in the $\mathrm{UV}$ yields $\mathrm{Mn}^{2+}$ emission in the green-yellow (peaks at 564 and $518 \mathrm{~nm}$ for $\mathrm{M}=\mathrm{Sr}$ and $\mathrm{Ba}$, respectively). However, the $\mathrm{Eu}^{2+}-\mathrm{Mn}^{2+}$ energy transfer is weakly efficient $(10 \%$ for $\mathrm{M}=\mathrm{Sr}$ and $5 \%$ for $\mathrm{M}=\mathrm{Ba}$ ) due to the limited spectral overlap between the $\mathrm{Eu}^{2+}$ emission and the $\mathrm{Mn}^{2+}$ absorption. 


\subsection{Green Phosphors-Other Hosts}

The double oxide $\mathrm{CaSc}_{2} \mathrm{O}_{4}$ doped with $\mathrm{Ce}^{3+}$ has been studied by Shimomura et al. [132]. The material doped with $1 \%$ of the dopant was prepared by solid state reaction above $1400{ }^{\circ} \mathrm{C}$ in a reducing atmosphere. The luminescence peak is located at $515 \mathrm{~nm}$ with a shoulder to longer wavelength, as typical of $\mathrm{Ce}^{3+}$ (Fig. 18). The excitation spectrum has a maximum at $450 \mathrm{~nm}$, which is suitable for excitation with a blue InGaN LED. The quantum efficiency is high $(90 \%$ of the value observed for $\mathrm{Ca}_{3} \mathrm{Sc}_{2} \mathrm{Si}_{3} \mathrm{O}_{12}: \mathrm{Ce}^{3+}$ [32]) and the thermal stability is good. The effects of the introduction of other cations, such $\mathrm{Mg}^{2+}, \mathrm{Sr}^{2+}, \mathrm{Lu}^{3+}$, were examined; they are reflected in shifts of the emission peak and changes in the peak intensity.

The borate material $\mathrm{LiBaBO}_{3}: \mathrm{Tb}^{3+}$ has been investigated by $\mathrm{Li}$ et al. [133]. Phosphors containing various amounts of $\mathrm{Tb}^{3+}$ were obtained by solid state reaction at $700{ }^{\circ} \mathrm{C}$. Only emission from the ${ }^{5} D_{4}$ level is observed, presumably due to fast multiphonon relaxation from the upper level ${ }^{5} D_{3}$ induced by high frequency vibrations of the borate host. The optimal concentration is $3 \% \mathrm{of} \mathrm{Tb}^{3+}$. Emission peaks at $544 \mathrm{~nm}$, whilst the excitation profile comprises two structured bands peaking at $242-277$ and $368-381 \mathrm{~nm}$. This latter band is due to $4 f-4 f$ transitions and, therefore, is relatively weak. The CIE coordinates of the emission are in the green region at $(0.249,0.578)$. The addition of charge compensating alkali ions appears to increase the emission intensity from ${ }^{5} D_{4}$. $\mathrm{SrMoO}_{4}$ doped with various amounts of $\mathrm{Tb}^{3+}$ and $\mathrm{Na}^{+}$(for charge compensation) has been proposed as a yellowish green phosphor by $\mathrm{Li}$ et al. [134]. Emission is strong from ${ }^{5} D_{4}$ at $548 \mathrm{~nm}$. However, excitation maxima are located at 488 or $375 \mathrm{~nm}$, corresponding to $4 f-$ $4 f$ transitions from the ${ }^{7} F_{6}$ ground state to ${ }^{5} D_{4}$ and ${ }^{5} D_{3}$, respectively. Despite the efficient emission, the excitation probability is weak and it is doubtful that these phosphors can find practical applications for pcLEDs.

The oxyfluoride $\mathrm{Ca}_{2} \mathrm{Al}_{3} \mathrm{O}_{6} \mathrm{~F}$ doped with $\mathrm{Eu}^{2+}(0.5-20 \%)$ has been investigated by Xia et al. [19]. The material can be synthesized by high temperature solid state reaction under reducing atmosphere; it was thoroughly characterized from a structural and morphological point of view. The luminescence spectra demonstrate a

Fig. 18 Photoluminescence and photoluminescence excitation spectra of $\mathrm{CaSc}_{2} \mathrm{O}_{4}: \mathrm{Ce}^{3+}$ (1 $\mathrm{mol} \%$ ), adapted from [32]

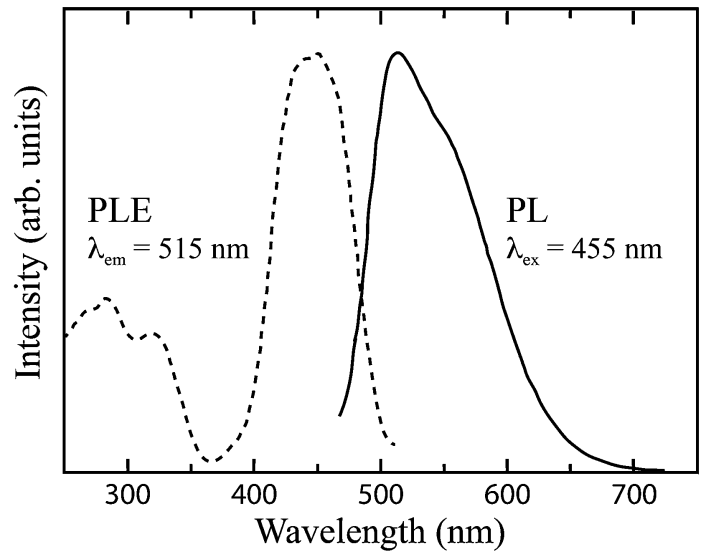


very broad excitation band spanning the range $250-450 \mathrm{~nm}$, and emission peaking at $502 \mathrm{~nm}$ with a FWHM of $70 \mathrm{~nm}$. The emission intensity reaches a maximum for the $5 \%$ sample, whilst the decay times decrease from 0.68 to $0.25 \mu \mathrm{s}$ in the $0.5-20 \%$ concentration range. The emission intensity decreases to $39 \%$ of the RT value at $150{ }^{\circ} \mathrm{C}$. The measured internal $\mathrm{QE}$ of this green phosphor is $34 \%$ upon excitation at $400 \mathrm{~nm}$, and the CIE coordinates are (0.171, 0.470) (Fig. 19).

The authors conclude that the efficiency can be improved by optimizing the particle size, size distribution, morphology, and crystalline defects. Xia and Liu have also reported on the same host $\mathrm{Ca}_{2} \mathrm{Al}_{3} \mathrm{O}_{6} \mathrm{~F}$ co-doped with $\mathrm{Ce}^{3+}$ and $\mathrm{Tb}^{3+}$ [135]. Luminescence spectra and decay curves of these materials (containing $8 \%$ of $\mathrm{Ce}^{3+}$ and variable amounts of $\mathrm{Tb}^{3+}$ ) clearly show the presence of very efficient energy transfer from the former ion to the latter. Green $\mathrm{Tb}^{3+}$ emission from ${ }^{5} D_{4}$ $(542 \mathrm{~nm})$ is obtained upon excitation of the allowed $4 f-5 d$ transitions of the $\mathrm{Ce}^{3+}$ sensitizer in the NUV region (320-400 nm), with maximum intensity for $5 \% \mathrm{~Tb}^{3+}$. Emission peaking at $413 \mathrm{~nm}$ from the $\mathrm{Ce}^{3+}$ ion becomes rapidly weaker when the $\mathrm{Tb}^{3+}$ concentration is increased. The energy transfer efficiency is very high, being almost $92 \%$ for the sample containing $5 \% \mathrm{~Tb}^{3+}$ (Fig. 20). The CIE coordinates for this composition are $(0.287,0.455)$, indicating that this material is a potential green emitting candidate phosphor for NUV LEDs. Moreover, the emitted color can be tuned from blue to blue-greenish, green, and greenish-yellow by changing the concentration of the two dopants.

Setlur et al. [136] have proposed oxyfluoride and fluoride phosphors for energyefficient, high-color rendering LED lamps. Among them, it is worth mentioning the oxyfluoride $(\mathrm{Sr}, \mathrm{Ca})_{3}(\mathrm{Al}, \mathrm{Si}) \mathrm{O}_{4}(\mathrm{~F}, \mathrm{O}): \mathrm{Ce}^{3+}$ yellow-green emitting materials. These phosphors are made by solid state reaction at high temperature in a reducing atmosphere using $\mathrm{SrF}_{2}$ as a flux. The luminescence spectra are dominated by a strong emission around 540-550 nm; excitation shows two broad peaks in the range 250-500 $\mathrm{nm}$. The QE at RT (excitation at $450 \mathrm{~nm}$ ) appears to be comparable to commercial $\mathrm{Ce}^{3+}$ doped garnet phosphors $(>80 \%)$. The thermal quenching of the

Fig. 19 CIE coordinates and digital photo under $365 \mathrm{~nm}$ UV lamp of the $\mathrm{Ca}_{1.95} \mathrm{Al}_{3} \mathrm{O}_{6} \mathrm{~F}: 0.05 \mathrm{Eu}^{2+}$ phosphor, adapted from [19]

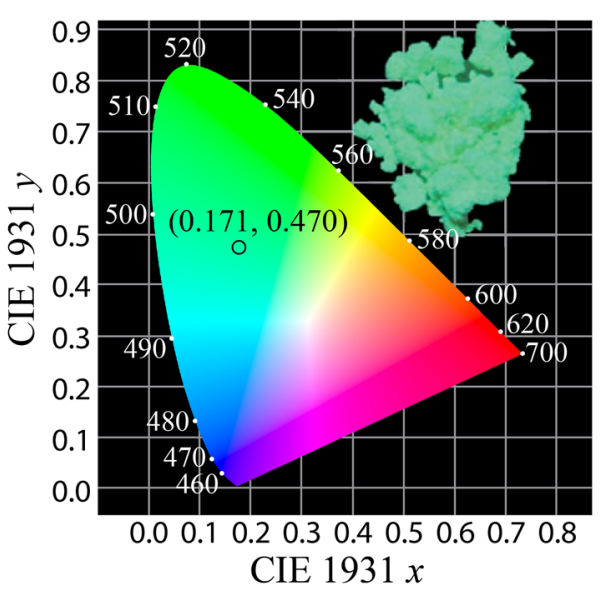


Fig. 20 Dependence of the $\mathrm{Ce}^{3+}$ emission, $\mathrm{Tb}^{3+}$ emission, and energy transfer efficiency of $\mathrm{Ce}^{3+}-\mathrm{Tb}^{3+}$ on $\mathrm{Tb}^{3+}$ doping concentration for $\mathrm{Ca}_{2} \mathrm{Al}_{3} \mathrm{O}_{6} \mathrm{~F}: 0.08 \mathrm{Ce}^{3+}, y \mathrm{~Tb}^{3+}$ phosphors, adapted from [135]

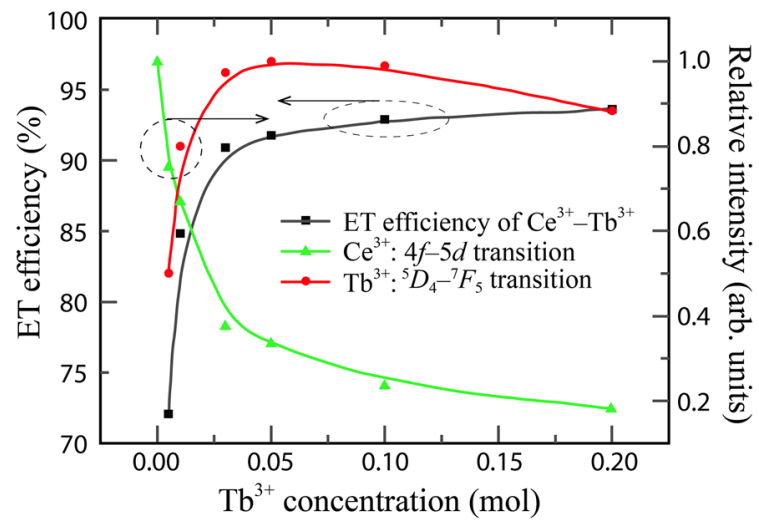

compositions $\left(\mathrm{Sr}_{0.98} \mathrm{Na}_{0.01} \mathrm{Ce}_{0.01}\right)_{3} \mathrm{AlO}_{4} \mathrm{~F}$ and $\left(\mathrm{Sr}_{0.595} \mathrm{Ca}_{0.4} \mathrm{Ce}_{0.005}\right)_{3} \mathrm{Al}_{0.6} \mathrm{Si}_{0.4} \mathrm{O}_{4.415-}$ $\mathrm{F}_{0.585}$ is weak $\left(<15 \%\right.$ loss at $\left.150{ }^{\circ} \mathrm{C}\right)$ (Fig. 21).

Oxynitrides and nitrides form an important family of green phosphors for SSL, with interesting optical properties [8]. In particular, SiAlONs are hosts that have been widely investigated. As an example, $\beta$-SiAlON doped with $\mathrm{Eu}^{2+}$ (with a composition $\mathrm{Eu}_{x} \mathrm{Si}_{6-z} \mathrm{Al}_{z} \mathrm{O}_{z} \mathrm{~N}_{8-z}$, with $x=0.018$ and $z=0.23$ ) has been considered by Ryu et al. [137]. Samples were obtained by gas-pressured solid state reaction. This material emits in the green region at $539 \mathrm{~nm}$, and shows excitation peaks at 300,358 , and $407 \mathrm{~nm}$, superimposed to a very broad band. Thermal quenching is weak, as at $150{ }^{\circ} \mathrm{C}$ the emission intensity is reduced to $85 \%$ of that measured at RT. The results show that $\beta-\mathrm{SiAlON}: \mathrm{Eu}^{2+}$ is a promising green phosphor for pcLED applications. Another example is given by the green emitting material $\alpha$ SiAlON doped with $\mathrm{Yb}^{2+}$ [138]. In this case, the doping ion shows luminescence spectra due to $4 f^{14} \leftrightarrow 4 f^{13} 5 d^{1}$ interconfigurational transitions [139]. The oxynitride

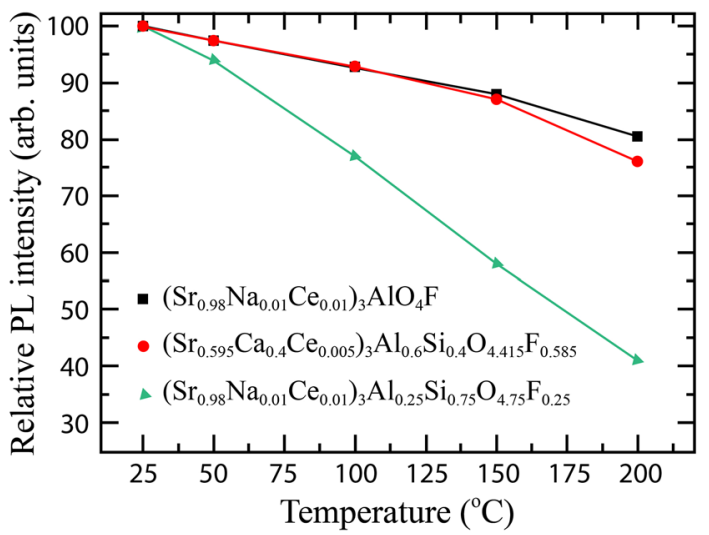

Fig. 21 Integrated intensity vs. temperature $\left(\lambda_{\mathrm{ex}}=405 \mathrm{~nm}\right)$ for $\left(\mathrm{Sr}_{0.98} \mathrm{Na}_{0.01} \mathrm{Ce}_{0.01}\right)_{3} \mathrm{AlO}_{4} \mathrm{~F}$, $\left(\mathrm{Sr}_{0.595} \mathrm{Ca}_{0.4} \mathrm{Ce}_{0.005}\right)_{3} \mathrm{Al}_{0.6} \mathrm{Si}_{0.4} \mathrm{O}_{4.415} \mathrm{~F}_{0.585}$ and $\left(\mathrm{Sr}_{0.98} \mathrm{Na}_{0.01} \mathrm{Ce}_{0.01}\right)_{3} \mathrm{Al}_{0.25} \mathrm{Si}_{0.75} \mathrm{O}_{4.75} \mathrm{~F}_{0.25}$. The lines are only guides to the eye, adapted from [136] 
material is characterized by a single broad band centered at $549 \mathrm{~nm}$ (Fig. 22). The low energy spectral position of this transition is attributed to a large ligand field splitting of the $4 f^{13} 5 d^{1}$ configuration and to a large nephelauxetic effect induced by the nitrogen coordination of $\mathrm{Yb}^{2+}$. Excitation spectra show several broad peaks in the UV and blue region, in particular one located at $445 \mathrm{~nm}$, which makes this phosphor suitable for blue LED excitation. Concentration quenching is efficient, so that the optimal $\mathrm{Yb}^{2+}$ concentration seems to be relatively low. The CIE coordinates of $\alpha$-SiAlON: $\mathrm{Yb}^{2+}$ are $(0.323,0.601)$. This phosphor is potentially useful to create white light when coupled with a red phosphor and a blue LED chip.

A green emitting phosphor of composition $\mathrm{SrSi}_{2} \mathrm{O}_{2} \mathrm{~N}_{2}$ codoped with $\mathrm{Eu}^{2+}$ and $\mathrm{Mn}^{2+}$ has been developed by Song et al. [140]. Materials containing $2 \% \mathrm{Eu}^{2+}$ and various amounts of $\mathrm{Mn}^{2+}$ have been synthesized via a solid state reaction. XRD showed that the main product is the desired $\mathrm{SrSi}_{2} \mathrm{O}_{2} \mathrm{~N}_{2}$ phase, but some traces of impurities are present. The materials only containing $\mathrm{Eu}^{2+}$ show a broad emission band centered at $530 \mathrm{~nm}$ in the green, with excitation spanning the UV-visible region from 250 to almost $500 \mathrm{~nm}$. It was found that addition of $\mathrm{Mn}^{2+}$ leads to energy transfer from this ion to $\mathrm{Eu}^{2+}$, increasing the excitation pathways in the NUV, the optimum content of $\mathrm{Mn}^{2+}$ appears to be $3 \%$. Tang et al. have investigated the phosphor $\mathrm{Ba}_{3} \mathrm{Si}_{6} \mathrm{O}_{12} \mathrm{~N}_{2}: \mathrm{Eu}^{2+}$ and reported its synthesis, characterization, and theoretical simulation [141]. The excitation spectra of the doped materials are characterized by a very broad band in the $200-500 \mathrm{~nm}$ range, and the emission is located in the green at $527 \mathrm{~nm}$. The maximum intensity is obtained for relatively high $\mathrm{Eu}^{2+}$ concentration, and therefore, it appears that concentration quenching is not effective. The excitation matches well with blue and NUV LEDs. The CIE coordinates are compatible with high green color purity. Theoretical simulations attempt an explanation of the high absorption intensity of this phosphor in the NUV and blue region. The novel oxynitride material $(\mathrm{Ba}, \mathrm{Sr}) \mathrm{Y}_{2} \mathrm{Si}_{2} \mathrm{Al}_{2} \mathrm{O}_{2}$ $\mathrm{N}_{5}: \mathrm{Eu}^{2+}$ has been studied by Liu et al. [142]. Phosphors containing various proportions of $\mathrm{Ba}^{2+}$ and $\mathrm{Sr}^{2+}$, and of the dopant $\mathrm{Eu}^{2+}$ have been prepared by sintering in reducing atmosphere and suitably characterized by XRD. The
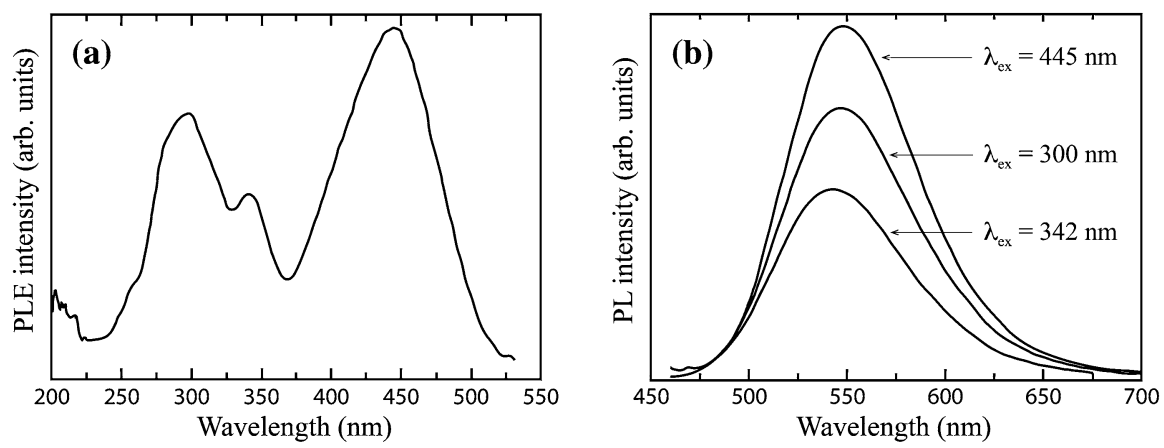

Fig. 22 a Excitation and $\mathbf{b}$ emission spectra of the $\mathrm{Yb}^{2+}$-doped $\mathrm{Ca}-\alpha-\mathrm{SiAlON}$. The excitation spectrum was monitored at $\lambda_{\mathrm{em}}=549 \mathrm{~nm}$ and the emission spectrum was recorded at $\lambda_{\mathrm{ex}}=342,300$, and $445 \mathrm{~nm}$. Both figures are adapted from [138] 
luminescence spectra of $\mathrm{BaY}_{2} \mathrm{Si}_{2} \mathrm{Al}_{2} \mathrm{O}_{2} \mathrm{~N}_{5}: \mathrm{Eu}^{2+}$ are dominated by a broad emission band that shifts from 510 to $533 \mathrm{~nm}$ when the dopant concentration is increased. The excitation is broad with features at 291, 354, and $426 \mathrm{~nm}$. In this case, the optimal $\mathrm{Eu}^{2+}$ concentration is $8 \%$, and the corresponding $\mathrm{QE}$ is $32.5 \%$ upon $400 \mathrm{~nm}$ excitation. Addition of $\mathrm{Sr}^{2+}$ leads to a red shift and to an increase of the emission intensity. The CIE coordinates could be tuned from $(0.292,0.577)$ to $(0.417,0.516)$. The thermal quenching behavior of $\mathrm{BaY}_{2} \mathrm{Si}_{2} \mathrm{Al}_{2} \mathrm{O}_{2} \mathrm{~N}_{5}$ doped with $8 \% \mathrm{Eu}^{2+}$ is similar to the one for the commercial phosphor $(\mathrm{Ba}, \mathrm{Sr})_{2} \mathrm{SiO}_{4}: \mathrm{Eu}^{2+}$.

The sulfide phosphor $\mathrm{Sr}_{1-x} \mathrm{Ca}_{x} \mathrm{Ga}_{2} \mathrm{~S}_{4}: \mathrm{Eu}^{2+}$ (with doping in the region of $2 \%$ ) has been considered by Do et al. [143]. Samples were prepared by $\mathrm{NaBr}$-aided solid state reaction in flowing $\mathrm{H}_{2} \mathrm{~S}$. Excitation at $455 \mathrm{~nm}$ yields a broad symmetric emission band in the range $500-625 \mathrm{~nm}$, whose maximum is red shifted from 535 to 555 with increasing $x$ (moving from $\mathrm{SrGa}_{2} \mathrm{~S}_{4}$ to $\mathrm{CaGa}_{2} \mathrm{~S}_{4}$ ). This red shift is interpreted on the basis of a stronger ligand field around $\mathrm{Eu}^{2+}$ when $\mathrm{Sr}^{2+}$ is replaced by $\mathrm{Ca}^{2+}$. The excitation spectra are extremely broad in the NUV and the blue regions and are compatible with excitation using NUV, violet, and blue LED chips. The emission efficiency appears to decrease only slightly with increasing $x$, i.e., when the emission color shifts from green to greenish-yellow.

\section{Red Phosphors}

As for the green phosphors, red emitting materials can be employed for SSL both upon excitation of a NUV or a blue LED, and therefore, they must be able to convert efficiently radiation in the ranges $380-410$ or $450-480 \mathrm{~nm}$ to light centered in the red region $(625-740 \mathrm{~nm})$. This is not trivial to do in an efficient way, as in many hosts the most common activator ions for pcLEDs phosphors $\left(\mathrm{Ce}^{3+}\right.$ and $\left.\mathrm{Eu}^{2+}\right)$ do not emit strongly in the red region. In order to achieve efficient red emission based on $5 d-4 f$ excitation and emission transitions, it is necessary to rely on host materials in which (1) the centroid of the $4 f^{\mathrm{n}-1} 5 d^{1}$ configuration is shifted to low energy (nephelauxetic effect, due to increased covalency) and/or (2) the ligand field is strong, lowering the energy of the lowest (emitting) level belonging to the $4 f^{\mathrm{n}-1} 5 d^{1}$ configuration. This occurs only in few hosts, as shown below.

The alternative is the use of activator ions that emit in the red region, exploiting intraconfigurational transitions. Two such examples are $\mathrm{Eu}^{3+}$ and $\mathrm{Mn}^{4+}$, that provide luminescence through $4 f-4 f$ and $3 d-3 d$ transitions, respectively. As mentioned above, these intraconfigurational transitions are parity-forbidden through the electric dipole mechanism and are, therefore, weak, and this is not ideal for phosphor performance. These issues will be discussed below.

As in the section above, conventional oxide-based hosts, such as phosphates, silicates, and borates, will be discussed in Sect. 7.1. Molybdates, tungstates, niobates, and tantalates, which are hosts commonly proposed for $\mathrm{Eu}^{3+}$, will be considered in Sect. 7.2. All other host compositions (e.g., nitrides and oxynitrides) will be finally reviewed in Sect. 7.3. 


\subsection{Red Phosphors-Oxide Hosts: Phosphates, Silicates, Borates}

It is well known that the $\mathrm{Eu}^{2+}$ ion in phosphate hosts shows emission bands located in the NUV, blue, and green regions. However, Srivastava et al. [144] have reported on a family of materials, the pyrophosphates $\mathrm{Cs}_{2} \mathrm{CaP}_{2} \mathrm{O}_{7}$ and $\mathrm{Cs}_{2} \mathrm{SrP}_{2} \mathrm{O}_{7}$ doped with $1 \% \mathrm{Eu}^{2+}$, which is characterized by relatively sharp emission bands centered at 601 and $567 \mathrm{~nm}$, respectively, i.e., in the orange and yellow spectral regions. The excitation spectra of these bands in both materials show two features extending from 300 to $450 \mathrm{~nm}$, and from 200 to $300 \mathrm{~nm}$, respectively (Fig. 23). The former band exhibits the "staircase" profile which derives from the transition from the $4 f^{7}$ ground state to the multiplets $(J=0-6)$ belonging to the $4 f^{6}\left[{ }^{7} F_{\mathrm{J}}\right] 5 d^{1}$ excited configuration [145], and that is typical of $\mathrm{Eu}^{2+}$. The decay time of the luminescence is $1.2-1.3 \mu \mathrm{s}$, characteristic of $\mathrm{Eu}^{2+}$, and the Stokes shift exceeds $8000 \mathrm{~cm}^{-1}$. This is much larger than the most frequent value for $\mathrm{Eu}^{2+}$ emission in solids $\left(1350 \mathrm{~cm}^{-1}\right)$, and explains the location in the yellow-orange region of the $\mathrm{Eu}^{2+}$ emission. After a thorough discussion, the authors conclude that this is an extreme case of $\mathrm{Eu}^{2+}$ interconfigurational transition. This conclusion is reflected in the lack of $\mathrm{Eu}^{2+}$ doped phosphate materials emitting in the red spectral region and suitable as red phosphors.

A different approach was used by Peng et al. [146] who proposed the borophosphate materials $\mathrm{MBPO}_{5}(\mathrm{M}=\mathrm{Ba}, \mathrm{Sr}, \mathrm{Ca})$ doped with the $\mathrm{Bi}^{2+}$ ion as novel orange and red phosphors for pcLEDs. In this case, the optical features of $\mathrm{Bi}^{2+}$ (valence shell $6 s^{2} 6 p^{1}$ ) are transitions of the $6 p-6 p$ type that gain intensity due to mixing with higher even parity states [147]. The materials can be obtained via solid state reaction with a doping level of $0.5 \%$ under air atmosphere, and were characterized by XRD and vibrational spectroscopy. Emission spectra present strong bands peaking at $650-660 \mathrm{~nm}$ with shoulders at higher wavelengths. Broad excitation bands occur in the NUV blue $(350-450 \mathrm{~nm})$ with weaker bands at higher wavelength, close to $600 \mathrm{~nm}$, and at lower wavelength, close to $370 \mathrm{~nm}$. The emission transition is assigned to ${ }^{2} P_{3 / 2} \rightarrow{ }^{2} P_{1 / 2}$. For $\mathrm{M}=\mathrm{Ba}$, the decay time of the

Fig. 23 The excitation (solid line $; \lambda_{\mathrm{em}}=600 \mathrm{~nm}$ ) and the emission (dotted line;

$\lambda_{\mathrm{ex}}=360 \mathrm{~nm}$ ) spectra of $\mathrm{Cs}_{2} \mathrm{CaP}_{2} \mathrm{O}_{7}: \mathrm{Eu}^{2+}$ at $T=80 \mathrm{~K}$, adapted from [144]

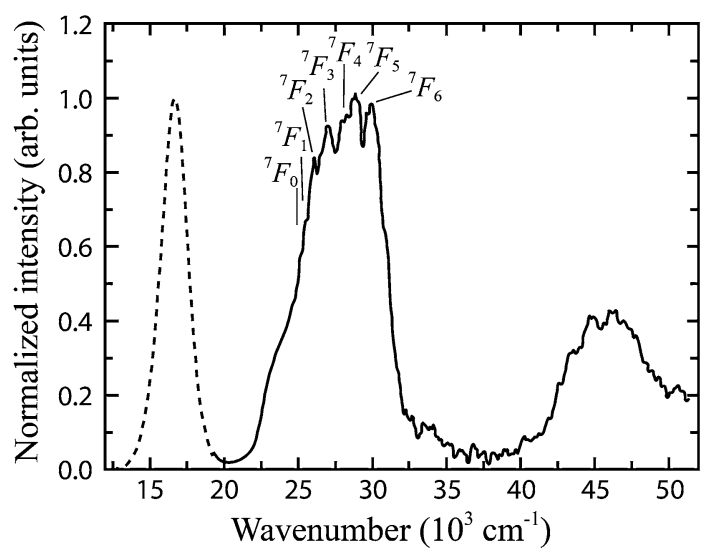


emission is $22 \mu \mathrm{s}$. The strong absorption in the blue indicates that these materials could be suitable red phosphors for SSL.

The crystal chemistry and the luminescence of the $\mathrm{Lu}_{2} \mathrm{CaMg}(\mathrm{Si}, \mathrm{Ge})_{3} \mathrm{O}_{12}$ materials doped with $\mathrm{Ce}^{3+}$ has been investigated by $\mathrm{Ye}$ et al. [28]. Samples containing 4-6\% (nominal) of the dopant ions were prepared by solid state reaction under reducing atmosphere at $1300-1450{ }^{\circ} \mathrm{C}$. The composition regions for phase stability in this system have been established. It was found that in these materials the $\mathrm{Ce}^{3+}$ ion gives rise to luminescence that is significantly located more clearly in the red than for typical Al-based garnet phosphors. For instance, $\left(\mathrm{Lu}_{0.94} \mathrm{Ce}_{0.06}\right)_{2 \text { - }}$ $\mathrm{CaMg}_{2} \mathrm{Si}_{2.2} \mathrm{Ge}_{0.8} \mathrm{O}_{12}$ gives rise to a broad band peaking at about $600 \mathrm{~nm}$ upon excitation at $470 \mathrm{~nm}$. For this composition the thermal quenching is slightly more efficient than for YAG:Ce ${ }^{3+}$. These phosphors are in general characterized by a high QE.

A different approach to the development of red phosphors has been proposed by Carrasco et al. [148] who have investigated materials with composition $\mathrm{Ca}_{3} \mathrm{~Tb}_{2}$ ${ }_{x} \mathrm{Eu}_{x} \mathrm{Si}_{3} \mathrm{O}_{12}(x=0-2)$ having the silico-carnotite structure. In this case, the $4 f-$ $4 f$ emission of $\mathrm{Eu}^{3+}$ occurs from the ${ }^{5} D_{0}$ excited level and is composed of a dominant sharp peak located at $612 \mathrm{~nm}$. This efficient emission is normally difficult to excite due the small absorption cross section of the $4 f-4 f$ transition of the dopant. However, in the compositions with $x$ in the range $0.02-0.10$, the ${ }^{5} D_{0}$ luminescence can be efficiently sensitized by the $\mathrm{Tb}^{3+}$ ion, which is present with a concentration 20-100 times higher than the activator. In fact, excitation at $377 \mathrm{~nm}$, in the ${ }^{5} D_{3}$ level of $\mathrm{Tb}^{3+}$, gives rise to fast migration in the $\mathrm{Tb}^{3+}$ subset followed to energy transfer processes populating the ${ }^{5} D_{0}$ level of $\mathrm{Eu}^{3+}$. The overall transfer efficiency reaches $94 \%$ in the sample with $x=0.10$. So, a NUV chip can be used to excite red emission efficiently. This concept was proposed by Bettinelli et al. [149] for the

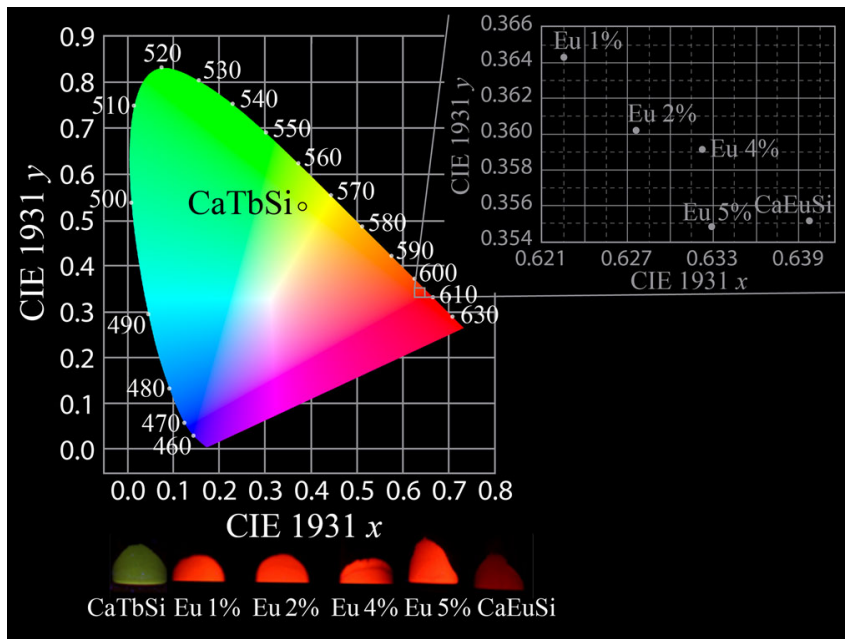

Fig. $24 \mathrm{CIE}$ diagram coordinates of $\mathrm{Ca}_{3} \mathrm{~Tb}_{2} \mathrm{Si}_{3} \mathrm{O}_{12}(\mathrm{CaTbSi})$ and $\mathrm{Ca}_{3} \mathrm{~Tb}_{2-x} \mathrm{Eu}_{x} \mathrm{Si}_{3} \mathrm{O}_{12}$ excited at $377 \mathrm{~nm}$ and $\mathrm{Ca}_{3} \mathrm{Eu}_{2} \mathrm{Si}_{3} \mathrm{O}_{12}(\mathrm{CaEuSi})$ excited at $393 \mathrm{~nm}$, and a typical picture of the phosphors when excited at $365 \mathrm{~nm}$, adapted from [148] 
eulytite material $\mathrm{Sr}_{3} \mathrm{~Tb}_{0.90} \mathrm{Eu}_{0.10}\left(\mathrm{PO}_{4}\right)_{3}$ (where the transfer efficiency is $93 \%$ ) and by Xia et al. [150] for the chloroborate $\mathrm{Ba}_{2} \mathrm{~Tb}\left(\mathrm{BO}_{3}\right)_{2} \mathrm{Cl}: \mathrm{Eu}$ (where both $\mathrm{Eu}^{3+}$ and $\mathrm{Eu}^{2+}$ coexist, and the transfer efficiency is $72 \%$ ). In the case of the $\mathrm{Ca}_{3} \mathrm{~Tb}_{2-}$ ${ }_{x} \mathrm{Eu}_{\mathrm{x}} \mathrm{Si}_{3} \mathrm{O}_{12}$ silico-carnotite with $x=0.10$, the CIE coordinates upon $377 \mathrm{~nm}$ excitation are $(0.633,0.355)$ (Fig. 24), in the red region, and the $\mathrm{Eu}^{3+}$ emission decay time is only weakly temperature dependent.

\subsection{Red Phosphors-Oxide Hosts: Molybdates, Tungstates, Niobates, and Tantalates}

A wealth of papers have appeared in the literature dealing with oxyanion compounds of transition metal ions (in particular molybdates, tungstates, niobates, and tantalates) containing $\mathrm{Eu}^{3+}$ ions [151-167]. These studies involve the luminescence from the ${ }^{5} \mathrm{D}_{0}$ level of this ion, having a sharp peak located at about 610-620, i.e., in the pure red region (see above) (Fig. 25). In fact, $\mathrm{Y}_{2} \mathrm{O}_{3}$ and $\mathrm{YVO}_{4}$ doped with $\mathrm{Eu}^{3+}$ have been employed as red phosphors for a long time [168, 169]. Moreover, it has been shown that the optimum red phosphor for a warm-white pcLED having simultaneously a high luminous efficacy and a high CRI should have

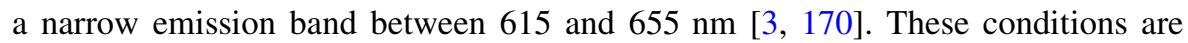
perfectly met by the ${ }^{5} D_{0} \rightarrow{ }^{7} F_{2}$ band. NUV and blue chips in principle can excite the $\mathrm{Eu}^{3+}$, having absorption bands peaking around 395 and $465 \mathrm{~nm}$, but the absorption cross sections of these bands is quite low, due to the fact that they are due to $4 f-4 f$ transitions $\left({ }^{7} F_{0} \rightarrow{ }^{5} L_{6}\right.$ and ${ }^{7} F_{0} \rightarrow{ }^{5} D_{2}$, respectively).

Intuitively, phosphor performance should increase with increasing concentration of $\mathrm{Eu}^{3+}$, as this should lead to an increase in the population of the emitting level
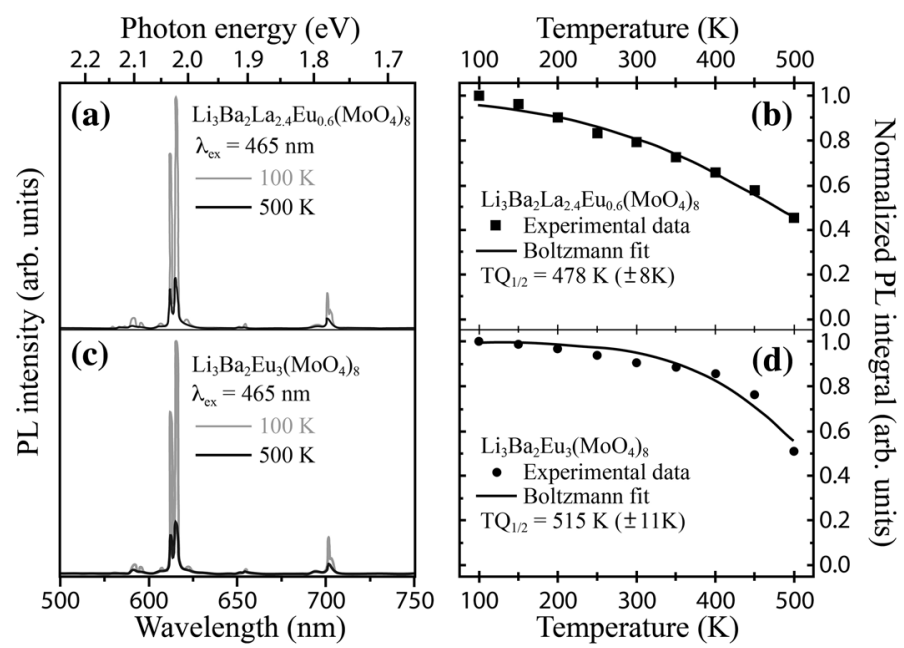

Fig. 25 Temperature dependent emission spectra $\left(\lambda_{\mathrm{ex}}=310 \mathrm{~nm}\right)$ of $\mathrm{Li}_{3} \mathrm{Ba}_{2} \mathrm{La}_{3}\left(\mathrm{MoO}_{4}\right)_{8}: \mathrm{Eu}^{3+}$ samples (a) doped with $20 \% \mathrm{Eu}^{3+}$ and its (b) estimation of $T_{q}\left(\mathrm{TQ}_{1 / 2}\right)$, temperature at which the intensity decreases to $50 \%$; (c) doped with $100 \% \mathrm{Eu}^{3+}$ and its $(\mathbf{d})$ estimation of $\mathrm{T}_{\mathrm{q}}\left(\mathrm{TQ}_{1 / 2}\right)$. All figures are adapted from [151] 
and, therefore, to higher emission intensity. However, this is not the case, as the increased concentration of the activator ions usually results in a decrease of the emission QE. This is due to the activation of energy transfer processes involving the excited states of $\mathrm{Eu}^{3+}$ and depopulating in a non-radiative way the light emitting levels. This behavior is known as concentration quenching and is normally limited to a few percent of the activator ion concentration in a given host in order to obtain the optimum QE and emission intensity [171]. On the other hand, energy transfer processes between $\mathrm{Eu}^{3+}$ ions strongly depend on the interionic distance [172]. If these ions are kept a long way apart one from another by large, bulky anions, high QEs can be achieved even for fully concentrated hosts. Good results have been obtained for concentrated molybdates [151] in which concentration quenching is prevented by the presence of large anions between $\mathrm{Eu}^{3+}$ centers. Another approach is based on the presence of efficient energy transfer from the ligand-to-metal CT states of the oxyanion (molybdate, tungstate, etc.) to the excited states of $\mathrm{Eu}^{3+}$. This can increase the excitation efficiency of the $\mathrm{Eu}^{3+}$ ion, but can be useful only when the electric dipole allowed CT absorption bands are located in spectral ranges where NUV or blue chips emit [152]. As mentioned above, molybdate, tungstate, niobate, and tantalate hosts activated with $\mathrm{Eu}^{3+}$ have been widely investigated [151-167], also exploting co-doping with $\mathrm{Sm}^{3+}$, but only in a limited number of cases the two strategies described above (high $\mathrm{Eu}^{3+}$ concentration and $\mathrm{CT} \rightarrow \mathrm{Eu}^{3+}$ energy transfer) have been successfully exploited. For this reason, not all the phosphors that have been suggested are really fully suitable for pcLEDs applications.

\subsection{Red Phosphors-Other Hosts}

Oxyfluorides, and especially fluorides, have been proposed as materials for red phosphors applications. Huang et al. [17] have investigated the $\mathrm{Ca}_{2} \mathrm{RF}_{4} \mathrm{PO}_{4}$ : $\mathrm{Eu}^{3+}$ $(\mathrm{R}=\mathrm{Gd}, \mathrm{Y})$ new oxyfluoride phosphors. Samples were prepared by solid state reaction and characterized by XRD. The excitation band of the sharp main emission line at $611 \mathrm{~nm}$ consists of a broad band around $280 \mathrm{~nm}$ of CT nature, and sharp lines comprising the ${ }^{7} F_{0} \rightarrow{ }^{5} L_{6}$ at $394 \mathrm{~nm}$ and the ${ }^{7} F_{0} \rightarrow{ }^{5} D_{2} 4 f-4 f$ transitions. The $\mathrm{Eu}^{3+}$ concentration can be increased up to $40 \%$ with relatively weak concentration quenching. The reported QE values are (presumably for $5 \% \mathrm{Eu}^{3+}$ doping) $64 \%$ for $\mathrm{R}=\mathrm{Gd}$ and $48 \%$ for $\mathrm{R}=\mathrm{Y}$ upon excitation at $394 \mathrm{~nm}$, and the thermal quenching is weak up to $150{ }^{\circ} \mathrm{C}$.

Setlur et al. [136] have proposed the development of a red phosphor for pcLEDs based on the ion $\mathrm{Mn}^{4+}$ as a dopant in octahedral coordination. This ion has a $3 d^{3}$ configuration (like $\mathrm{Cr}^{3+}$ ) and in octahedral sites it has a ${ }^{4} A_{2} \rightarrow{ }^{4} T_{2}$ spin allowed, parity forbidden transition that matches excitation in the violet or blue spectral regions. The emission transition is ${ }^{2} E \rightarrow{ }^{4} A_{2}$ with a sharp profile and peaking around $632 \mathrm{~nm}$ in fluoride hosts [173] (Fig. 26). Because of the strong and broad absorption/excitation bands in blue and sharp emission peaks in red for $\mathrm{K}_{2} \mathrm{SiF}_{6}$ :$\mathrm{Mn}^{4+}$, Lv et al. [174] have suggested that $\mathrm{K}_{2} \mathrm{SiF}_{6}: \mathrm{Mn}^{4+}$ is fairly suitable to be used in the pcWLEDs made of yellow phosphor YAG: $\mathrm{Ce}^{3+}$ and blue LEDs to obtain a warm white light emission $(C C T=3900 \mathrm{~K}$ ) with a high CRI (89.9) and a high efficiency $(\mathrm{LE}=116 \mathrm{~lm} / \mathrm{W})$. Another fluoride red phosphor $\mathrm{K}_{2} \mathrm{TiF}_{6}: \mathrm{Mn}^{4+}$ also 
(a)

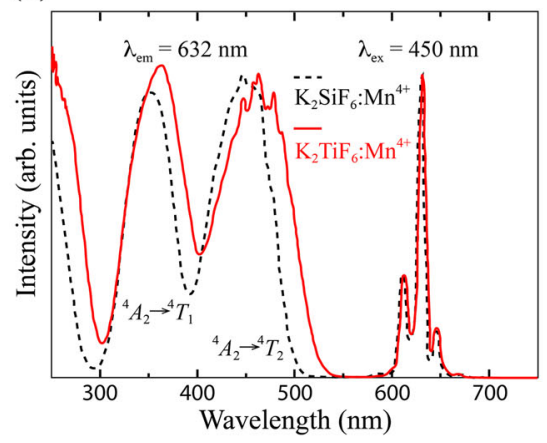

(b)

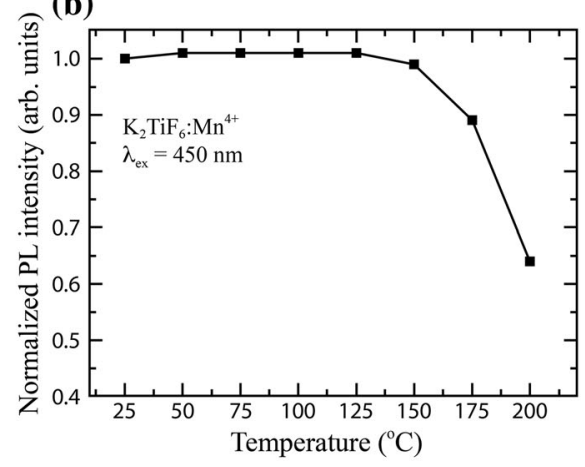

Fig. 26 a Excitation $\left(\lambda_{\mathrm{em}}=632 \mathrm{~nm}\right)$ and emission spectra $\left(\lambda_{\mathrm{ex}}=450 \mathrm{~nm}\right)$ for $\mathrm{K}_{2} \mathrm{TiF}_{6}: \mathrm{Mn}^{4+}$ (solid line) and $\mathrm{K}_{2} \mathrm{SiF}_{6}: \mathrm{Mn}^{4+}$ (dotted line). b Relative intensity vs. temperature $\left(\lambda_{\mathrm{ex}}=450 \mathrm{~nm}\right.$ ) for $\mathrm{K}_{2} \mathrm{TiF}_{6}: \mathrm{Mn}^{4+}$. The line in panel (b) is a guide to the eye. Both figures are adapted from [136]

shows a bright and warm white emission with a high CRI as employed with YAG: $\mathrm{Ce}^{3+}$ and blue LEDs [175]. The phosphors $\mathrm{K}_{2} \mathrm{TiF}_{6}: \mathrm{Mn}^{4+}$ and $\mathrm{K}_{2} \mathrm{SiF}_{6}: \mathrm{Mn}^{4+}$ show $\mathrm{QE}$ values similar to commercial garnets doped with $\mathrm{Ce}^{3+}$, and their thermal quenching at $150{ }^{\circ} \mathrm{C}$ is less than $5 \%$. They could suffer from saturation based quenching due the long decay time of ${ }^{2} E \rightarrow{ }^{4} A_{2}$, but this issue can be virtually eliminated by using a remote phosphor configuration reducing the incident radiation flux [176]. The thermal stability for $\mathrm{K}_{2} \mathrm{TiF}_{6}: \mathrm{Mn}^{4+}$ (activation energy $\Delta E=0.34 \mathrm{eV})$ has shown to be better than nitride compounds $(\Delta E \approx 0.25 \mathrm{eV})$ based on thermal quenching of emission intensity [175]. Apart from the temperature effect, the relative emission intensity of $\mathrm{K}_{2} \mathrm{TiF}_{6}: \mathrm{Mn}^{4+}$ and $\mathrm{K}_{2} \mathrm{SiF}_{6}: \mathrm{Mn}^{4+}$ is shown to depend on the initial $\mathrm{KMnO}_{4}$ concentration, where $\mathrm{KMnO}_{4}$ is used as the source of $\mathrm{Mn}^{4+}$ dopants when $\mathrm{Mn}^{7+}$ in $\mathrm{KMnO}_{4}$ is reduced by $\mathrm{H}_{2} \mathrm{O}_{2}$ in $\mathrm{HF}$ solution. The decrease of emission intensity because of too high concentrations of $\mathrm{KMnO}_{4}$ is attributed to the concentration quenching effect [175] or the formation of the $\mathrm{MnO}_{2}$ phase [174]. These materials are very interesting phosphors. The investigation of this class of luminescent materials has been extended by the research group based at Gunma University in Japan, which has considered and investigated the hosts above, and several additional ones $\left(\mathrm{Na}_{2} \mathrm{SnF}_{6}, \mathrm{Cs}_{2} \mathrm{SnF}_{6}, \mathrm{Cs}_{2} \mathrm{SiF}_{6}, \mathrm{Cs}_{2} \mathrm{GeF}_{6}, \mathrm{KNaSiF}_{6}\right)$ doped with $\mathrm{Mn}^{4+}$ [177-180]. All these phosphors emit in the red region, and their synthesis, characterization and spectral properties have been reported. These ideas have been extended to oxide hosts (e.g., $\mathrm{SrGe}_{3.495} \mathrm{Mn}_{0.005} \mathrm{Si}_{0.5} \mathrm{O}_{9}$ [181]).

Le Toquin and Cheetham [182] have proposed for the first time a $\mathrm{Ce}^{3+}$ doped nitride phosphor emitting in the red spectral region. The material has composition $\mathrm{CaSiN}_{2}$ doped with $3 \% \mathrm{Ce}^{3+}$ and was synthesized at high temperature under flowing $\mathrm{N}_{2}$. The emission profile shows a broad band extending from 550 to $700 \mathrm{~nm}$ with maximum at $625 \mathrm{~nm}$. The corresponding excitation peaks around $535 \mathrm{~nm}$ and spans the region between 425 and $575 \mathrm{~nm}$. Upon laser excitation at $515 \mathrm{~nm}$ an external QE of about $40 \%$ is obtained. Substitution of $\mathrm{Ca}$ with $\mathrm{Mg}$ or $\mathrm{Sr}$, and of $\mathrm{Si}$ with $\mathrm{Al}$, allows shifting the emission and excitation maxima, confirming the 
potential of these phosphors in combination with a blue LED. The nitride $\mathrm{SrAlSi}_{4} \mathrm{~N}_{7}$ has been proposed as a host for the lanthanide ions $\mathrm{Ce}^{3+}$ and $\mathrm{Yb}^{2+}$ by Zhang et al. [183]. $\mathrm{SrAlSi}_{4} \mathrm{~N}_{7}$ codoped with $\mathrm{Ce}^{3+}$ and $\mathrm{Li}^{+}$(for charge compensation) is characterized by a broad emission band in the range 450-700 $\mathrm{nm}$, peaking at about $500 \mathrm{~nm}$, with a complex excitation spectra dominated by broad features around 275 and $425 \mathrm{~nm}$. On the other hand, $\mathrm{SrAlSi}_{4} \mathrm{~N}_{7}: \mathrm{Yb}^{2+}$ gives rise to a single peak at $600 \mathrm{~nm}$ with excitation in the NUV-blue region between 325 and $500 \mathrm{~nm}$. Concentration quenching has been observed and the optimal concentrations for the two phosphors are around $1 \% . \mathrm{Ce}^{3+}$ retains $80 \%$ of the emission intensity when temperature is increased from 30 to $200{ }^{\circ} \mathrm{C}$, whilst $\mathrm{Yb}^{2+}$ decreases to $40 \%$ from 50 to $150{ }^{\circ} \mathrm{C}$. The two phosphors emit yellow-red and red light, respectively, and could be useful for pcLED applications.

$\mathrm{Eu}^{2+}$ doped phosphors in the nitride system $\mathrm{Ca}_{3} \mathrm{~N}_{2}-\mathrm{AlN}-\mathrm{Si}_{3} \mathrm{~N}_{4}$ have been investigated by Uheda et al. [18]. The authors found the new red phosphor $\mathrm{CaAlSiN}_{3}: \mathrm{Eu}^{2+}$, that can be synthesized at high temperature under $\mathrm{N}_{2}$ pressure. This material can be effectively excited using blue GaN and NUV InGaN LED chips and exhibits a broad emission band peaking around $650 \mathrm{~nm}$. The optimum concentration of the dopant is $1.6 \%$ and the CIE color coordinates of the emission are $(0.667$, 0.327) (for $0.8 \% \mathrm{Eu}^{2+}$ ). Wang el al. [184] have found that the strongest emission intensity is from $\mathrm{CaAlSiN}_{3}: x \% \mathrm{Eu}^{2+}(x=1.5)$ and further increasing $\mathrm{Eu}^{2+}$ content gradually reduce emission intensity due to energy transfer between activator ions. A red shift effect was observed as increasing $\mathrm{Eu}^{2+}$ content from 0.05 to $2.0 \%$. This phenomenon was elucidated by the site-to-site energy transfer, i.e., there are more chances to have energy transfer to lower energy sites at the local environments of $\mathrm{Eu}^{2+}$. To solve the red-deficiency problem for some types of pcWLEDs, Lin et al. [185] have fabricated a warm pcWLED by introducing a red $\mathrm{CaAlSiN}_{3}$ : $\mathrm{Eu}^{2+}$ phosphor layer onto a yellow YAG: $\mathrm{Ce}^{3+}$ layer coupling to a InGaN LED chip. When $\mathrm{Eu}^{2+}$ concentrations vary from 0 to $50 \mathrm{wt} \%$, the emitting white light become warmer and high color saturated (CCT: from 5426 to $2763 \mathrm{~K}$, CRI: from 67.3 to 80.2); however, the LE decreases from 113.3 to $78.7 \mathrm{~lm} / \mathrm{W}$. As for thermal stability of $\mathrm{CaAlSiN}_{3}: \mathrm{Eu}^{2+}$, Piao et al. [186] indicated that the thermal quenching is inefficient as $\mathrm{CaAlSiN}_{3}: \mathrm{Eu}^{2+}$ shows $83 \%$ of its initial (RT) emission efficiency at $150{ }^{\circ} \mathrm{C}$ as compared to $60 \%$ of RT emission efficiency for YAG:Ce ${ }^{3+}$ [186]. Furthermore, they have demonstrated that $\mathrm{Ca}_{0.98} \mathrm{Eu}_{0.02} \mathrm{AlSiN}_{3}$ is chemically stable at high temperature. More specially, $\mathrm{Ca}_{0.98} \mathrm{Eu}_{0.02} \mathrm{AlSiN}_{3}$ is not oxidized until $400{ }^{\circ} \mathrm{C}$ which is rather higher than the operating temperature for pcWLEDs. Another interesting $\mathrm{Eu}^{2+}$-doped red nitridosilicate phosphor, $\mathrm{Sr}_{2} \mathrm{Si}_{5} \mathrm{~N}_{8}: \mathrm{Eu}^{2+}$, has been reported by Xie et al. [187]. They have synthesized this phosphor by utilizing a solid-state reaction, which is a rather simple, cheap and high-yield method. Although the synthesized phosphor are complex phosphors of $\mathrm{Sr}_{2} \mathrm{Si}_{5} \mathrm{~N}_{8}: \mathrm{Eu}^{2+}(\sim 64$ wt $\%)$ and $\mathrm{Sr}_{2} \mathrm{SiO}_{4}: \mathrm{Eu}^{2+}(\sim 36 \mathrm{wt} \%), \mathrm{Sr}_{2} \mathrm{SiO}_{4}: \mathrm{Eu}^{2+}$ has only $0.04 \%$ of the emission intensity of $\mathrm{Sr}_{2} \mathrm{Si}_{5} \mathrm{~N}_{8}: \mathrm{Eu}^{2+}$, implying that the luminescence from $\mathrm{Sr}_{2} \mathrm{SiO}_{4}: \mathrm{Eu}^{2+}$ can be ignored. Additionally, the complex phosphors have shown comparable luminescence properties with respect to $\mathrm{Sr}_{2} \mathrm{Si}_{5} \mathrm{~N}_{8}: \mathrm{Eu}^{2+}$ prepared by traditional methods. The excitation spectrum has revealed a strong and broad band in the range of 200-600 nm. The emission band is centered at $618 \mathrm{~nm}$ under $450 \mathrm{~nm}$ excitation. 
The emission becomes more red shifted as increasing $\mathrm{Eu}^{2+}$ concentration although the excitation spectrum is not affected significantly. Its internal and external quantum efficiency were measured to be around 75-80 and $64 \%$, respectively. As observed for $\mathrm{CaAlSiN}{ }_{3}: \mathrm{Eu}^{2+}$, the emission intensity of $\mathrm{Sr}_{2} \mathrm{Si}_{5} \mathrm{~N}_{8}: \mathrm{Eu}^{2+}$ is about $86 \%$ of that at RT as increasing temperature to $150{ }^{\circ} \mathrm{C}$, indicating promising thermal stability in lighting brightness. Thus, CaAlSiN ${ }_{3}: \mathrm{Eu}^{2+}$ and $\mathrm{Sr}_{2} \mathrm{Si}_{5} \mathrm{~N}_{8}: \mathrm{Eu}^{2+}$ can be suitably used for SSL applications, particularly for lowering CCT and increasing CRI.

A different approach was followed by Liu et al. [30] who studied a $\beta$-SiAlON oxynitride host activated with $\mathrm{Pr}^{3+}$. In this case, excitation occurs at $460 \mathrm{~nm}$ (corresponding to the emission of a blue chip) and is due to the $4 f-4 f$ transition ${ }^{3} \mathrm{H}_{4} \rightarrow{ }^{3} \mathrm{P}_{2}$. The emission spectrum for the sample of composition $\mathrm{Si}_{5.9} \mathrm{Al}_{0.1} \mathrm{O}_{0.1-}$ $\mathrm{N}_{7.9}: \operatorname{Pr}_{0.016}$ is dominated by several sharp bands in the region $600-660 \mathrm{~nm}$, attributed to the $4 f-4 f$ transitions originating from the levels ${ }^{1} D_{2}$ (to ${ }^{3} H_{4}$ ) and ${ }^{3} P_{0}$ (to ${ }^{3} H_{6}$ and ${ }^{3} F_{2}$ ). At temperatures above RT, emission bands from ${ }^{3} P_{0}$ become weaker, and from ${ }^{1} D_{2}$ stronger, due to ${ }^{3} P_{0^{-}}{ }^{1} D_{2}$ non-radiative relaxation. This causes the integrated emission intensity to increase up to $423 \mathrm{~K}$, and then slightly decrease up to $573 \mathrm{~K}$. However, the colour coordinates of the emission only shift from $(0.688$, $0.312)$ at $298 \mathrm{~K}$ to $(0.685,0.315)$ at $573 \mathrm{~K}$. The high thermal stability of $\beta$ SiAlON: $\mathrm{Pr}^{3+}$ makes it an alternative for red emitting pcLEDs phosphors, despite the relatively low absorption cross section for excitation.

The chalcogenide phosphors $\mathrm{Ca}_{1-x} \mathrm{Sr}_{x}\left(\mathrm{~S}_{y} \mathrm{Se}_{1-y}\right): \mathrm{Eu}^{2+}$ have been considered by Nazarov and Yoon [188]. Upon excitation at $460 \mathrm{~nm}$, these phosphors emit in the red, orange, or yellow spectral ranges depending on the $x$ and $y$ values. The authors have proposed a simple empirical model to choose the composition, in terms of $x$ and $y$ values, that can provide emission spectra peaking at a selected wavelength. In the case of red phosphors, emitting between 600 and $650 \mathrm{~nm}$, the sum $x+y$ must be in the range $0 \leq x+y<1.25$. Kuo et al. [29] have proposed the oxysulfide $\mathrm{CaZnOS}$ doped with $\mathrm{Eu}^{2+}$ as a candidate red phosphor working upon blue excitation. Single phase $\mathrm{Ca}_{1-x} \mathrm{Eu}_{x} \mathrm{ZnOS}$ materials can be synthesized by solid state reaction at high temperature under a reducing atmosphere. The composition with $x=0.04$ was found to be optimal in terms of emission intensity; it is characterized by a broad excitation feature extending from 400 to $600 \mathrm{~nm}$ and the emission peaks at about $650 \mathrm{~nm}$. The $\mathrm{Ca}_{0.96} \mathrm{Eu}_{0.04} \mathrm{ZnOS}$ phosphor was found to have CIE coordinates of $(0.69,0.31)$ and a $\mathrm{QE}$ of $35.5 \%$. The thermal stability of the emission is superior to the one of $\mathrm{SrS}: \mathrm{Eu}^{2+}$ in the temperature range $50-125^{\circ} \mathrm{C}$.

\section{Conclusions}

In this chapter dedicated to inorganic phosphors and their characteristics for SSL, our goal was to give to the readers an idea of the basics, the scope and the diversity of this research field. We have tried to point out the current main avenues of research and to indicate the most important topics, especially the ones still needing major advancements or breakthroughs. In our opinion, it is important to highlight that the study of inorganic materials for pcLEDs is a truly interdisciplinary field that 
requires competence and creative research in many different areas of investigation, such as luminescence and optical spectroscopy, inorganic chemistry, solid state physics, and materials science. In particular, we have given a snapshot of current research and demonstrated the important role of detailed local structural and dynamical investigations of phosphors such as YAG:Ce ${ }^{3+}$. Although YAG and other garnet-type host lattices continue to be considered very promising materials, it should be noted that a variety of other classes of phosphors have been developed and are now attracting increased attention. Examples of such are silicates [189], nitrides [190-192], and oxy-nitrides [193, 194], to name a few.

With a view to the future, it is clear that there exists great scope for further structural and dynamical investigations in order to increase the current understanding of these phosphors. In particular, we foresee an increasing use of PDF analysis and reverse Monte-Carlo modeling of neutron and X-ray total scattering data for the investigation (and re-investigation) of local structural details, such as bond distances and angles, and nature of the activator ion sites, for example, of both well-known and new phosphors. Furthermore, we will follow with great interest the upgrade and methodological developments of instruments and techniques in a wide context. As an example, the development of new neutron and X-ray sources and free electron laser (FEL) facilities, will soon allow for investigations that have previously not been within reach.

Similarly, the use and development of computational techniques are equally important. Computational modeling of materials is particularly useful prior to experiments to predict the outcome and thus optimize the use of experiment beam time, as well as to guide future experiments. Likewise, experimental data can be used to test and benchmark computational methods and results.

Another interesting perspective for the future comes from the observation that an efficient way to discover and develop new phosphors for pcLEDs derives from the modification of the local structure and luminescence tuning of existing phosphor materials. This concept consists basically on strategies such as control of the doping level, cationic substitution, anionic substitution, cationic-anionic substitution, crystal-site engineering, and mixing of nanophases, and is discussed at length in an important recent review on $\mathrm{Ce}^{3+}$ and $\mathrm{Eu}^{2+}$ doped phosphors [195]. These strategies were successfully employed in the tailoring of novel phosphors for wLEDs, as shown in recent papers [196-198]. This approach seems to be promising for significant advancements in the development of new and improved luminescent materials.

We would like to conclude this last section with a caveat. Phosphors for LEDs are a very important and fast developing field, and this should always be taken into account. In some cases, fast development may lead to fast publication, and it may happen that in some articles the interpretation of the experimental results on the basis of solid and reliable models may not be entirely correct. For this reason, we point out that in a few of the multitude of papers cited above the interpretation of the experimental results is not flawless, and must be taken with some due care, especially when energy transfer and relaxation mechanisms are discussed in detail. We have decided to make reference to these papers anyway, due to the presentation of highly interesting experimental data. 
Acknowledgments Financial support from the Swedish Research Council (Grant Number 2010-3519), the Swedish Research Council Formas (Grant Number 2013-1723), the Swedish National Graduate School in Materials Science (NFSM), and University of Verona is gratefully acknowledged.

\section{References}

1. European Commission (2011) Green Paper Lighting the Future: Accelerating the deployment of innovative lighting technologies. http://ec.europa.eu/newsroom/dae/document.cfm?doc_id=1127. Accessed 30 Mar 2016

2. Nakamura S, Mukai T, Senoh M (1994) Appl Phys Lett 64:1687-1689

3. Pimputkar S, Speck JS, DenBaars SP, Nakamura S (2009) Nat Photonics 3:180-182

4. George NC, Denault KA, Seshadri R (2013) Annu Rev Mater Res 43:481-501

5. Jüstel T, Nikol H, Ronda C (1998) Angew Chem Int Ed 37:3084-3103

6. Lin CC, Liu R-S (2011) J Phys Chem Lett 2:1268-1277

7. Höppe HA (2009) Angew Chem Int Ed 48:3572-3582

8. Xie R-J, Hirosaki N (2007) Sci Technol Adv Mater 8:588-600

9. Smet PF, Parmentier AB, Poelman D (2011) J Electrochem Soc 158:R37-R54

10. Chen L, Lin C-C, Yeh C-W, Liu R-S (2010) Materials 3:2172

11. Rohwer LS, Srivastava AM (2003) Electrochem Soc Interface 12:36-40

12. McKittrick J, Hannah ME, Piquette A, Han JK, Choi JI, Anc M, Galvez M, Lugauer H, Talbot JB, Mishra KC (2013) ECS J Solid State Sci Technol 2:R3119-R3131

13. Ye S, Xiao F, Pan YX, Ma YY, Zhang QY (2010) Mater Sci Eng, R 71:1-34

14. http://hyperphysics.phy-astr.gsu.edu/hbase/vision/specol.html. Accessed 30 Mar 2016

15. http://hyperphysics.phy-astr.gsu.edu/hbase/vision/cie.html. Accessed 30 Mar 2016

16. McCamy CS (1992) Color Res Appl 17:142-144

17. Huang Y, Nakai Y, Tsuboi T, Seo HJ (2011) Opt Express 19:6303-6311

18. Uheda K, Hirosaki N, Yamamoto H (2006) Phys Status Solidi A 203:2712-2717

19. Xia Z, Liu R-S, Huang K-W, Drozd V (2012) J Mater Chem 22:15183-15189

20. Ratnam BV, Jayasimhadri M, Kumar GB, Jang K, Kim SS, Lee YI, Lim JM, Shin DS, Song TK (2013) J Alloys Compd 564:100-104

21. Wang J, Zhang Z, Zhang M, Zhang Q, Su Q, Tang J (2009) J Alloys Compd 488:582-585

22. Chen Y, Wang J, Zhang X, Zhang G, Gong M, Su Q (2010) Sens Actuators, B 148:259-263

23. Gong X, Huang J, Chen Y, Lin Y, Luo Z, Huang Y (2014) Inorg Chem 53:6607-6614

24. Yim DK, Cho I-S, Lee CW, Noh JH, Roh HS, Hong KS (2011) Opt Mater 33:1036-1040

25. Chiu Y-C, Liu W-R, Chang C-K, Liao C-C, Yeh Y-T, Jang S-M, Chen T-M (2010) J Mater Chem 20:1755-1758

26. Kim JS, Jeon PE, Choi JC, Park HL, Mho SI, Kim GC (2004) Appl Phys Lett 84:2931-2933

27. Zhang X, Tang X, Zhang J, Wang H, Shi J, Gong M (2010) Powder Technol 204:263-267

28. Setlur AA, Heward WJ, Gao Y, Srivastava AM, Chandran RG, Shankar MV (2006) Chem Mater 18:3314-3322

29. Kuo T-W, Liu W-R, Chen T-M (2010) Opt Express 18:8187-8192

30. Liu T-C, Cheng B-M, Hu S-F, Liu R-S (2011) Chem Mater 23:3698-3705

31. Katelnikovas A, Sakirzanovas S, Dutczak D, Plewa J, Enseling D, Winkler H, Kareiva A, Jüstel T (2013) J Lumin 136:17-25

32. Shimomura Y, Honma T, Shigeiwa M, Akai T, Okamoto K, Kijima N (2007) J Electrochem Soc 154:J35-J38

33. Zhang X, Tang X, Zhang J, Gong M (2010) J Lumin 130:2288-2292

34. Setlur AA (2009) Electrochem Soc Interface 16:32

35. Krames MR, Shchekin OB, Mueller-Mach R, Mueller G, Zhou L, Harbers G, Craford MG (2007) J Disp Technol 3:160-175

36. Katelnikovas A, Bareika T, Vitta P, Jüstel T, Winkler H, Kareiva A, Žukauskas A, Tamulaitis G (2010) Opt Mater 32:1261-1265

37. Xie R-J, Hirosaki N, Mitomo M, Takahashi K, Sakuma K (2006) Appl Phys Lett 88:101104

38. Dorenbos P, Andriessen J, van Eijk CWE (2003) J Solid State Chem 171:133-136

39. Dorenbos P (2013) J Lumin 134:310-318

40. Rack PD, Holloway PH (1998) Mater Sci Eng R 21:171-219 
41. Rogers EG, Dorenbos P (2014) J Lumin 155:135-140

42. Lorenzo A, Jaffrezic H, Roux B, Boulon G, García-Solé J (1995) Appl Phys Lett 67:3735-3737

43. Shannon RD, Prewitt CT (1969) Acta Crystallogr. Sect B Struct Sci 25:925-946

44. Lupei A, Gross H, Reiche P (1995) J Phys Condens Matter 7:5701

45. Maglia F, Buscaglia V, Gennari S, Ghigna P, Dapiaggi M, Speghini A, Bettinelli M (2006) J Phys Chem B 110:6561-6568

46. Lupei, V., Lupei, A., Boulon, G. (1994) J Phys IV France 04:C4-407-C4-410

47. Pujats A, Veispals A, Jansons J (1997) Proc SPIE 2967:69-73

48. Kuklja MM, Pandey R (1999) J Am Ceram Soc 82:2881-2886

49. Egami, T., Billinge, S. J. L. (2003) Underneath the Bragg Peaks: Structural Analysis of Complex Materials 16, Elsevier Science

50. Robertson JM (1981) Tol MWv, Smits WH, Heynen JPH. Philips J Res 36:15-30

51. Pan YX, Wang W, Liu GK, Skanthakumar S, Rosenberg RA, Guo XZ, Li KK (2009) J Alloys Compd 488:638-642

52. Furman JD, Gundiah G, Page K, Pizarro N, Cheetham AK (2008) Chem Phys Lett 465:67-72

53. Ghigna P, Pin S, Ronda C, Speghini A, Piccinelli F, Bettinelli M (2011) Opt Mater 34:19-22

54. George NC, Pell AJ, Dantelle G, Page K, Llobet A, Balasubramanian M, Pintacuda G, Chmelka BF, Seshadri R (2013) Chem Mater 25:3979-3995

55. Gracia J, Seijo L, Barandiarán Z, Curulla D, Niemansverdriet H, van Gennip W (2008) J Lumin 128:1248-1254

56. Muñoz-García AB, Seijo L (2011) J Phys Chem A 115:815-823

57. Wu JL, Gundiah G, Cheetham AK (2007) Chem Phys Lett 441:250-254

58. Luo Y, Xia Z (2014) J Phys Chem C 118:23297-23305

59. Muñoz-García AB, Seijo L (2010) Phys Rev B 82:184118

60. Maniquiz MC, Jung KY, Jeong SM (2010) J Electrochem Soc 157:H1135-H1139

61. Tien TY, Gibbons EF, DeLosh RG, Zacmanidis PJ, Smith DE, Stadler HL (1973) J Electrochem Soc $120: 278-281$

62. Chiang C-C, Tsai M-S, Hon M-H (2008) J Electrochem Soc 155:B517-B520

63. Shao Q, Dong Y, Jiang J, Liang C, He J (2011) J Lumin 131:1013-1015

64. Kanke Y, Navrotsky A (1998) J Solid State Chem 141:424-436

65. Kalaji A, Saines PJ, George NC, Cheetham AK (2013) Chem Phys Lett 586:91-96

66. Seijo L, Barandiarán Z (2013) Opt Mater 35:1932-1940

67. Menzer G (1929) Z Kristallogr 69:300-396

68. Geller S (1967) Z Kristallogr 125:1-47

69. Dobrzycki Ł, Bulska E, Pawlak DA, Frukacz Z, Woźniak K (2004) Inorg Chem 43:7656-7664

70. Vegard L (1921) Z Phys A-Hadron Nucl 5:17-26

71. Seijo L, Barandiaran Z (2013) Phys Chem Chem Phys 15:19221-19231

72. Robbins DJ (1979) J Electrochem Soc 126:1550-1555

73. Ueda J, Tanabe S, Nakanishi T (2011) J Appl Phys 110:053102

74. Bachmann V, Ronda C, Meijerink A (2009) Chem Mater 21:2077-2084

75. Ueda J, Dorenbos P, Bos AJJ, Meijerink A, Tanabe S (2015) J Phys Chem C 119:25003-25008

76. Hansel RA, Allison SW, Walker DG (2009) Appl Phys Lett 95:114102

77. Stanek CR, McClellan KJ, Levy MR, Milanese C, Grimes RW (2007) Nucl Instrum Methods Phys Res. Sect A 579:27-30

78. Muñoz-García AB, Barandiaran Z, Seijo L (2012) J Mater Chem 22:19888-19897

79. Varshni YP (1967) Physica 34:149-154

80. Kim JS, Park YH, Kim SM, Choi JC, Park HL (2005) Solid State Commun 133:445-448

81. Blasse G (1992) Int Rev Phys Chem 11:71-100

82. Huang K, Rhys A (1950) P Roy Soc Lond A Mat 204:406-423

83. Henderson, B., Imbusch, G. F. (1989) Optical Spectroscopy of Inorganic Solids, Clarendon Press

84. Blasse G, Grabmaier BC, Grabmaier BC (1994) Luminescent materials 44. Springer-Verlag, Berlin

85. Papagelis K, Ves S (2003) J Appl Phys 94:6491-6498

86. Moore RK, White WB, Long TV (1971) Am Mineral 56:54

87. Hurrell JP, Porto SPS, Chang IF, Mitra SS, Bauman RP (1968) Phys Rev 173:851-856

88. Lin Y-C, Erhart P, Bettinelli M, George NC, Seshadri R, Parker SF, Karlsson M (to be published)

89. Xie R-J, Hirosaki N, Sakuma K, Yamamoto Y, Mitomo M (2004) Appl Phys Lett 84:5404-5406

90. Seong TY, Han J, Amano H, Morkoc H (2014) III-Nitride based light emitting diodes and applications, Springer Science and Business Media 
91. Park JK, Kim CH, Park SH, Park HD, Choi SY (2004) Appl Phys Lett 84:1647-1649

92. Saradhi MP, Varadaraju UV (2006) Chem Mater 18:5267-5272

93. Yamaga M, Masui Y, Sakuta S, Kodama N, Kaminaga K (2005) Phys Rev B 71:205102

94. Senden T, Rabouw FT, Meijerink A (2015) ACS Nano 9:1801-1808

95. Raukas M, Basun SA, Schaik Wv, Yen WM, Happek U (1996) Appl Phys Lett 69:3300-3302

96. Happek U, Basun SA, Choi J, Krebs JK, Raukas M (2000) J Alloys Compd 303-304:198-206

97. Dorenbos P (2003) J Lumin 104:239-260

98. Dorenbos P (2003) J Phys Condens Matter 15:4797

99. Dorenbos P (2001) Phys Rev B 64:125117

100. Dorenbos P (2002) Phys Rev B 65:235110

101. Shang M, Li G, Geng D, Yang D, Kang X, Zhang Y, Lian H, Lin J (2012) J Phys Chem C 116:10222-10231

102. Im WB, Yoo HS, Vaidyanathan S, Kwon KH, Park HJ, Kim Y-I, Jeon DY (2009) Mater Chem Phys 115:161-164

103. Zhang X, Mo F, Zhou L, Gong M (2013) J Alloys Compd 575:314-318

104. Ta N, Chen D (2009) J Alloys Compd 484:514-518

105. Sun J, Shen G, Wang X, Shen D (2013) Mater Lett 93:169-171

106. Liu L, Xie R-J, Hirosaki N, Li Y, Takeda T, Zhang C-N, Li J, Sun X (2010) J Am Ceram Soc 93:2018-2023

107. Hölsä J, Kirm M, Laamanen T, Lastusaari M, Niittykoski J, Novák P (2009) J Lumin 129:1560-1563

108. Jung KY, Kim JH, Kang YC (2009) J Lumin 129:615-619

109. Zhou J, Xia Z, Yang M, Shen K (2012) J Mater Chem 22:21935-21941

110. Park JK, Choi KJ, Kang HG, Kim JM, Kim CH (2007) Electrochem Solid-State Lett 10:J15-J18

111. Wang ZL, Cheah KW, Tam HL, Gong ML (2009) J Alloys Compd 482:437-439

112. Cui S, Jiao H, Li G, Su M (2010) J Electrochem Soc 157:J88-J91

113. Li G, Lai Y, Cui T, Yu H, Liu D, Gan S (2010) Mater Chem Phys 124:1094-1099

114. Li H-L, Xie R-J, Zhou G-H, Hirosaki N, Sun Z (2010) J Electrochem Soc 157:J251-J255

115. Tang J-Y, Xie W-J, Huang K, Hao L-Y, Xu X, Xie R-J (2011) Electrochem Solid-State Lett 14:J45$\mathrm{J} 47$

116. Ryu JH, Won HS, Park Y-G, Kim SH, Song WY, Suzuki H, Yoon C-B, Kim DH, Park WJ, Yoon C (2010) Electrochem Solid-State Lett 13:H30-H32

117. Mikami M, Kijima N (2010) Opt Mater 33:145-148

118. Yu R, Wang J, Zhang M, Zhang J, Yuan H, Su Q (2008) Chem Phys Lett 453:197-201

119. Guo C, Xu Y, Ding X, Li M, Yu J, Ren Z, Bai J (2011) J Alloys Compd 509:L38-L41

120. Luo Q, Fan X, Qiao X, Yang H, Wang M, Zhang X (2009) J Am Ceram Soc 92:942-944

121. Hsu C-H, Liaw C-L, Lu C-H (2010) J Alloys Compd 489:445-450

122. Danielson E, Devenney M, Giaquinta DM, Golden JH, Haushalter RC, McFarland EW, Poojary DM, Reaves CM, Weinberg WH, Wu XD (1998) Science 279:837-839

123. van Pieterson L, Soverna S, Meijerink A (2000) J Electrochem Soc 147:4688-4691

124. Sun J, Zeng J, Sun Y, Du H (2012) J Alloys Compd 540:81-84

125. Robbins DJ, Cockayne B, Lent B, Glasper JL (1976) Solid State Commun 20:673-676

126. Zhang M, Wang J, Ding W, Zhang Q, Su Q (2007) Appl Phys B 86:647-651

127. Roh H-S, Hur S, Song HJ, Park IJ, Yim DK, Kim D-W, Hong KS (2012) Mater Lett 70:37-39

128. Liu Y, Zhuang W, Hu Y, Gao W, Hao J (2010) J Alloys Compd 504:488-492

129. Zhang X, Zhang J, Wang R, Gong M (2010) J Am Ceram Soc 93:1368-1371

130. Xia Z, Zhou J, Mao Z (2013) J Mater Chem C 1:5917-5924

131. Ye S, Liu Z-S, Wang X-T, Wang J-G, Wang L-X, Jing X-P (2009) J Lumin 129:50-54

132. Shimomura Y, Kurushima T, Kijima N (2007) J Electrochem Soc 154:J234-J238

133. Li P, Pang L, Wang Z, Yang Z, Guo Q, Li X (2009) J Alloys Compd 478:813-815

134. Li X, Yang Z, Guan L, Guo Q (2009) Mater Lett 63:1096-1098

135. Xia Z, Liu R-S (2012) J Phys Chem C 116:15604-15609

136. Setlur AA, Radkov EV, Henderson CS, Her J-H, Srivastava AM, Karkada N, Kishore MS, Kumar NP, Aesram D, Deshpande A, Kolodin B, Grigorov LS, Happek U (2010) Chem Mater 22:4076-4082

137. Ryu J, Won H, Park Y-G, Kim S, Song W, Suzuki H, Yoon C (2009) Appl Phys A 95:747-752

138. Xie R-J, Hirosaki N, Mitomo M, Uheda K, Suehiro T, Xu X, Yamamoto Y, Sekiguchi T (2005) J Phys Chem B 109:9490-9494 
139. Lizzo S, Klein EP, Nagelvoort N, Erens R, Meijerink A, Blasse G (1997) J Phys Chem Solids 58:963-968

140. Song X, Fu R, Agathopoulos S, He H, Zhao X, Zeng J (2009) Mater Sci Eng, B 164:12-15

141. Tang J, Chen J, Hao L, Xu X, Xie W, Li Q (2011) J Lumin 131:1101-1106

142. Liu W-R, Yeh C-W, Huang C-H, Lin CC, Chiu Y-C, Yeh Y-T, Liu R-S (2011) J Mater Chem 21:3740-3744

143. Do YR, Ko K-Y, Na S-H, Huh Y-D (2006) J Electrochem Soc 153:H142-H146

144. Srivastava AM, Comanzo HA, Camardello S, Chaney SB, Aycibin M, Happek U (2009) J Lumin 129:919-925

145. Freiser MJ, Methfessel S, Holtzberg F (1968) J Appl Phys 39:900-902

146. Peng M, Da N, Krolikowski S, Stiegelschmitt A, Wondraczek L (2009) Opt Express $17: 21169-21178$

147. Srivastava AM (1998) J Lumin 78:239-243

148. Carrasco I, Bartosiewicz K, Nikl M, Piccinelli F, Bettinelli M (2015) Opt Mater 48:252-257

149. Bettinelli M, Speghini A, Piccinelli F, Ueda J, Tanabe S (2010) Opt Mater 33:119-122

150. Xia Z, Zhuang J, Liao L (2012) Inorg Chem 51:7202-7209

151. Katelnikovas A, Plewa J, Sakirzanovas S, Dutczak D, Enseling D, Baur F, Winkler H, Kareiva A, Justel T (2012) J Mater Chem 22:22126-22134

152. Dutta PS, Khanna A (2013) ECS J Solid State Sci Technol 2:R3153-R3167

153. Chang Y-C, Liang C-H, Yan S-A, Chang Y-S (2010) J Phys Chem C 114:3645-3652

154. Kim T, Kang S (2007) J Lumin 122-123:964-966

155. Wang Z, Liang H, Zhou L, Wu H, Gong M, Su Q (2005) Chem Phys Lett 412:313-316

156. Hu Y, Zhuang W, Ye H, Wang D, Zhang S, Huang X (2005) J Alloys Compd 390:226-229

157. Jin H, Wu H, Tian L (2012) J Lumin 132:1188-1191

158. Yi L, He X, Zhou L, Gong F, Wang R, Sun J (2010) J Lumin 130:1113-1117

159. Liao J, You H, Zhou D, Wen H-R, Hong R (2012) Opt Mater 34:1468-1472

160. Wang X-X, Xian Y-L, Wang G, Shi J-X, Su Q, Gong M-L (2007) Opt Mater 30:521-526

161. Ci Z, Wang Y, Zhang J, Sun Y (2008) Phys B 403:670-674

162. Thomas M, Rao PP, Deepa M, Chandran MR, Koshy P (2009) J Solid State Chem 182:203-207

163. Ju Z, Wei R, Gao X, Liu W, Pang C (2011) Opt Mater 33:909-913

164. Cao F-B (2012) J Lumin 132:641-644

165. Neeraj S, Kijima N, Cheetham AK (2004) Chem Phys Lett 387:2-6

166. Cao F-B, Tian Y-W, Chen Y-J, Xiao L-J, Wu Q (2009) J Lumin 129:585-588

167. Nyman M, Rodriguez MA, Shea-Rohwer LE, Martin JE, Provencio PP (2009) JACS 131:11652-11653

168. Pappalardo RG, Hunt RB (1985) J Electrochem Soc 132:721-730

169. Hersh HN, Forest H (1970) J Lumin 1-2:862-868

170. Zukauskas A, Shur MS, Gaska R (2002) Introduction to solid-state lighting, Wiley

171. Dexter DL, Schulman JH (1954) J Chem Phys 22:1063-1070

172. Di Bartolo B (1984) Energy transfer processes in condensed matter 114. Springer, US

173. Paulusz AG (1973) J Electrochem Soc 120:942-947

174. Lv L, Jiang X, Huang S, Chen X, Pan Y (2014) J Mater Chem C 2:3879-3884

175. Han T, Lang T, Wang J, Tu M, Peng L (2015) RSC Adv 5:100054-100059

176. Narendran N, Gu Y, Freyssinier-Nova JP, Zhu Y (2005) Phys Status Solidi A 202:R60-R62

177. Arai Y, Adachi S (2011) J Lumin 131:2652-2660

178. Arai Y, Adachi S (2011) J Electrochem Soc 158:J179-J183

179. Adachi S, Abe H, Kasa R, Arai T (2011) J Electrochem Soc 159:J34-J37

180. Kasa R, Adachi S (2012) J Electrochem Soc 159:J89-J95

181. Suzuki R, Takahashi Y, Iwasaki K, Terakado N, Fujiwara T (2015) Appl Phys Express 8:072603

182. Toquin RL, Cheetham AK (2006) Chem Phys Lett 423:352-356

183. Zhang Z, ten Kate OM, Delsing ACA, Man Z, Xie R, Shen Y, Stevens MJH, Notten PHL, Dorenbos P, Zhao J, Hintzen HT (2013) J Mater Chem C 1:7856-7865

184. Wang J, Zhang H, Lei B, Xia Z, Dong H, Liu Y, Zheng M, Xiao Y (2015) J Mater Chem C 3:4445-4451

185. Lin Z, Lin H, Xu J, Huang F, Chen H, Wang B, Wang Y (2015) J Alloys Compd 649:661-665

186. Piao X, Machida K-I, Horikawa T, Hanzawa H, Shimomura Y, Kijima N (2007) Chem Mater 19:4592-4599

187. Xie R-J, Hirosaki N, Suehiro T, Xu F-F, Mitomo M (2006) Chem Mater 18:5578-5583 
188. Nazarov M, Yoon C (2006) J Solid State Chem 179:2529-2533

189. Ananias D, Kostova M, Almeida Paz FA, Ferreira A, Carlos LD, Klinowski J, Rocha J (2004) JACS 126:10410-10417

190. Duan CJ, Wang XJ, Otten WM, Delsing ACA, Zhao JT, Hintzen HT (2008) Chem Mater 20:1597-1605

191. Zeuner M, Pagano S, Matthes P, Bichler D, Johrendt D, Harmening T, Pöttgen R, Schnick W (2009) JACS 131:11242-11248

192. Yeh C-W, Chen W-T, Liu R-S, Hu S-F, Sheu H-S, Chen J-M, Hintzen HT (2012) JACS 134:14108-14117

193. Zeuner M, Pagano S, Schnick W (2011) Angew Chem Int Ed 50:7754-7775

194. Chen W-T, Sheu H-S, Liu R-S, Attfield JP (2012) JACS 134:8022-8025

195. Li G, Tian Y, Zhao Y, Lin J (2015) Chem Soc Rev 44:8688-8713

196. Xia Z, Ma C, Molokeev MS, Liu Q, Rickert K, Poeppelmeier KR (2015) JACS 137:12494-12497

197. Xia Z, Molokeev MS, Im WB, Unithrattil S, Liu Q (2015) J Phys Chem C 119:9488-9495

198. Xia Z, Miao S, Chen M, Molokeev MS, Liu Q (2015) Inorg Chem 54:7684-7691 